\title{
THE REMOVAL OF PHENOLIC COMPOUNDS FOR THE PRODUCTION OF HIGH-QUALITY CANOLA PROTEIN ISOLATES
}

By

\section{Lei Xu}

A thesis submitted in conformity with the requirements for the degree of DOCTOR OF PHILOSOPHY

Graduate Department of Chemical Engineering and Applied Chemistry University of Toronto

() Copyright by Lei Xu 1999 
National Library of Canada

Acquisitions and Bibliographic Services

395 Wellington Street Onawa ON KIA ONA Canada
Bibliothèque nationale du Canada

Acquisitions et services bibliographiques

395. rue Wellington Ottawa ON K1A ON4 Canada
The author has granted a nonexclusive licence allowing the National Library of Canada to reproduce, loan, distribute or sell copies of this thesis in microform, paper or electronic formats.

The author retains ownership of the copyright in this thesis. Neither the thesis nor substantial extracts from it may be printed or otherwise reproduced without the author's permission.
L'auteur a accordé une licence non exclusive permettant à la Bibliothèque nationale du Canada de reproduire, prêter, distribuer ou vendre des copies de cette thèse sous la forme de microfiche/film, de reproduction sur papier ou sur format électronique.

L'auteur conserve la propriété du droit d'auteur qui protège cette thèse. $\mathrm{Ni}$ la thèse ni des extraits substantiels de celle-ci ne doivent être imprimés ou autrement reproduits sans son autorisation. 


\title{
THE REMOVAL OF PHENOLIC COMPOUNDS FOR THE PRODUCTION OF HIGH-QUALITY CANOLA PROTEIN ISOLATES
}

\author{
Lei Xu \\ Ph.D. 1999 \\ Department of Chemical Engineering and Applied Chemistry \\ University of Toronto
}

\begin{abstract}
A BSTRACT
A membrane-based protein isolation process was originally developed to produce two protein isolates from defatted canola meal. Both products had high protein content while low in phytates and essentially free of glucosinolates, thus representing a potential source of food-grade protein. As phenolic compounds present in canola bind to the proteins, and cause the dark colour and undesirable taste of these protein products or their aqueous solutions, the interactions between phenolic compounds and canola proteins were investigated using a series of chemical treatments in combination with membrane processing to break phenolicprotein complexes and separate the phenolics from the proteins. Approximately $50 \%$ of the phenolic compounds extractable in aqueous media was thus identified to be bound to canola protein by different mechanisms: ionic bonding, hydrophobic interactions, hydrogen bonding, and covalent bonding. Based on the study of phenolic-protein interactions, a variety of treatments was tested for the removal of phenolic compounds from canola protein. The combined use of these treatments was able to reduce the phenolic contents in the products by $80-90 \%$. The original protein isolation process was then modified with the treatments to remove phenolics. The modified process produced two high-quality canola protein isolates, both of high protein content $(>85 \%)$, low in phenolic acids $(-200 \mathrm{mg} / 100 \mathrm{~g})$, and essentially free of tannins, and the removal of phenolic compounds improved the colour and taste of
\end{abstract}


canola protein isolates. Also, as a necessary tool in this study, a new analytical method was developed for the determination of total phenolic acid content in canola protein products, giving accurate quantification in a reasonable time. 


\section{ACKNOWLEDGEMENT}

My thesis supervisor, Professor L. L. Diosady deserves my utmost gratitude for it would have been impossible for me to carry out this program without his guidance, support, encouragement, and above all, his faith in my capability of pursuing a Ph.D. degree. To me he has been and will always be a great mentor. I am also very grateful to the other two members of my reading committee, Professors M. J. Phillips and D. G. B. Boocock, who gave much valuable advise and many constructive suggestions throughout the program. All the members on my oral defense committee have obliged me with their important input to my thesis, among whom are Professor M. Naczk from St. Francis Xavier University, Professor E. Edwards, Dr. T. Khow, and Professor A. V. Rao from Department of Nutritional Science.

I appreciate Dr. L. Endrenyi from Department of Pharmacology and Professor C. E. Chaffey very much for their help in statistics. Dr. Yu-Ming Li from Department of Nutritional Science and Ramin Ganjavi, a fourth year student made their special contributions to my thesis, hence my sincere thanks to them.

Finally, I must say thank you so much to my colleagues in Food Engineering Group, who have spent days and nights working side by side with me, and shared with me countless moments of frustration, success, sadness, and joy, and whose help, understanding, comfort and moral support were indispensable to the completion of my program. Among them are Joseph Alberti, Francesca Apruzzese, Joaquin Caviedes, Bih-King Chen, Flora Lui, Haoqun Luo, Sonia Pittioni, Taya Puzanov, Kavita Ramcharan, and Thomas Varga. These wonderful people were once part of life, and shall remain in my memory forever. I wish them well wherever they are. 


\section{TABLE OF CONTENT}

ABSTRACT i

ACKNOWLEDGEMENT iii

TABLE OF CONTENT IV

LIST OF TABLES viii

LIST OF FIGURES $\quad$ ix

1. INTRODUCTION I

1.1. Objective of Study 5

2. LITERATURE REVIEW 6

2. 1. Rapeseed and Its Utilization 6

2.2. Rapeseed Protein and Its Isolation 10

2.2.1. Rapeseed protein characterization 10

2.2.2. Rapeseed protein isolation: extraction and precipitation II

2.3. Phenolic Compounds 15

$\begin{array}{ll}2.3 .1 . \text { Occurrence and classification } & 16\end{array}$

$\begin{array}{ll}2.3 .1 .1 . & \text { Phenolic acids } \\ & 17\end{array}$

2.3.1.2. Flavonoids 20

2.3.1.3. Tannins 22

2.3.2. Interactions between phenolic compounds and proteins 22

2.3.2.1. Hydrogen bonding $\quad 24$

2.3.2.2. Ionic bonding 25

2.3.2.3. Hydrophobic interactions 27

2.3.2.4. Covalent bonding $\quad 30$

2.3.3. Effects of phenolic compounds on food quality 32

2.3.3.1. Organoleptic effects 32

2.3.3.2. Nutritional implications 33

2.3.4. Removal of phenolic compounds from oilseed proteins 34

2.3.4.1. Organic solvents and dilute alkali or acids 34

2.3.4.2. Other treatments 36

2.3.5. Effects of reducing or oxidizing agents on phenolic compounds 38 and colour of oilseed proteins 
2.3.6. Analytical methods for determination of phenolic compounds 39 in rapeseed/canola

2.3.6.1. Total phenolic acids 39

2.3.6.2. Condensed tannins 40

2.4. Membrane Processing 43

2.4.1. Introduction 43

2.4.2. Ultrafiltration 47

2.4.3. Diafiltration 50

2.4.4. Production of rapeseed/canola protein isolates by 52 membrane processing

2.5. Colour Measurement 55

2.6. Sensory Evaluation 57

3. EXPERIMENTAL METHODS 60

3.1. Analytical Methods 60

3.1.1. Development of a rapid method for total phenolic acid 60 determination in rapeseed/canola meals

3.1.2. Validation of the analytical method for condensed 63 tannin determination

3.2. Study of Interactions between Canola Protein and 64 Phenolic Compounds

3.2. 1. Extractability of phenolic compounds from canola meal 64

3.2.2. Membrane processing unit 64

3.2.3. Determination of rejection coefficients of phenolic 65 compounds for membrane processing

3.2.4. Fractionation of phenolic compounds in alkaline extract 66 and acidic solution of canola protein

3.3. Process Development for Production of High-Quality Canola 69

Protein by Removing Phenolic Compounds

3.3.1. Removal of phenolic compounds by treatments 69 prior to isoelectric precipitation

3.3.2. Treatment with reduced amount of SDS and elimination 71 of the second diafiltration

3.3.3. Study of the effects of PVP on removal of phenolic acids 72

3.3.4. Study of the effects of $\mathrm{Na}_{2} \mathrm{SO}_{3}$ on removal of phenolic acids 74 
3.3.5. The further modified process to produce high-quality canola protein isolates by removing phenolic compounds

3.4. Colorimetric and Sensory Characterization of the Final Products

3.4.1. Colour measurement

3.4.2 Sensory evaluation $\quad 78$

3.5. Chemical Analyses $\quad 79$

4. RESULTS AND DISCUSSION 81

4.1 Analytical Methods 81

4.1.1. Development of a rapid method for total phenolic acid 81 determination in rapeseed/canola meals

4.1.2. Validation of the analytical method for condensed 85 tannins determination

4.2. Study of Ineractions between Canola Protein and 89 Phenolic Compounds

4.2.1. Extractability of phenolic compounds from canola meal 89

4.2.2. Rejection coefficients of phenolic compounds 92

4.2.3. Fractionation of phenolic compounds in alkaline extract 95 and acidic solution of canola protein

4.3. Process Development for Production of High-Quality Canola 102

Protein by Removing Phenolic Compounds

4.3.1. Removal of phenolic compounds by treatments in combination $\quad 102$ with diafiltration prior to isoelectric precipitation

4.3.2. Modification of SDS treatment and elimination 109 of the second diafiltration

4.3.3. Effects of PVP on the removal of phenolic acids 112

4.3.4. Effects of $\mathrm{Na}_{2} \mathrm{SO}_{3}$ on the removal of phenolic acids 115

$\begin{array}{ll}\text { 4.3.5. The further modified process to remove phenolic compounds } & 118\end{array}$ for production of high-quality canola protein isolates

4.4. Colorimetric and Sensory Evaluation 125

4.4.1. Colour measurement 125

$\begin{array}{ll}\text { 4.4.2. Sensory evaluation } & 129\end{array}$

4.5. Economic Assessment 136

5. CONCLUSIONS 140 
6. RECOMMENDATIONS 143

7. REFERENCES 145

8. APPENDICES 156

8.1. Determination of Protein (Kjeldahl Method) 156

8.2. Determination of Sodium Dodecyl Sulphate (SDS) Content 158

8.3. Statistical Analyses 159

8.3.1. Determination of phenolic acids using $\quad 159$ different methods

8.3.2. Effects of the treatments on composition of the products 161

8.3.3. Effects of reduced SDS amount and elimination of second $\quad 164$ diafiltration on composition of the products

$\begin{array}{ll}\text { 8.3.4. Effects of PVP on removal of phenolic acids } & 167\end{array}$

8.3.5. Effects of $\mathrm{Na}_{2} \mathrm{SO}_{3}$ on removal of phenolic acids 168

$\begin{array}{ll}\text { 8.3.6. Comparison in composition of the products from } & 169\end{array}$ different modified processes

8.3.7. Comparison between 10\% and 1\% PVP treatment on SPI 171

$\begin{array}{ll}\text { 8.3.8. Sensory evaluation } & 172\end{array}$ 


\section{LIST OF TABLES}

Table 1. Total phenolic acid content in canola determined by the new method (expressed as $\mathrm{mg}$ sinapic acid equivalent/100 $\mathrm{g}$ defatted meal)

Table 2. Tests of the new method with samples spiked with sinapic acid or sinapine standards

Table 3. Effects of number of $70 \%$ acetone extractions on condensed tannin removal from Tower meal

Table 4. Catechin recovery with the analytical method for tannin determination by Shahidi and Naczk (1989)

Table 5. Mass and protein reoveries in the protein products

Table 6. Effects of the treatments on protein and phenolic contents

Table 7. Retention of phenolic acids and tannins in the products

Table 8. Effects of reduced SDS amount and elimination of second

Table 9. Protein and phenolic contents of the products from different

Table 10. Comparison between $10 \%$ and $1 \%$ PVP treatment on soluble protein isolate (SPI)

Table 11. Comparison of different modified processes in mass and protein recoveries

Table 12. Mass and protein distribution among major process streams of further modified process

Table 13. Colour measurement of precipitated protein isolates (PPI)

Table 14. Comparison of taste intensity of precipitated protein isolates (PPI)

Table 15. Comparison of taste pleasantness of precipitated protein isolates (PPI)

Table 16. Comparison of taste intensity of soluble protein isolates (SPI)

Table 17. Comparison in taste pleasantness of soluble protein isolates (SPI)

Table 18. Results of statistical analysis by ANOVA of taste intensity and pleasantness of canola protein isolates

Table 19. Turkey's mutiple comparison test for precipitated protein isolates (PPI)

Table 20. Turkey's mutiple comparison test for soluble protein isolates (SPI) 


\section{LIST OF FIGURES}

$\begin{array}{ll}\text { Figure 1. Structures of basic phenolic acids in rapeseed/canola } & 18\end{array}$

$\begin{array}{ll}\text { Figure 2. Sinapine and its hydrolytic cleavage products } & 19\end{array}$

$\begin{array}{ll}\text { Figure 3. Structure of basic flavonoids of oilseeds } & 21\end{array}$

Figure 4. Structure of a typical condensed tannin of oilseeds $\quad 23$

Figure 5. Electrostatic interaction between sinapine and protein at $\mathrm{pH}$ values 26 above the isoelectric point of the protein

Figure 6. Protein precipitation by tannins through hydrophobic interactions $\quad 28$

Figure 7. Covalent bonding of phenolic acid to protein 31

Figure 8. The analytical method of Naczk et al. (1992) for phenolic acid determination

Figure 9. The analytical method of Ismail and Eskin (1979) for 42 phenolic acid determination

Figure 10. Schematic representation of a cross-flow membrane process 45

Figure 11. Schematic representation of gel layer formation and 46 concentration in ultrafiltration

Figure 12. Schematic diagram of an ultrafiltration process $\quad 48$

Figure 13. Schematic diagram of a diafiltration process 51

Figure 14. Flowsheet for the membrane-based canola protein isolation $\quad 54$ process developed by Tzeng et al. (1990a)

Figure 15 . The $L$, a, b colours system reflecting three-dimensional 56 opponent-colour theory

Figure 16. A new analytical method for total phenolic acid determination of rapeseed/canola samples

Figure 17. Fractionation system of phenolic compounds in canola extract or solution

Figure 18. Processing scheme with treatments to remove phenolic compounds prior to protein isolation

Figure 19. Study of the effects of PVP on removal of phenolic acids 73

Figure 20. Study of the effects of $\mathrm{N}_{2} \mathrm{SO}_{3}$ on removal of phenolic acids 75

Figure 21. The further modified process to remove phenolic compounds 76 for the production of high-quality canola protein isolates

Figure 22. Extractability of protein, phenolic acids, and tannins of canola meal at different pH's 
Figure 23. Determination of rejection coefficients for phenolic acids and tannins

Figure 24. Fractionation of phenolic compounds in $\mathrm{pH} 12.0$ canola protein extract 97

Figure 25. Fractionation of phenolic compounds in $\mathrm{pH} 3.5$ canola protein solution 97

Figure 26. Comparison of ionically-bonded fraction of phenolic acids 99 with different concentrations of $\mathrm{NaCl}$

Figure 27. Effects of PVP on removal of phenolic acids in $\mathrm{pH} 12.0$ canola protein extract or $\mathrm{pH} 3.5$ solution

Figure 28. Effects of $\mathrm{N}_{2} \mathrm{SO}_{3}$ on covalently bonded phenolic acids

Figure 29. Spectra of solutions of soluble protein isolates (SPI)

Figure 30. Minimum cost evaluation of products 


\section{INTRODUCTION}

The term "canola" refers to the special rapeseed varieties developed in Canada, which were genetically improved to contain low levels of two undesirable components: erucic acid $(<2 \%)$ in oil and glucosinolates $(<30 \mu \mathrm{mol} / \mathrm{g})$ in the meal.

Canola is now widely grown in Canada, and used as a major source of edible oils in many countries. Similarly to conventional rapeseed varieties, the seeds contain about $40 \%$ oil and 17 to $26 \%$ protein. Thus, after oil extraction canola meal could contain up to $50 \%$ protein. Previous researchers reported a well-balanced amino acid composition for rapeseed/canola meal protein (Ohlson and Anjou. 1979; Sarwar et al., 1984; Delisle et al., 1984), indicating the great potential of canola as a source of food-grade protein. However, the presence of many undesired components, including glucosinolates, phytates, and hulls, poses serious problems for the utilization of canola meal as a protein source for human consumption, hence, currently the meal is only used in animal feed.

Among all the undesired constituents in canola meal, only glucosinolates are considered toxic because they can be readily hydrolyzed by an endogenous enzyme, myrosinase, to form toxic compounds such as thiocyanates, isothiocyanates, and nitriles. These hydrolysis products interfere with thyroid function, thus reducing the body growth (VanEtten et al., 1969). Clearly, they must be removed before canola protein can be consumed by human beings. A lot of research has been dedicated to the removal of glucosinolates from rapeseed/canola meals, mostly involving aqueous and/or alcohol processing (Tape et al., 1970; Sosulski et al., 1972; Ohlson, 1979; Jones and Holme, 1979; Maheshwari et al., 1981). 
Another meal component, phytic acid (present as phytates) is a strong chelating agent which affects the utilization of many trace metallic elements, especially zinc and iron by binding these ions to make them unavailable for metabolism (Cheryan, 1980). Most studies showed an inverse relationship between mineral absorption and phytate content. Therefore, in order for canola protein to be used in food it is desirable to reduce its phytate content to a level equal to or lower than the $1.5 \%$ present in soy protein isolate. The techniques for the removal of phytates have been well documented. These include selective separation of phytate-containing fractions by mechanical milling (Donnelly and Tabekhia, 1977), enzyme treatment by phytase (Kon et al., 1973; Chang et al., 1977), autoclaving at high temperatures (O'Dell, 1969), water extraction at defined $\mathrm{pH}$ values (Gillberg and Tomell, 1976; Goodnight et al., 1978), and addition of EDTA or some salts followed by further processing such as dialysis (Okubo et al., 1975; deRahm and Jost, 1979; Serraino and Thompson, 1984).

The hulls, accounting for approximately $30 \%$ weight of the oil-free meal, are mostly made of indigestible fibers, which may also be considered as antinutrients. Although various dehulling methods were studied to produce hull-free rapeseed/canola flours (Sosulski and Zadernowski, 1979; Diosady et al., 1983), the oil loss during dehulling made these processes uneconomical.

Despite the intensive research on processing techniques in the past, no commercially viable process has yet been developed to produce canola protein products, due to low recovery of protein, poor quality of products, or high cost of processing. Further research remains to be done to solve these problem before food-grade canola protein is available on the market. 
In the last decade, a unique membrane-based process was invented in our laboratories for canola protein isolation with defatted meals as the starting materials. It consisted of five main steps: alkaline extraction, isoelectric precipitation, ultrafiltration followed by diafiltration, and finally, drying (Tzeng et al., 1990a). This process was promising as it was able to produce two canola protein isolates: precipitated and soluble, both of high protein content $(>90 \%)$, low in phytates $(<1 \%)$, and essentially free of glucosinolates $(<2 \mu \mathrm{mol} / \mathrm{g})$. Many of their functional properties were comparable to those of soy protein (Igor et al., 1993; Xu and Diosady, 1994).

However, the studies also showed that, although both canola protein isolates had significant nutritional potential, the use of these products was prevented by their undesirable colour and taste. Both the precipitated protein isolate and the solution of the soluble protein isolate were dark in colour, and their unpleasant taste was easy to perceive. The literature attributes these organoleptic problems to the presence of a group of phenolic compounds in rapeseed/canola. Rapeseed contains about ten times the quantity of phenolic compounds found in soybean (Zadernowski and Kozlowska, 1983). They tend to bind to the seed protein through different mechanisms such as hydrogen bonding (Gustavson, 1956; Loomis and Battaile, 1966), covalent bonding (Mason, 1955), and hydrophobic interactions (Oh et al., 1980; Butler, 1989; Cai et al., 1990). They have a bitterness intensity similar to caffeine (Ismail et al., 1981), and may cause feed palatability problems (Blair and Reichert, 1984). They readily undergo enzymatic and non-enzymatic oxidation to produce quinones which can then react with protein, causing a dark colour in the final product (Blouin et al., 1982). Hence, they are responsible for the green and brown colours of the alkali-treated rapeseed protein products (Kozlowska et al., 1975; Keshavarz et al., 1977). In addition, phenolic 
compounds, as such, or their oxidized forms may interact with essential amino acids and other nutrients and render them unavailable for utilization (Ohlson and Anjou, 1979).

Since the use of the canola protein isolates depends on the significant improvement in their colour and taste, it is obvious that, like any other undesirable canola components, the phenolic compounds also must be removed or substantially reduced prior to the incorporation of these canola protein isolates into any food formulation. Numerous processes have been proposed for the removal of phenolic compounds from oilseed protein sources, including organic solvent systems (Fan et al., 1976; Sodini and Canella, 1977; Sripad and Rao, 1987; Prasad, 1990), dilute alkali or acids (Sosulski et al., 1973; McGregor et al. 1983; Shahidi and Naczk, 1989), reducing and or oxidizing agents (Gheysuddin et al., 1970; Keshavarz et al., 1977), activated carbon and ion exchange (Carey, 1966; How and Morr, 1982), and insoluble polyvinylpyrrolidone (Loomis and Battaile, 1966). All these methods seemed to suffer from such problems as incomplete removal, loss of protein, and use of expensive reagents.

While a large body of literature focuses on the phenolic compounds in sunflower and other oilseeds, the available knowledge on this subject for rapeseed/canola is fragmentary. 


\subsection{Objective of Study}

The objective of this study was to develop a technically viable process to remove phenolic sompounds from canola protein for the improvement of colour and taste of the protein isolates prepared by the current method (Tzeng et al., 1990a). In order to achieve this goal, it was essential to understand the interactions between canola protein and phenolic compounds, especially those in aqueous media since canola protein was processed mainly with water in this study. In spite of the scattered information on phenolic-protein complexing, little work had been done systematically with canola by previous researchers. Hence the behaviour of phenolic compounds in canola protein extracts had yet to be explored in an attempt to search for efficient means to break phenolic-canola protein complexes, so these compounds could be eventually removed by membrane processing during canola protein isolation. 


\section{LITERATURE REVIEW}

\subsection{Rapeseed and Its Utilization}

Rapeseed is one of the major oilseeds grown worldwide. Since $1987 / 1988$, it has been ranked third in the world production among all oilseeds, exceeded only by soybean and cottonseed. In the 1996/1997 crop year, the world production of rapeseed reached 30.97 million tonnes (ISTA, 1998). China, India, Canada, and EU are the main producers of rapeseed. China is by far the largest producer in 1996/1997 with a production of 9.20 million tonnes while Canada the largest exporter of rapeseed and rapeseed products (ISTA, 1998). Canada produced 5.06 million tonnes of rapeseed in the 1996/1997 crop year, about half of which, 2.52 million tonnes was exported to the foreign markets, along with 507,000 tonnes of rapeseed oil and 1.06 million tonnes of rapeseed meal. The total export of rapeseed and rapeseed products in that year was worth over a billion dollars (ISTA, 1998).

The rapeseed cultivars grown in Canada underwent significant changes in their composition during the 1960's and 1970's. The need for these changes came as a result of the extensive studies on the nutritional aspects of rapeseed. Erucic acid contained in rapeseed oil may cause heart, adrenal and ovarian tissue lesions in rats (Carroll and Noble, 1957; Beare et al., 1963). This led to the first development of low-erucic-acid rapeseed (LEAR) varieties that reduced encic acid content from about $40 \%$ to $5 \%$. These varieties were further improved by genetic manipulations to lower the content of glucosinolates, another undesired rapeseed component. Based on the close collaboration of Canadian researchers in the areas of plant breeding, nutrition, biochemistry and physiology, the first cultivar low in both erucic acid ( $<5 \%$ in oil) and glucosinolates $(<30 \mu \mathrm{mol} / \mathrm{g}$ meal) emerged, and was licensed in 1974 . In 1978, the rapeseed industry in Canada adopted the name "canola" to identify the "double- 
low" varieties of rapeseed (Vaisey-Genser and Eskin, 1987). At present, the erucic acid levels in canola are typically $1 \%$ or less.

Canola oil was granted GRAS (Generally Recognized As Safe) status by the U. S. Food and Drug Administration. The acceptance of canola oil as edible oil boosted exports of canola seed to the United States from only 300 to 271,600 tonnes between $1980 / 1981$ and 1995/1996 (Canola Council of Canada, 1998).

Canola oil is now generally considered as a nutritionally superior oil to most vegetable oils due to its high content of many desirable unsaturated fatty acids such as oleic, linoleic, and linolenic acid. Its consumption in Canada has been growing steadily, now accounting for over $60 \%$ of all edible vegetable oil products manufactured in Canada. Most of the oil produced today is used for salad dressings, cooking oils, margarine, and shortenings.

After the removal of oil from rapeseed/canola by prepressing and solvent extraction, a meal containing 34 to $40 \%$ protein can be obtained. Most of the canola meal produced in Canada is utilized as a supplement in livestock and poultry feeds (Canola Council of Canada, 1983). The rapeseed meal found less valuable use in some Asian countries, as a organic fertilizer simply because the varieties grown in Asia are conventional types of rapeseed which contain much higher levels of glucosinolates in their meals (over $100 \mu \mathrm{mol} / \mathrm{g}$ meal) than canola cultivars. So far canola has not been grown over there due to its low yield compared to that of rapeseed and its likely reversion to conventional varieties.

The potential value of rapeseed protein in the human diet was first reported in 1970's (Lo and Hill, 1971; Holmes, 1975; Beare-Rogers, 1978). It was found to have a wellbalanced amino acid composition (Sosulski and Sarwar, 1973; Ohlson and Anjou, 1979) 
which, unlike most vegetable proteins, was rich in lysine and methionine. Rapeseed protein also contained a relatively high percentage of other essential amino acids (Jones, 1977; Ohlson and Anjou, 1979) which made it even more favourable to human adults than the WHO/FAO recommended pattern of essential amino acids (WHO/FAO, 1985). Sarwar et al. (1984) indicated that, in terms of nutritional quality, rapeseed is comparable to casein and superior to other vegetable proteins.

Since rapeseed is so widely available, it is essential for the future of the industry to utilize rapeseed protein as a food ingredient to compete with the well-established protein products based on soybean. As indicated earlier, the direct use of rapeseed meal as a protein source is prevented by its significant contents of glucosinolates, phytates, phenolics, and fibres. These are either toxic compounds or have antinutritional effects. Therefore, before any rapeseed protein product can be incorporated into food, these undesirable meal components must be removed or substantially reduced. In the last three decades, a tremendous amount of research has been conducted to deal with these components for upgrading the meal. Glucosinolates among all of them received particular attention from the researchers because of the toxicity of their hydrolysis products, thiocyanates, isothiocyanates, and nitriles. All processes developed to produce high-quality rapeseed meals were based on various glucosinolate-removing techniques.

The hydrolysis of glucosinolates is catalyzed by an endogenous enzyme, myrosinase. The inactivation of myrosinase can hinder the hydrolysis process, hence reducing the toxicity of the meal. Myrosinase is inactivated most commonly by heat treatment (Maheshwari et al., 1981). The inactivation may also be achieved by alcohol (Bhatty and Sosulski, 1972). Water was reported to be an effective solvent for glucosinolates extraction. Sosulski et al. (1972) 
described a diffusion extraction method for whole rapeseed in which the seed coat acted as a semipermeable membrane, allowing low-molecular-weight compounds such as glucosinolates out of the seed while retaining the proteins. In 1970's, two similar aqueous processes were developed at Agriculture Canada's Food Research Institute (Tape et al., 1970) and by the Karlshamns Company in cooperation with Alfa-Laval in Sweden (Ohlson, 1979). In both processes myrosinase in cracked rapeseed meal was inactivated with boiling water (Tape et al., 1970) or dry heat (Ohlson, 1979). Glucosinolates were then removed by water extraction, and the detoxified meal was dried to obtain a pale yellow product. Food Research Institute of Agriculture Canada also developed another process in which dehulled and defatted seed was ground and detoxified by repetitive washing with isopropanol-water mixtures. These processes, however, were not viable due to large protein losses.

In 1980's, the researchers in our laboratories invented a unique rapeseed processing system called "two-phase solvent extraction". In the method the seed was slurry ground with methanol containing ammonia and water, then extracted with hexane (Rubin et al., 1984 and 1986; Diosady et al., 1987). After solvent recovery and meal drying, an edible oil and a meal essentially free of glucosinolates $(<2.2 \mu \mathrm{mol} / \mathrm{g})$ were obtained. Although the meal thus produced on bench top still contained some residual oil, on a semi-pilot-plant scale using a Karr extraction column the meal was almost oil free. This process was effective with various canola cultivars, and the tests on a typical Chinese rapeseed variety, Nin-you 7 also proved successful (Liu et al., 1994). Like all conventional varieties, Chinese rapeseed has high glucosinolate contents ( $>100 \mu \mathrm{mol} / \mathrm{g}$ meal $)$.

Even though a variety of processing techniques has been developed in an attempt to make rapeseed meal a protein source for human consumption, no process is being 
commercially practiced at present due to problems with the cost, product quality, protein recovery, etc.. Consequently, rapeseed meals are still utilized as fertilizers and animal feed.

\subsection{Rapeseed Protein and Its Isolation}

\subsubsection{Rapeseed protein characterization}

The rapeseed proteins can, in the same way as any other seed protein, be considered to have a structural function (membrane components), a catalytic function (membrane-bound or free enzymes), and/or a 'storage' function (protein bodies). In view of the small amounts of enzyme protein generally involved in enzymatic reactions, it has been shown that the major portion of the rapeseed proteins represent storage proteins with no enzymatic activity (Appelquist, 1972).

The great complexity of the solutions of rapeseed proteins was noted in studies on the albumins and globulins of different rapeseed species using acrylamide electrophoresis in conjunction with serological techniques, dye binding, and other protein analytical methods (Appelquist, 1972). In attempts to isolate pure proteins from rapeseed, a group of Canadian researchers (Bhatty et al., 1968) used combinations of gel filtration and ion exchange chromatography to achieve the isolation of a basic protein (name A-IV-S) with a molecular weight of about 14,000 . They also identified another major component which had a rather larger molecular weight with a sedimentation coefficient of 12S, which appeared homogeneous in alkaline solution, but dissociated into two subunits of $3 S$ and $7.2 S$, respectively in acidic conditions. This component was denoted B-I. It was salt-soluble, but precipitated upon dialysis against distilled water, and is thus a globulin according to classical nomenclature. The B-I protein made up about $35 \%$ of the rapeseed proteins whereas in 
soybean proteins there was also a globulin with similar characteristics accounting for approximately $65 \%$ of the protein mass. These two fractions, B-I and A-IV-S were isolated from various cultivars of rapeseed (Finlayson et al., 1969), and yet significant differences were observed in their content and amino acid composition among different cultivars.

In the work by Swedish researchers, the presence of a great number of proteins has been demonstrated in aqueous and alkaline extracts of rapeseed protein using molecular sieve chromatography (Lonnnerdal et al., 1977), among which were about 20 weakly acidic proteins, 20 or so neutral proteins, and 5 basic proteins. The basic proteins accounted for about $20 \%$ of the total and had molecular weights in the range $15-20,000$. Only approximately $5 \%$ of the total soluble proteins had molecular weights of $50-75,000$, and a major portion had molecular weights from 120,000 to 150,000 .

\subsection{Rapeseed protein isolation: extraction and precipitation}

Protein isolates are defined either as the products obtained by extraction, purification, and recovery of proteins or as the products containing $90 \%+$ protein. Since rapeseed meals, as mentioned earlier, contain up to only $50 \%$ protein and have high levels of undesired components if not properly treated, a favourable alternative to the treatment of the meal would be the production of rapeseed protein isolates which are high in protein, low in antinutrients, and free of toxic compounds. Thus, a variety of methods developed to isolate rapeseed protein has been investigated extensively with meals, flours or even concentrates as starting materials. Most of these methods involved the extraction and precipitation of rapeseed protein. 
For rapeseed protein extraction, dilute alkali has been used effectively as protein solvent. Sosulski and Bakal (1969) tested the nitrogen solubility of rapeseed meal with different extractants, using a two-stage operation at a solvent-to-meal ratio of 12.5:1. The extraction with $0.2 \% \mathrm{NaOH}$ gave a nitrogen solubility of approximately $85 \%$. Girault (1973) obtained about $90 \%$ nitrogen solubility by extracting with $0.1 \mathrm{~N} \mathrm{NaOH}$. Similar results were reported by Finlayson et al. (1976). Gillberg and Tornell (1976) also asserted that a nitrogen solubility of over $90 \%$ was obtainable by running the extraction at $\mathrm{pH} 11$.l. El Nockrashy et al. (1977) used a four-stage countercurrent alkaline extraction process for rapeseed protein isolation and achieved a $94 \%$ nitrogen extractability. On scale-up a modified process was able to extract $92 \%$ of nitrogen in the meal (Blaicher et al., 1983), in which the extraction was conducted at $\mathrm{pH} 9.5$ and $\mathrm{pH} 12.0$ in two consecutive stages.

Sodium chloride solution was also one of the common solvents used by previous researchers to carry out the extraction. Smith et al. (1959) conducted rapeseed protein extraction experiments with a variety of solvents to compare nitrogen solubility. Maximum extractability, $68.8 \%$, was attained with $0.6 \mathrm{~N} \mathrm{NaCl}$. Bhatty et al. (1968) extracted rapeseed protein with $10 \% \mathrm{NaCl}$ at a ratio of $30: 1$ in a three-stage operation and reported a total nitrogen solubility of $67.0 \%$. Over $80 \%$ nitrogen solubility was achieved with $10 \% \mathrm{NaCl}$ and a ratio of $30: 1$ by Lo and Hill (1971). Owen (1973) extracted only $53 \%$ of the nitrogen in the meal with $1 \mathrm{~N} \mathrm{NaCl}$ and a solvent-to-meal ratio of 10:1. Siy and Talbot (1981) dissolved 75\% of the nitrogen in the rapeseed with $10 \% \mathrm{NaCl}$ at a ratio of $50: 1$. Finnigan and Lewis (1985) showed a low nitrogen extractability of their rapeseed meal $(57 \%)$ using $0.2 \mathrm{~N} \mathrm{NaCl}$ and a ratio of 20:1. They also reported a very little increase in nitrogen solubility as a result of the increase in $\mathrm{NaCl}$ concentration. 
The use of sodium hexametaphosphate (SHMP) to extract rapeseed protein has been reported although it is a complexing agent. Thompson et al. (1976) demonstrated a doublestage process for protein extraction from rapeseed flour with $2 \%$ SHMP solution at $\mathrm{pH} 7.0$. The flour was first extracted at a solvent-to-meal ratio of 10:1, then 6:1. After these two extractions, a nitrogen extractability as high as $97 \%$ was achieved. The process was modified and scaled up by the same group of researchers to produce a product with a protein recovery of $65 \%$ (Thompson et al., 1982).

As shown by the above studies, even with the same extraction reagent there could be a great variability in rapeseed protein solubility among different researchers. This was probably associated with the different processing treatments applied to produce the rapeseed meals in each case such as heat treatment during cooking and desolventizing. Gillberg and Tornell (1976) revealed that rapeseed meal prepared without heat treatment has a greater quantity of soluble protein than the meal from seed heated in a rotating drum at $90^{\circ} \mathrm{C}$ to inactivate myrosinase. Finnigan and Lewis (1985) have noted similar phenomena with heated commercial meal. Researchers in our laboratories (Tzeng et al., 1990a) applied the alkaline extraction conditions to the methanol/ammonia/water/hexane-extracted rapeseed meal and found the nitrogen solubility was about $50 \%$ lower than that of low-heat hexane-defatted meal. This decrease could be attributed to protein denaturation. In addition to the effects of the treatments on the meals, varietal differences of rapeseed may also contribute to this variability in protein solubility.

Upon extraction, recovery of rapeseed protein from the extraction solutions was most commonly accomplished by isoelectric precipitation. The precipitate, which was usually washed and dried, constituted the protein isolate. The earliest report by Pokorny et al. (1963) 
indicated that dissolved rapeseed protein was precipitated around $\mathrm{pH} 6.0$, with a protein recovery of $49 \%$. Sosulski and Bakal (1969) isoelectrically precipitated rapeseed protein at 4.5 with a low yield of about $40 \%$. pH 2.5 was found to be suitable to precipitate the protein extracted from commercial meal (Owen et al., 1971). Girault (1973) used pH 6.5 to isolate the rapeseed protein dissolved in $0.1 \mathrm{~N} \mathrm{NaOH}$ solution as aforementioned, resulting in a protein recovery of $56 \%$. The variations of the isoelectric points and protein recovery of the precipitation were believed to be due to the differences in protein composition among rapeseed varieties. The highest protein recovery ever reported for a single isoelectric precipitation, 65.7\%, was achieved at pH 3.6 (El Nockrashy et al., 1977). Sometimes heat coagulation was applied to aid isoelectric precipitation (Thompson, 1977), but it did not increase the protein recovery significantly.

As shown above, isoelectric precipitation gave rather low protein yields. This may be the consequence of a very complicated protein composition in rapeseed with widely spread out isoelectric points (Gillberg and Tornell, 1976). Accordingly, some researchers have studied multi-isoelectric precipitation. Yield was increased by successive precipitations at different $\mathrm{pH}$ values. Kodagoda et al. (1973) used $\mathrm{pH} 2.6,3.8$, and 4.2 as isoelectric points to precipitate rapeseed protein extracted at $\mathrm{pH} 5.7,2.0$, and 10.0, respectively, resulting in three protein products containing $72.5,73.5$, and $73.9 \%$ crude protein with a total protein recovery of $59.1 \%$ of the meal protein. In similar work by Keshavarz et al. (1977), a meal was first extracted at $\mathrm{pH} 8.0,2.0$, and 10.0, and the proteins dissolved at these three $\mathrm{pHs}$ were then precipitated at $\mathrm{pH} 2.6,3.8$, and 7.0 , respectively. A combined protein yield of $62.3 \%$ was obtained with a protein isolate of over $90 \%$ crude protein, which was precipitated at $\mathrm{pH} 7.0$ from $\mathrm{pH} 10.0$ extract. 
Gillberg and Tornell (1976) also examined the feasibility of increasing the yield by carrying out precipitation in two successive steps. The first step precipitated $45 \%$ of the dissolved protein at $\mathrm{pH}$ 6.6. The maximum recovery in the second precipitation was found to occur around $\mathrm{pH} 3.5$, amounting to approximately $18 \%$ of the total dissolved protein. This was equivalent to a theoretical total yield of $63 \%$ based on the original solution. The rapeseed protein extracted using the four-stage countercurrent extraction process developed by El Nockrashy et al. (1977) was also consecutively precipitated by a two-step procedure at pH 6.0 and 3.6 , respectively. As much as $72 \%$ of the meal protein was recovered in the resulting protein isolates which had a crude protein content of over $90 \%$ and were free of glucosinolates. This process was scaled up and modified by Blaicher et al. (1983). Similar results for protein contents and recoveries were obtained with the scaled-up process, but very high phytic acid contents of 9.8 and $4.3 \%$ in the protein isolates were also experienced. They thus introduced a procedure involving acidic extraction of phytates from rapeseed meal at $\mathrm{pH}$ 4.0 prior to countercurrent extraction of the protein at $\mathrm{pH} 11.0$, which indeed lowered the phytic acid contents in the protein isolates although the protein yield was thereby considerably reduced (Blaicher et al., 1983).

\subsection{Phenolic Compounds}

As mentioned earlier, in search of new proteins for human consumption rapeseed meal and its derivative products such as rapeseed flour, protein concentrates and isolates are considered as potential sources for food-grade protein. However, the application of these products in human diet is prevented by their high levels of the undesired components, among which both glucosinolates and phytates, including their removal from rapeseed protein, have 
been well documented. Another major antinutritional component, phenolic compounds received much less attention although extensive research on this group of compounds was done with some other crops such as sunflowerseed, soybean, and sorghum. Phenolic compounds are known to be responsible for the dark colour and unpleasant taste of commercially processed rapeseed meals (Shahidi, 1992). They also cause the dark greenish or brownish colour of the aqueous protein extracts from rapeseed meals (Keshavarz et al., 1977). In addition, phenolic compounds, as such or in their oxidized forms may interact with essential amino acids and other nutrients in the meal and render them unavailable for utilization (OhIson and Anjou, 1979). It is obvious that, like other undesired rapeseed components, they must be removed prior to the incorporation of rapeseed protein products into human food formulations.

\subsubsection{Occurrence and classification}

The term 'phenolic compounds' can be defined chemically as substances which possess aromatic rings bearing one or more hydroxyl substitutes, including functional derivatives such as esters and glycosides. Phenolic compounds are actually widely distributed in plant parts from the roots to the seeds. Some of them are essential secondary metabolites, others have complex structures and unknown functions and may be unique to a particular plant family or genera. In rapeseed and other oilseeds, numerous phenolic compounds have been identified. they usually occur as phenolic acids, tannins, and flavonoids. 


\subsubsection{Phenolic acids}

Phenolic acids of oilseeds are hydroxylated derivatives of benzoic or cinnamic acids possessing $C_{6}-C_{1}$ or $C_{6}-C_{3}$ configurations respectively (Figure 1). They may exist in the free, esterified and insoluble bound forms, as defined by Krygier et al.(1982a, b), and can be isolated by methanol/acetone/water and alkaline hydrolysis. In rapeseed/canola the total contents of phenolic acids of various cultivars were reported to be in the range from 1300 to $1800 \mathrm{mg} / 100 \mathrm{~g}$ defatted meal, on a dry basis (Shahidi, 1992).

The free fraction constitutes $3-16 \%$ of the total phenolic acid content in rapeseed/canola meals (Krygier et al., 1982a, b; Naczk et al., 1992). Although this fraction only represents a small part of the total phenolic acids, it is believed that it makes a major contribution to the taste of meals and flours (Kozlowska et al., 1990). Numerous free phenolic acids have been identified in rapeseed, with sinapic acid being the predominant component (Krygier et al., 1982a, b). It comprises up to $91 \%$ of the free phenolic acids. Other phenolic acids found in this fraction include vanillic, gentistic, protocatechuic, syringic, $p$-coumaric, cis- and trans-ferulic, $p$-hydroxybenzoic, and caffeic acids (Krygier et al., 1982b). Chlorogenic acid is found only in trace quantities in rapeseed meals while it is the principal colour-forming phenolic compound in sunflowerseed (Milic et al., 1968).

Esterified phenolic acids account for up to $80 \%$ of the total phenolic acids present in rapeseed meals (Krygier et al., 1982b). The major component of this fraction is sinapine, the choline ester of sinapic acid (Figure 2). Tzagoloff (1963) provided evidence that sinapine is hydrolyzed to choline and sinapic acid during the germination of mustard seedling. While choline is an important metabolite in the methylation cycle, sinapic acid is required for the biosynthesis of lignin and flavonoids (Shahidi, 1992). Those minor phenolic acids found in 
Figure 1. Structures of basic phenolic acids in rapeseed/canola

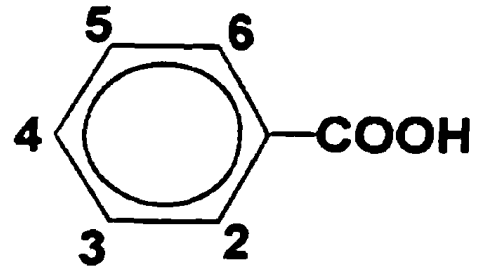

Benzoic acid

p-Hydroxybenzoic acid: 4-OH

Vanillic acid: 4-OH, 3- $-\mathrm{OCH}_{3}$

Syringic acid: 4-OH, 3,5- $\mathrm{diOCH}_{3}$

Gallic acid: 3,4,5-triOCH

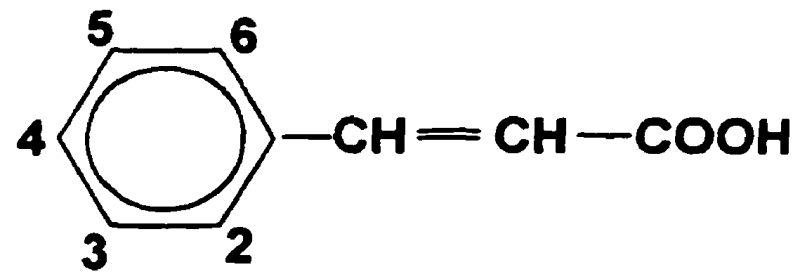

Cinnamic acid

Coumaric acid: $4-\mathrm{OH}$

Caffeic acid: 3,4-diOH

Ferulic acid: 4-OH, 3- $-\mathrm{OCH}_{3}$

Sinapic acid: 4-OH, 3,5-diOCH

Chlorogenic acid: 3,4-diOH,

(Caffeic acid ester with quinic acid) 
Figure 2. Sinapine and its hydrolytic cleavage products

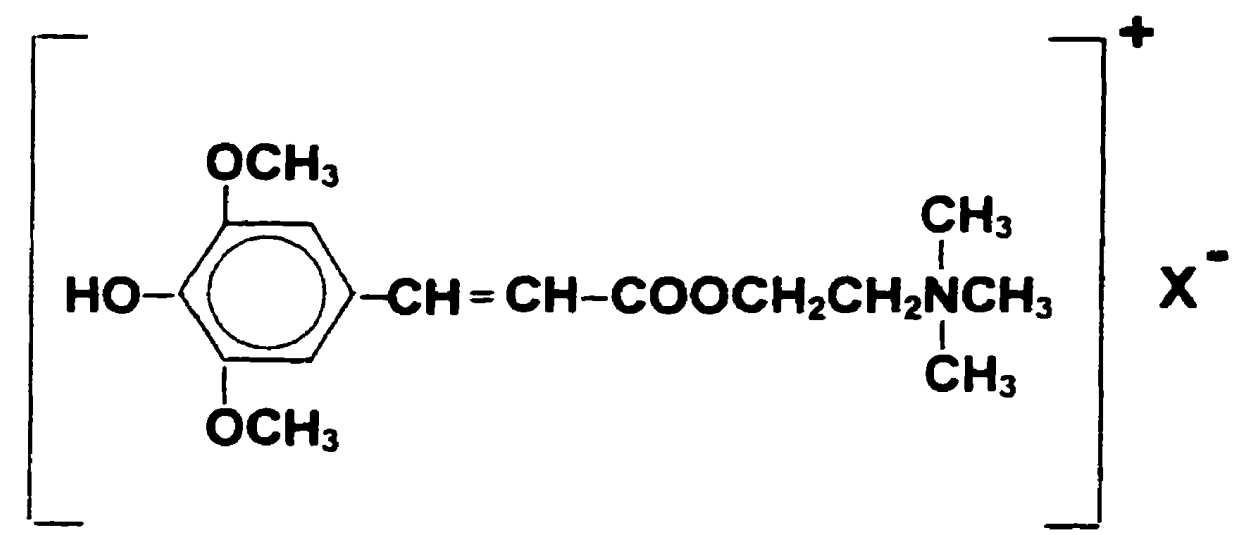

Sinapine

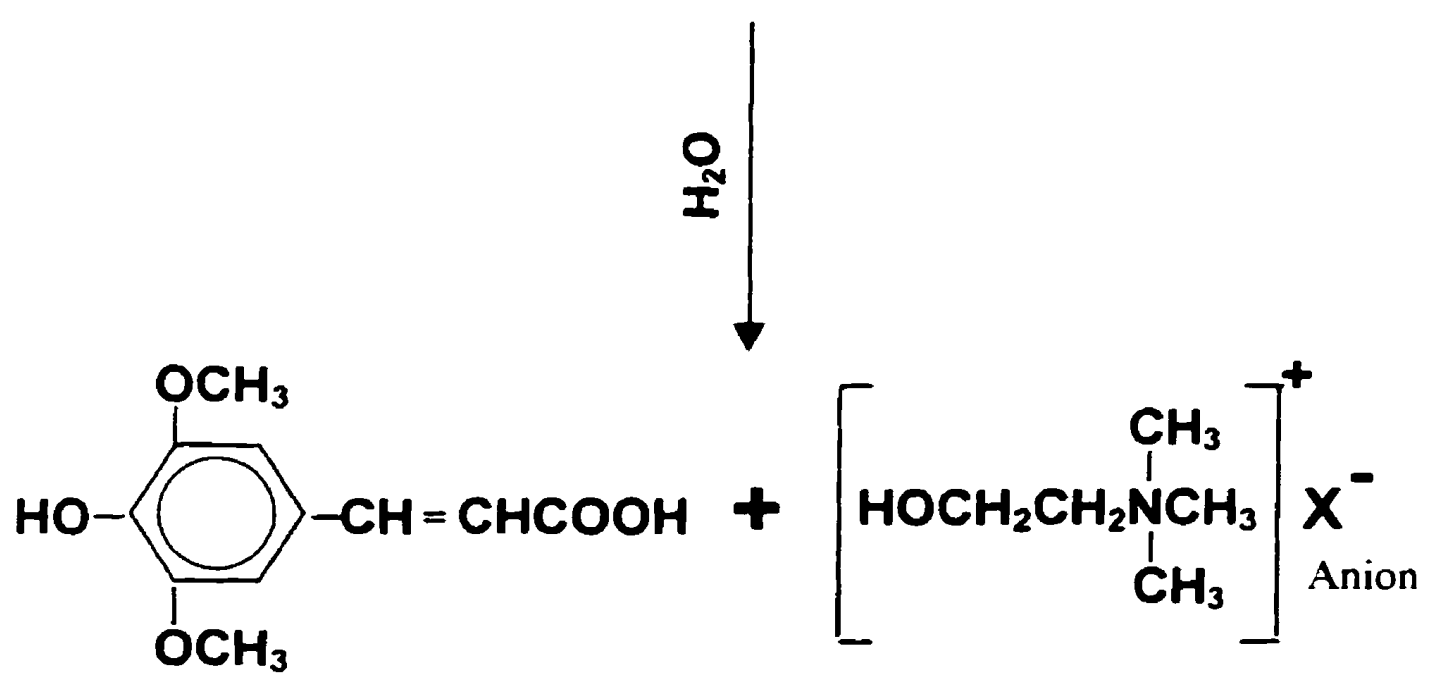

Sinapic acid

Choline 
the free form were also identified in the soluble ester form in small amounts (Kozlowska et al., 1983).

Most of the phenolic acids were found in the free or esterified form in rapeseed/canola meals. The relative levels of phenolic acids released by hydrolysis of the meal residues are quite low. These insoluble acids are presumably bound to proteins or carbohydrates and could be released during subsequent processing or cooking to contribute adverse flavours or colours to food products. Kozlowska et al. (1983) reported that the contribution of insoluble-bound phenolic acids ranged from $0.6-1.3 \%$ of the total content. Krygier et al. (1982b), on the other hand, failed to detect any insoluble phenolic acids bound to rapeseed meals. According to Kozlowska et al. (1983), sinapic acid was again the principal phenolic acid bound in rapeseed while other phenolic acids such as hydroxybenzoic, vanillic, protocatechuic, and caffeic acids were also found.

\subsubsection{Flavonoids}

The flavonoids are a group of plant phenolic compounds having the $C_{6}-C_{3}-C_{6}$ structure in common (Figure 3), among which are flavones, flavonols, flavanols, anthocyanidins, chalcones, aurones, etc.. They differ primarily in the $C_{3}$ group. Of these compounds the flavonols are by far the most common: quercetin and kaempferol are widely distributed in oilseeds (Sosulski, 1979). The flavonoids tend to show great reactivity through polymerization into "condensed tannins", therefore, in rapeseed most of these compounds exist in the forms of their polymers. 


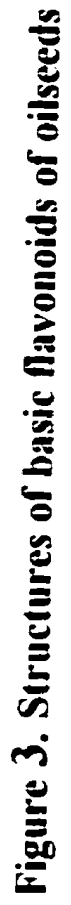
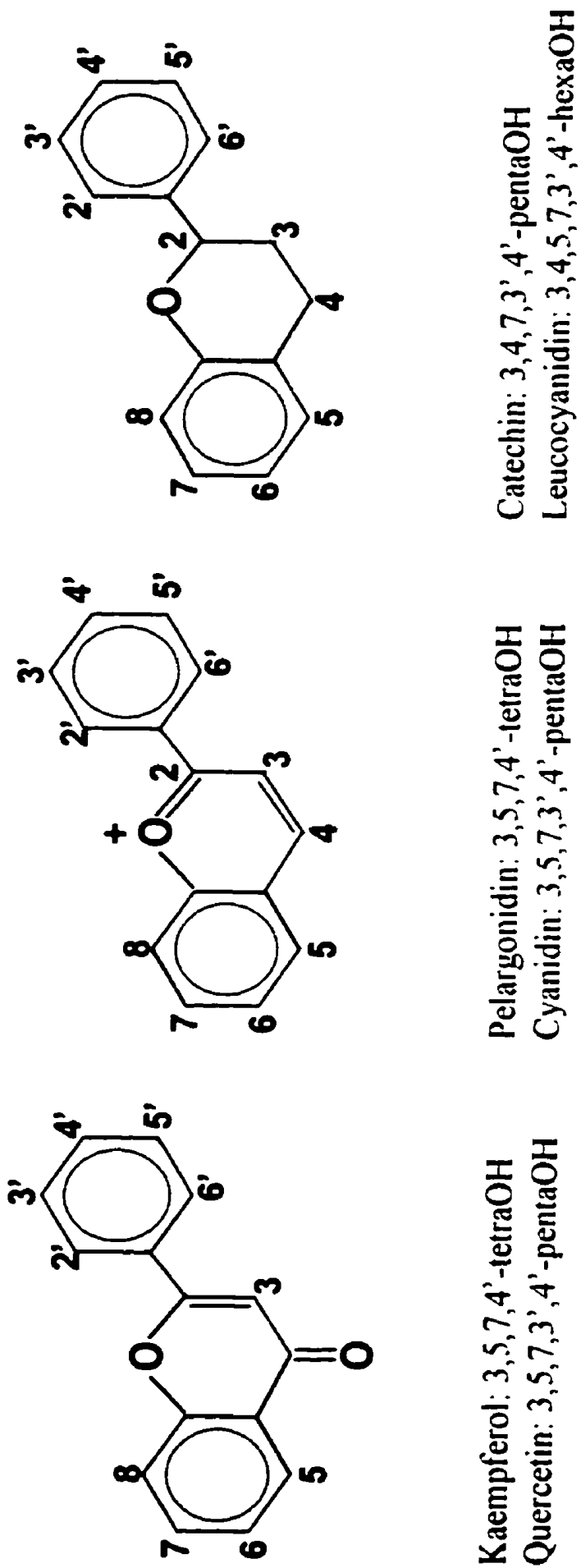


\subsubsection{Tannins in rapeseed/canola}

The term "tannin" is used loosely to describe a diverse group of plant phenolics which are unified by a single common property: the ability to precipitate protein from aqueous solution. They are formed by polymerization of low molecular weight phenolics. Molecular weights as high as 20,000 have been reported for some condensed tannins (Williams et al., 1983).

Tannins are divided into two major classes: condensed tannins, which are flavonoidbased polymers (Figure 4); and hydrolyzable tannins, which are polygalloyl esters. Condensed tannins do not undergo hydrolysis in acid or base. However, in hot alcohol they can be oxidatively cleaved to yield coloured anthocyanidins. The hydrolyzable tannins, on the other hand, can be hydrolyzed in acid or base or by esterase to produce the parent polyols and the phenolic acids (Shahidi, 1992).

Different levels of condensed tannins in rapeseed were reported (Leung et al., 1979; Mitaru et al., 1982; Blair and Reichert, 1984). Shahidi and Naczk (1989) found 0.68-0.72\% condensed tannins in defatted canola meals.

\subsubsection{Interactions between phenolic compounds and proteins}

The phenolic compounds in oilseeds tend to bind to the proteins through different interactions. While making these compounds antinutrients that reduce the protein utilizability, the binding also makes their removal from the meal complicated. Basically four types of interactions were identified between phenolic compounds and proteins in the meals or their aqueous extracts: hydrogen, ionic (electrostatic), and covalent bonding, and 
Figure 4. Structure of a typical condensed tannin of oilseeds

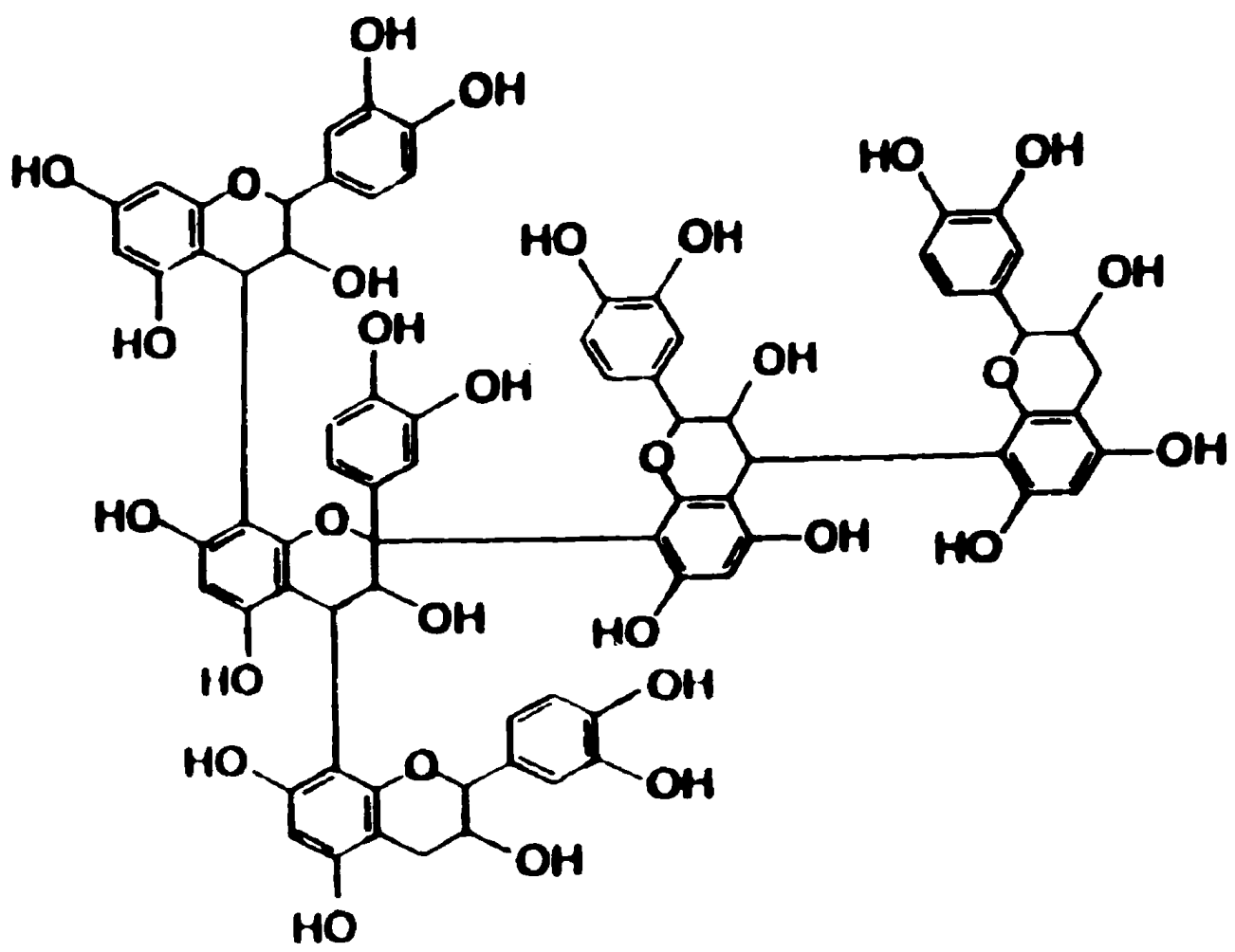


hydrophobic interactions. Covalent bonding usually occurs with phenolic acids whereas hydrophobic interactions are more involved in the formation of tannin-protein complexes.

\subsubsection{Hydrogen bonding}

It is known that all phenols, unless sterically hindered, take part in hydrogen bonding. The bond between phenolic hydroxyl and the amide carbonyl is a strong type of hydrogen bond (Loomis and Battaile, 1965). Experiments on the tanning of modified collagen and of synthetic polymers such as nylon and polyvinylpyrrolidone (PVP) have established the importance of the peptide or amide linkages in the formation of $\mathbf{H}$-bonded complexes between tannins and proteins (Gustavson, 1956). It is clear that only the $-\mathrm{CO}-\mathrm{N}$ group is required for the formation of complexes with vegetable tannins. From tanning experiments, it was also concluded that tannins form $\mathrm{H}$-bonds with the peptide linkage, probably through the peptide oxygen, and with the tannin furnishing the hydrogen. Under Gustavson's experimental conditions (1956) the amounts of tannins bound ranged from 31 to $44 \%$ of the dry weight of the substrate polymers. Two types of tannins, condensed and hydrolyzable, showed very different $\mathrm{pH}$ responses. Condensed tannins were bound almost independently of $\mathrm{pH}$ below 7-8 and the binding decreased rapidly above $\mathrm{pH} 8$. Hydrolyzable tannins on the other hand were bound very strongly at $\mathrm{pH} 3-4$ ( $80 \%$ of the weight of substrate), but the binding decreased above $\mathrm{pH}$. At $\mathrm{pH} 6$ the amount bound was approximately $25 \%$ of that bound at $\mathrm{pH} 3$, and at $\mathrm{pH} 7.5$ it decreased to 8-10\% (Gustavson, 1956). In the case of condensed tannins the $\mathrm{pH}$ effects indicated that the binding involved un-ionized phenolic hydroxyl groups. It seemed that these groups reacted to form $\mathrm{H}$-bonds with the amide groups of proteins or synthetic polymers. With hydrolyzable tannins the $\mathrm{pH}$ effects suggested that 
strong $\mathrm{H}$-bonds were formed by un-ionized carboxyl groups of tannins while weak H-bonds by un-ionized phenolic hydroxyl groups (Loomis and Battaile, 1966). Tannins can be removed from all of these complexes by $6-8 \mathrm{M}$ urea as it is very strong $\mathrm{H}$ donor able to break the H-bonds between tannins and proteins while forming its own H-bonds with proteins. Dilute alkali, or aqueous organic solvents which are capable of $\mathrm{H}$-bonding, such as alcohols or acetone, also have the ability of detanning.

\subsubsection{Ionic bonding}

Until recently little was known about ionic bonding between phenolic compounds and rapeseed/canola protein. Lownang in our laboratories (1994) studied the extractability of phenolic acids in canola meal. Since sinapine is the principal phenolic acid in rapeseed/canola (Krygier et al., 1982b), he postulated that this choline ester of sinapic acid possessed positive charge and may thus electrostatically bind to the extracted canola proteins which were negatively charged at $\mathrm{pH}$ values above their isoelectric points, forming a sinapine-protein complex (Figure 5). During alkaline extraction of canola protein, he added different levels of $\mathrm{CaCl}_{2}$ and found that the extractability of phenolic acids decreased with the increased addition of $\mathrm{CaCl}_{2}$. He attributed the decrease to the shift in the equilibria of the complexes due to the presence of excess $\mathrm{Ca}^{--}$ions as they were able to compete with sinapine to form complexes with the proteins.

In an investigation of the influences of sinapic and thomasidioc acid on the rheological characteristics of canola protein gels, Rubino et al. (1996) evaluated the 


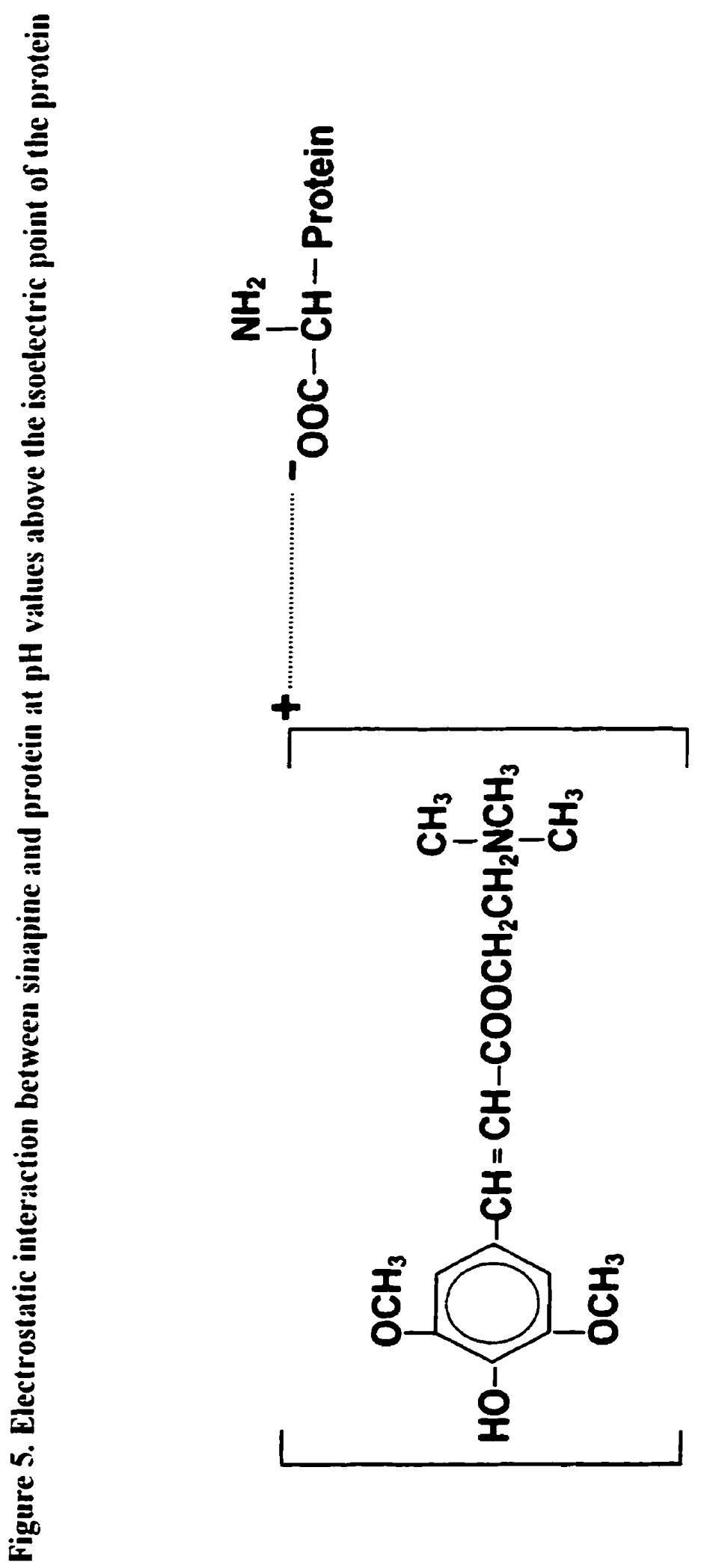


interactions between these phenolic compounds and the $12 \mathrm{~S}$ canola protein globulin. They

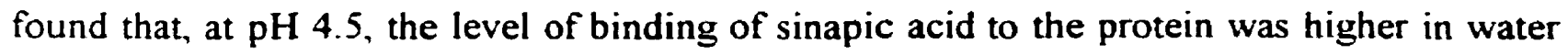
than in $0.1 \mathrm{M} \mathrm{NaCl}$, and explained that $\mathrm{pH} 4.5$ was below the isoelectric point of the protein, therefore the protein was positively charged, which created an environment encouraging electrostatic interactions between the positively-charged protein and the negatively-charged sinapic acid. In the presence of salt, the reduced level of binding reflected competition between the chloride ions and sinapic acid for positively-charged sites on the protein.

\subsubsection{Hydrophobic interactions}

Hydrophobic forces are involved in tannin-protein interactions (Hagerman and Butler, 1978: Oh et al., 1980; Martin et al., 1985). A model was developed by Cai et al. (1990) for the study of tannin-protein interactions in which the alkaloid caffeine is substituted for protein. Caffeine and the galloyl groups of gallotannins stack to form parallel layers stabilized by hydrophobic interactions. Similarly, hydrophobic bonding can result from the co-alignment of the phenolic groups of tannins and the aromatic side chains of proteins (Butler, 1989).

Haslam (1988) brought forward a theory for protein precipitation by polyphenols (tannins), in which he indicates that the effectiveness of polyphenols binding to protein derives from the fact that polyphenols are multidentate ligands able to bind simultaneously via different phenolic groups at more than one point to the protein surface. When polyphenols cause precipitation of proteins from solution, two situations may be envisaged. At low protein concentrations, the polyphenols associate at one or more sites on the protein surface, to give a monolayer that is relatively hydrophobic (Figure 6). Where the protein 


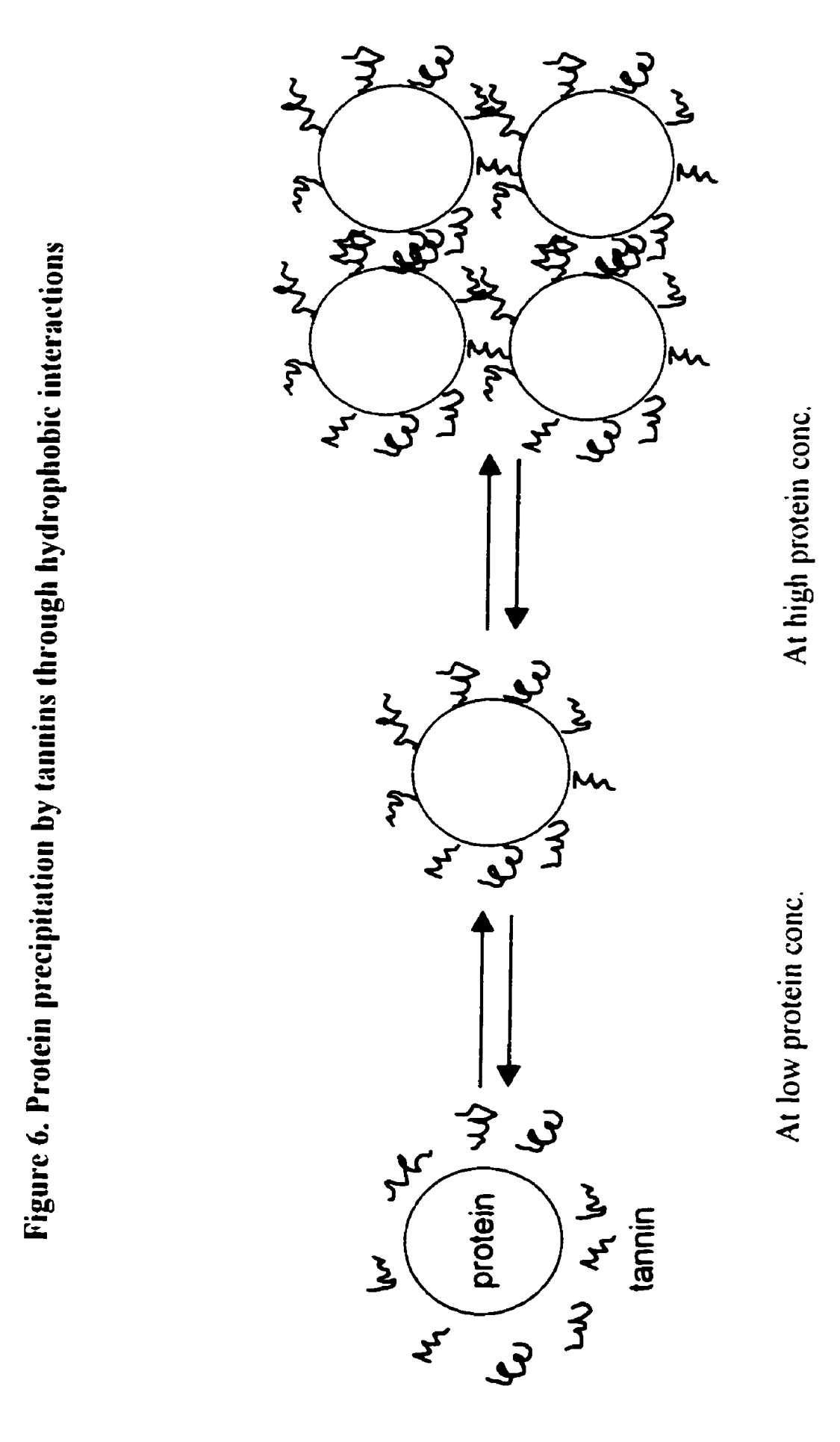


concentration is high, the more hydrophobic surface layer is formed by complexation of the polyphenols onto the protein and by cross-linking of different protein molecules by the multidentate polyphenols. Aggregation and precipitation then follow. This tendency to crosslink protein molecules at higher protein concentrations explains the changing stoichiometry of the aggregates with changing protein concentrations, i.e., more polyphenols are required to precipitate proteins from dilute solutions than from concentrated ones.

The tannin-protein interactions are strongly influenced by some factors such as $\mathrm{pH}$ and surfactants. Nonpolar solvents or detergents such as dioxane and sodium dodecyl sulfate (SDS) are able to inhibit the hydrophobic interactions between tannins and proteins. The precipitation of bovine serum albumin (BSA) by sorghum tannin can be completely prevented by the addition of $0.1 \%$ SDS (Hagerman and Butler, 1978). Martin et al. (1985) showed that the formation of tannin-protein complexes was hindered in the presence of $0.06 \%$ of lysolecithin. The effects of ionic strength on the tannin-protein interaction remain controversial. According to Hagerman and Butler (1978), the complexation of tannins and proteins is independent of the ionic strength produced by $\mathrm{NaCl}$ concentrations ranging from 0.05 to 5.0M. On the other hand, Martin et al. (1985) demonstrated that the presence of $\mathrm{Na}^{-}$, $\mathrm{K}^{*}, \mathrm{Ca}^{-2}$, and $\mathrm{Mg}^{-2}$ enhanced the precipitation of tannin-protein complexes. The discrepancies in the reported data may be due to the type of tannins and/or proteins as well as the methodology used. 


\subsubsection{Covalent bonding}

Although, as mentioned earlier, large amounts of phenolic compounds are bound to protein by hydrogen bonding, ionic bonding, and hydrophobic interactions, there have been many indications that other and more stable bonds are also formed, and that they are formed rapidly (Gustavson, 1956). It appears that these stable bonds result from oxidation of phenols to quinones, and copolymerization of the quinones with proteins. The enzymatic oxidation of phenols, and the reactions of quinones with proteins, have been reviewed by Mason (1955). Some dihydroxyl phenolic acids such as caffeic and chlorogenic acids may be oxidized to ortho-quinones by some copper-containing enzymes of plant tissue. Once formed, $o$ quinones may bond to proteins by 1,4 addition of sulfhydryl or free amino groups (Figure 7). Sulfhydryl and terminal $\alpha$-amino groups react much more readily than the $\varepsilon$-amino groups of lysine. The initial product of the above reaction is a catechol- or quinol-protein compound, which is readily oxidized by a free quinone to the corresponding quinone-protein. Quinones with a second reactive position available can react with a second reactive group of protein, resulting in cross-linking. Torchinskii and Dixon (1974) proposed a mechanism of the reactions of $\mathrm{SH}$-containing amino acids such as cysteine with quinones. They showed that the SH group combined with the carbon atom in position 2 or 3 of a quinone ring forming a thioether which had an absorption maximum at $420-430 \mathrm{~nm}$. They considered that the first product of the reaction was a substituted hydroquinone due to the presence of excess $\mathrm{SH}$ groups, and it was then oxidized to quinone by the free quinones around it. This is consistent with the results of Mason (1955). 
Figure 7. Covalent bonding of phenolic acid to protein
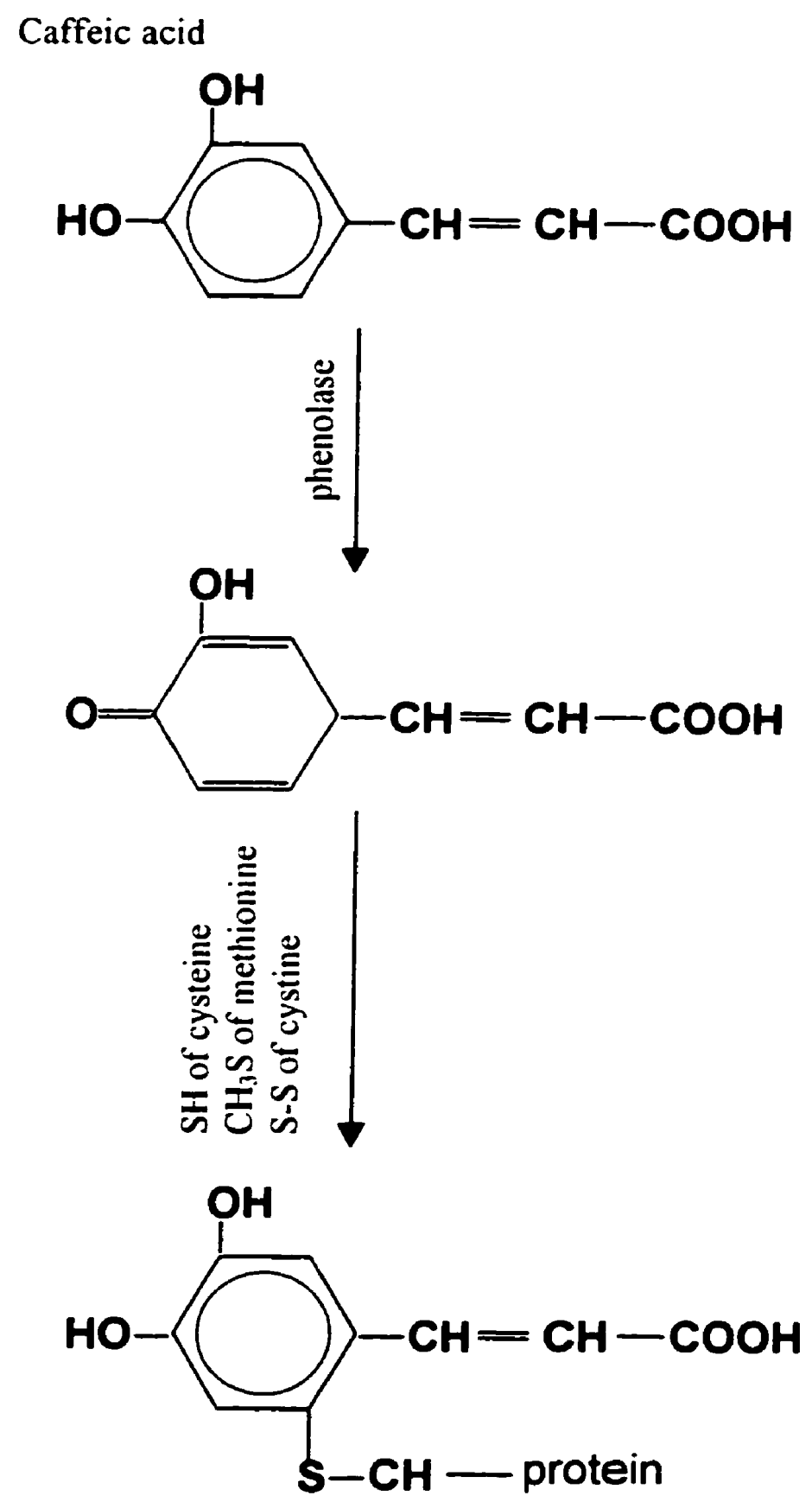


\subsubsection{Effects of phenolic compounds on food quality}

\subsubsection{Organoleptic effects}

The bitter and/or astringent taste and the undesirable colour of oilseed protein products, including defatted meals, flours, protein concentrates and isolates, have been persistent problems in expanding their food uses. Commonly, these problems have been attributed to the presence of phenolic compounds in these protein products. Arai et al. (1966) reported that a strongly flavoured ethanol extract of defatted soybean flour contained at least seven phenolic acids with syringic acid being the main phenolic component. Maga and Lorenz (1973) measured taste thresholds of phenolic acids, alone and in combinations, to show that the latter condition resulted in much lower taste thresholds of 40 to $90 \mathrm{ppm}$ than the individual acids ( 300 to $500 \mathrm{ppm}$ ). The major phenolic acids in all meals and flours occur in concentrations well above the taste thresholds, hence, the objectionable bitter flavours so obviously perceived in these protein products. The bitter taste component in rapeseed was reported to be sinapine (Sosulski et al., 1977) which constitutes about $1 \%$ of the meal mass. Sinapine is not subject to hydrolytic cleavage except during germination when the appropriate esterase is activated. Tannins may also cause bitter taste and astringency of rapeseed meals, probably due to their ability to precipitate the proteins in the mouth (Shahidi, 1992). Early in the 1950's, Bate-Smith (1954) already brought up the theory that astringency develops in the palate by precipitation of glycoproteins in the mucous secretions of salivary glands.

Phenolic compounds also cause the colour problem of the oilseed protein products primarily through the aforementioned quinone formation. Under alkaline conditions most oilseed protein solutions develop dark green or brown colours due to oxidation of phenolic 
compounds, and when the proteins are precipitated at their isoelectric points, the brown colours can not be washed from the protein isolates (Sosulski and Bakal, 1969). Chlorogenic acid is a typical phenolic compound known to be responsible for the green to brown colours of alkaline extracts because of quinone formation. The colour problem with chlorogenic acid under alkaline conditions represents a serious impediment to food utilization of sunflower protein products in which $70 \%$ of the total phenolics are reported to be chlorogenic acid and its hydrolysis product, caffeic acid. At the $\mathrm{pH}$ of bread (5.5), sunflower protein supplementation with flours and concentrates causes bread to develop light to medium brown colours in the crumbs depending on the levels of phenolic compounds present (Sosulski, 1979).

\subsubsection{Nutritional implications}

Studies on the nutritional effects of polyphenols in monogastrics have indicated that inclusion of condensed tannins in the feed leads to growth depression in chickens and ducklings (Griffiths, 1979). Both tannic acid and catechin decrease the activity of proteolytic enzymes by binding to them, thus reducing protein digestibility (Van Sumere et al., 1975). Also in quinoidal formation, the combined reaction of quinones on the $\varepsilon$-amino groups of lysine could make large blocks of amino acids, including other essential amino acids, resistant to digestive enzymes, thus lowering protein nutritive value. Phenolic compounds could also form association complexes with starch molecules through interactions with amylose and amylopectin and reduce their digestibility (Deshpande and Salunkhe, 1982). In addition, polyphenols are known to bind a wide range of essential minerals, thus decreasing their bioavailability as well (Faithful, 1984). 


\subsubsection{Removal of phenolic compounds from oilseed protein}

Numerous processing methods have been proposed for the removal of phenolics from oilseeds. Several kinds of reagents were used, including organic solvents, dilute alkali or acids, reducing agents, activated carbon, and ion exchange resins. These processes are based on the dissociation of phenolic-protein complexes or the prevention of phenolics from binding to protein.

\subsubsection{Organic solvents and dilute alkali or acids}

Since hydrogen bonding is the principal type of interaction between phenolic compounds and proteins, their complexes can be dissociated by adding competing hydrogen bonding agents to the system. Some organic solvents such as alcohols and acetone are capable of forming strong hydrogen bonds, therefore, many methods involving the use of various organic solvents have been described for the removal of phenolics. Early in 1940's, Smith and Johnson (1948) tried hot $70 \%$ ethanol and near-absolute methanol to remove chlorogenic acid (CGA), a typical phenolic acid in sunflower from the meal and achieved $90 \%$ removal. In the following decades, aqueous methanol or ethanol of different concentrations were tested for the removal of CGA on sunflower protein products by many researchers (Joubert, 1955; Milic et al., 1968; Mikalojcak et al., 1970). While more or less effective, none of the alcoholic solutions was able to remove CGA completely. Fan et al. (1976) compared several procedures for the extraction of chlorogenic acid from sunflower meals and flours and developed a countercurrent extraction process with water or aqueous ethanol, which removed $90 \%$ CGA from sunflower seeds at $80^{\circ} \mathrm{C}$. Sripad and Rao (1987) 
achieved efficiencies of $95-98 \%$ for phenolic removal by multi-step extraction of sunflower meal with $40 \%$ aqueous acetone, $40 \%$ aqueous ethanol, or $40 \%$ aqueous methanol.

Dilute aikali and acids are also capable of hydrogen bonding; thus, they can be used for phenolic removal as well. Although Sosulski et al. (1973) have described a method for diffusion extraction of sunflower kernels with dilute $\mathrm{HCl}$ alone $(0.001 \mathrm{~N})$ to reduce chlorogenic acid content from 2.0 to $0.3 \%$, in most cases both alkali and acids were used in combination with organic solvents to enhance the effects. Sodini and Canella (1977) described the ability of acidic 1-butanol to remove colour forming phenols (chlorogenic and caffeic acid) from sunflower. They repeatedly extracted sunflower meal with a solution of 1butanol and $0.005 \mathrm{~N} \mathrm{HCl}$ and produced a protein concentrate with a low chlorogenic residual content $(<0.05 \%)$. Rahma and Rao (1981) treated sunflower flour with various solvent systems to remove polyphenols. All solvent treatments resulted in markedly reduced chlorogenic acid content; the maximum decrease (from 3.26 to $0.07 \%$ ) was obtained by extraction with a mixture of $0.002 \mathrm{~N} \mathrm{HCl}, 70 \%$ aqueous ethanol and acidic l-butanol used in tandem. Prasad (1990) concluded that acidic aqueous acetone followed by aqueous acetone removed polyphenolic components from defatted sunflower meal more efficiently than acidic butanol. Treatments of rapeseed/canola with gaseous, aqueous or alcoholic ammonia were shown to be effective. It was reported that $0.2 \mathrm{M}$ ammonia in ethanol removed $39-82 \%$ of phenolics from canola meals (Goh et al., 1982). McGregor et al. (1983) used gaseous ammoniation to get rid of up to $74 \%$ of the sinapine in mustard meal. The methanol/ammonia/water hexane extraction of canola and rapeseed resulted in $72.4 \%$ removal of phenolic acids (Naczk et al., 1992). With this method esterified phenolic acids were preferentially removed (70-80\%) while free phenolic acids were reduced by about $50 \%$. 
The insoluble-bound phenolic acids remained unchanged, probably because they were bound to the protein covalently, hence could not be removed by the organic solvents. Methanol/ammonia treatment of canola and rapeseed also effectively reduced their tannin content. The treated meals retained only $4-33 \%$ of the condensed tannins originally present in them (Shahidi and Naczk, 1989).

\subsubsection{Other treatments}

Carey (1966) reported a process utilizing activated carbon to improve colour and flavour of soybean protein isolates. However, few data were presented. How and Morr (1982) studied the effectiveness of such activated carbon treatments for removing phenolic compounds from soy protein extracts to determine their benefits derived in flavour and colour. Activated carbon adsorption was compared with ion exchange in removing phenolic compounds. In the experiments, the protein extract was pumped 'up-flow' through a column packed with either Calgon CPG granular activated carbon at a flow rate of $25-30 \mathrm{~mL} / \mathrm{min}$ and at room temperature; or with Rexyn $10 \mathrm{I}$ in $\mathrm{Na}^{-}$form to remove polyvalent cations at a flow rate of $100-120 \mathrm{~mL} / \mathrm{min}$. It was found that activated carbon treatment resulted in soy protein isolates with superior overall odour and flavour while ion exchange processing was more effective than activated carbon in improving the colour of the products.

Those phenolic compounds forming hydrogen-bonded complexes with protein are effectively removed by adding large amounts of polymers that contain groups similar to the peptide linkage. The most effective polymer was polyvinylpyrrolidone (PVP). Various forms of PVP have been reported in the literature. Soluble PVP has been used for isolation of mitochondria, and insoluble PVP for purification of soluble enzymes (Loomis and Battaile, 
1966). Loomis and Battaile (1966) attempted to obtain active enzymes from leaves of peppermint. Extracts prepared by conventional techniques browned quickly, and no active enzyme could be found in them. It seemed likely that quinones formed through oxidation of phenolics were responsible for this phenomenon. Many extraction and purification procedures were tried, including the use of large amounts of buffer; addition of reducing agents, cyanide, and metal chelating agents; decolourizing with charcoal; dialysis and gel filtration to remove compounds of low molecular weights; addition of polyethylene glycol, soluble PVP, or albumin. However, none of these techniques proved effective with peppermint. It was found that addition of insoluble proteins such as collagen or hide powder, plus buffer and sodium ascorbates, during the homogenization of peppermint leaves, yielded extracts which did not brown rapidly, and in which the activity of several enzymes could not be detected. Since the use of foreign proteins might introduce contamination of the extract, a synthetic polymer, Polyclar AT (a commercially available insoluble PVP) was tested and found to be very effective. To determine the amount of Polyclar AT required, peppermint leaves were extracted with water in the presence of $0.5,1.0,1.25$, and $1.5 \mathrm{~g}$ of the polymer per gram of fresh tissue. With $0.5 \mathrm{~g}$ the extract was some what brown; with $1.0 \mathrm{~g}$ it was initially clear but there seemed to be very slight browning after 16 hours at room temperature. With 1.25 or $1.5 \mathrm{~g}$, the extract was clear and remained clear.

According to Krygier et al. (1982b), sinapine is the principal phenolic acid in rapeseed/canola. Lownang (1994) in our laboratories proposed an electrostatic interaction between this positively charged ester and negatively charged proteins at pH's above the isoelectric points of canola protein, thus forming a sinapine-protein complex. During alkaline extraction, he added $\mathrm{CaCl}_{2}$ at levels of $0,10,20,30 \%$ and found the extractability of phenolic 
acids decreased with the increased $\mathrm{CaCl}_{2}$ addition. He attributed the decrease to the shift in equilibra of the complexes due to the presence of excess $\mathrm{Ca}^{--}$ions as they are able to compete with sinapine to form complexes with proteins.

While these processing techniques were, to various extents, effective in the removal of phenolic compounds from protein systems, they were all associated with problems such as incomplete removal, loss of protein, and the use of expensive reagents. Therefore, further search for more efficient processes is necessary in order to improve the quality of the oilseed protein products such as canola protein isolates. The development of a technically viable process for phenolic removal from canola protein may involve the application of several of these methods in combination with separation techniques, e.g., membrane processing. Membrane-based canola protein isolation is reviewed in Section 2.4.

\subsubsection{Effects of reducing or oxidizing agents on phenolic compounds and colour of oilseed proteins}

As mentioned earlier, some phenolic acids are readily oxidized to quinones. Once formed, quinones can easily form covalent linkage with various groups on protein molecules, such as $-\mathrm{SH}, \alpha-\mathrm{NH}_{2}, \varepsilon-\mathrm{NH}_{2}$, and $=\mathrm{NH}$ groups, which may then lead to coloured protein products. In the production of light-coloured or colourless oilseed protein products, sodium sulphite was used as a reducing agent to prevent the accumulation of quinones. Gheysuddin et al. (1970) prepared a colourless sunflower protein isolate by extracting the meal with $0.25 \% \mathrm{Na}_{2} \mathrm{SO}_{3}$ solution at $\mathrm{pH} 10.5$. Besides reducing ability, the bleaching effect of sodium sulphite can also derive from its ability to disrupt some conjugated double bond systems that are responsible for colour. Keshavarz et al. (1977) designed a four-level experiment to 
determine the effects of different factors on decolourization of rapeseed protein extracts with sodium sulphite. They found that treating 5 to $7.5 \%$ protein solutions with $0.1 \% \mathrm{Na}_{2} \mathrm{SO}_{3}$ was the most effective for decolourization in practical processing. They also reported that gassing with sulphur dioxide for 1 minute was effective in obtaining colourless powders when applied to all the protein fractions. Some oxidizing agents are capable of bleaching as well. Their effects on the colour of rapeseed protein were studied by the same research group. Among potassium periodate, potassium persulphate, ammonium persulphate and hydrogen peroxide used as oxidizing agents, $\mathrm{H}_{2} \mathrm{O}_{2}$ was the most effective in decreasing the colour darkness. However, the amino acid analysis demonstrated significant decrease in methionine.

\subsubsection{Analytical methods for determination of phenolic compounds in rapeseed/canola}

The development of a viable process for the removal of phenolic compounds requires reliable analytical techniques for the determination of both phenolic acids and tannins. Hence, various analytical methods documented in the literature for these compounds were reviewed and compared in an attempt to find a suitable procedure to analyze each of these two groups of phenolic compounds.

\subsubsection{Total phenolic acids}

Phenolic acids in rapeseed, including its canola varieties, account for $-2 \%$ of the oilfree meal mass. A number of analytical techniques were reported for their analyses, including thin-layer chromatography (Durkee and Thivierge, 1975; Fenton et al., 1980), gas-liquid chromatography (Kozlowska et al., 1975; Krygier et al., 1982a, b), and gas chromatography- 
mass spectrometry (Krygier et al., 1982b). Unfortunately the thin-layer chromatographic method is not accurate enough, and the others require extensive preparatory work and expensive instrumentation. For total phenolic acid determination, therefore, it would be preferable to use a wet chemical method that is efficient and accurate. Two methods from the literature were thus examined in detail. In the method of Naczk et al. (1992), total phenolic acids are broken down into three fractions: free, esterified, and insoluble-bound; hence the method involves many steps for the extractions and fractionation of the phenolic acids followed by colorimetric measurement (Figure 8). It is tedious with many potential sources of experimental errors.

While the extraction step in the method of Ismail and Eskin (1979) is much simpler (Figure 9), it tends to overestimate the phenolic acid content of rapeseed/canola samples due to the presence of tannins. The fact that it is hazardous to prepare $\mathrm{TiCl}_{+}$in concentrated $\mathrm{HCl}$ for colorimetric measurement is also a deterrent to its regular use in a laboratory.

Apparently neither method is suitable for the analyses of phenolic acids in this study. It was, therefore, necessary to develop a new procedure that is simple, fast, and accurate.

\subsubsection{Condensed tannins}

The presence of condensed tannins in rapeseed was first reported by Bate-Smith and Ribereau-Gayon (1959). This finding was verified by Durkee (1971), who identified cyanidin, pelargonidin and an artifact n-butyl derivative of cyanidin in the hydrolysis products of rapeseed hulls. Clandinin and Heard (1968) reported the presence of approximately $3 \%$ tannins in the rapeseed meal as assayed by the method for tannin determination in cloves and allspice. However, Fenwick and Hoggan (1976) showed that this 


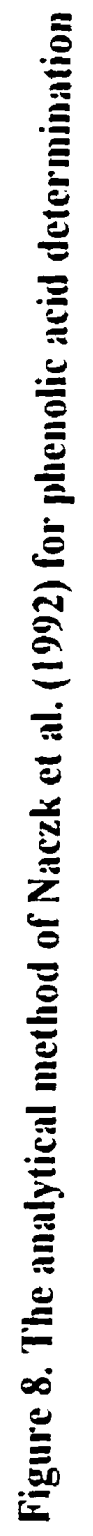

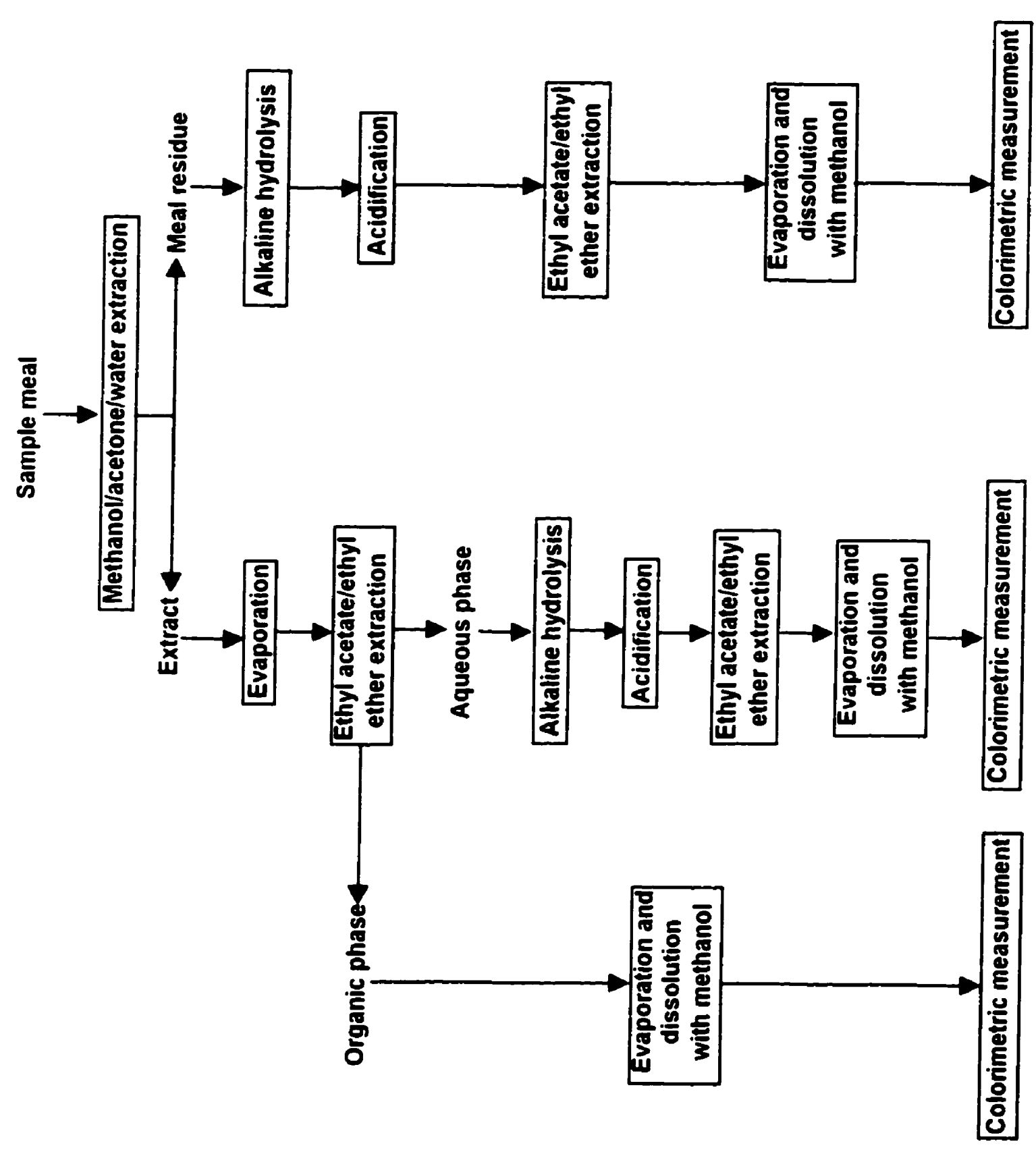


Figure 9. The analytical method of Ismail and Eskin (1979) for phenolic acid determination

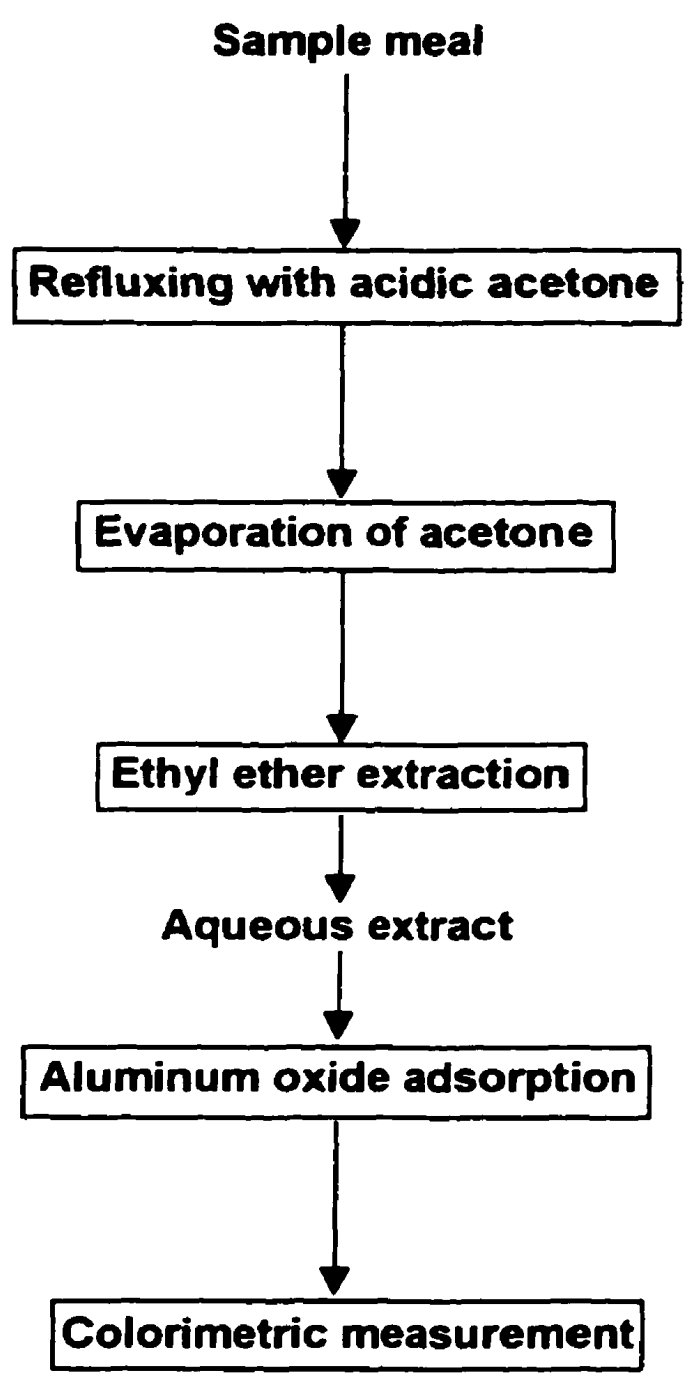


value included sinapine (up to $1.5 \%$ ). Thus, the tannin concentrations were actually $18-45 \%$ lower than those reported by Clandinin and Heard (1968).

Burns (1971) developed the vanillin assay for quantitative measurement of condensed tannins in sorghum grain. The chief advantage of this method appears to be its specificity for a narrow range of flavanols and dihydrochalcones. In contrast, redox methods such as FolinDenis and Prussian blue assays detect any phenol present with varying sensitivity. However, the procedure of Burns (1971) for the vanillin assay did not describe how the conditions were selected and which parameters must be closely controlled to ensure reproducibility between laboratories. Hence, considerable variability was observed in the results obtained by this method between and even within laboratories. Price et al. (1978) examined the factors that could affect the vanillin assay, and optimized several parameters. The revised procedure of Shahidi and Naczk (1989) offered a more precise means for studying the tannins from sources such as rapeseed/canola. They investigated the effectiveness of different solvents for the extraction of condensed tannins in rapeseed/canola, and determined extracted tannins using the method of Price et al. (1978). Their results were consistent with the findings of previous researchers (Leung et al., 1979).

\subsection{Membrane Processing}

\subsubsection{Introduction}

During rapeseed/canola protein extraction, the undesirable components in rapeseed/canola such as glucosinolates, phytates, and phenolic compounds also show substantial extractability in the protein solution. Most of these compounds, on the other hand, have much lower molecular weights than rapeseed proteins (Lonnerdal et al., 1977). 
Therefore, membrane processing has always been considered for the isolation and purification of rapeseed/canola proteins since it is a separation technique based on the ability of specially made membranes to selectively retain dissolved molecules of different sizes, shapes and flexibility.

In membrane processing the "filter" is a thin, tough and selectively permeable membrane made from polymers such as cellulose acetate, polysulfone, or polyamide (Lloyd and Meluch, 1985; McGregor, 1986). The membrane is able to hold back most molecules with molecular weights higher than a certain size, while most smaller molecules, including the solvent, can pass through the membrane into the filtrate, thus separating them quantitatively (Figure 10). This certain size is known as the "molecular weight cut-off" of the membrane, normally defined as the molecular weight of a solute 90 to $95 \%$ of which is retained by the membrane (Cheryan, 1986). It is one of the most important characteristics of the membrane. Besides various "molecular weight cut-off's, membranes can also be made in different configurations such as flat sheet, tubular, and hollow fibers to cater to diversified needs. Operating parameters such as viscosity concentration of the feed determine the choice of membrane configurations.

Membrane processing treats clear solutions containing no solids, hence no accumulation of retained solids on the filter surface. However, during the process the large solute molecules are retained by the membrane while solvent and small solute molecules passing through the membrane. The large-molecular-weight solute is concentrated at membrane surface when its diffusion into the bulk phase is slower than the rate of concentration (Michaels et al., 1971), thus building up into a gel layer (Figure 11). It was revealed that, at steady state, the major resistance in membrane processing may come from 
Figure 10. Schematic representation of a cross-now membrane process

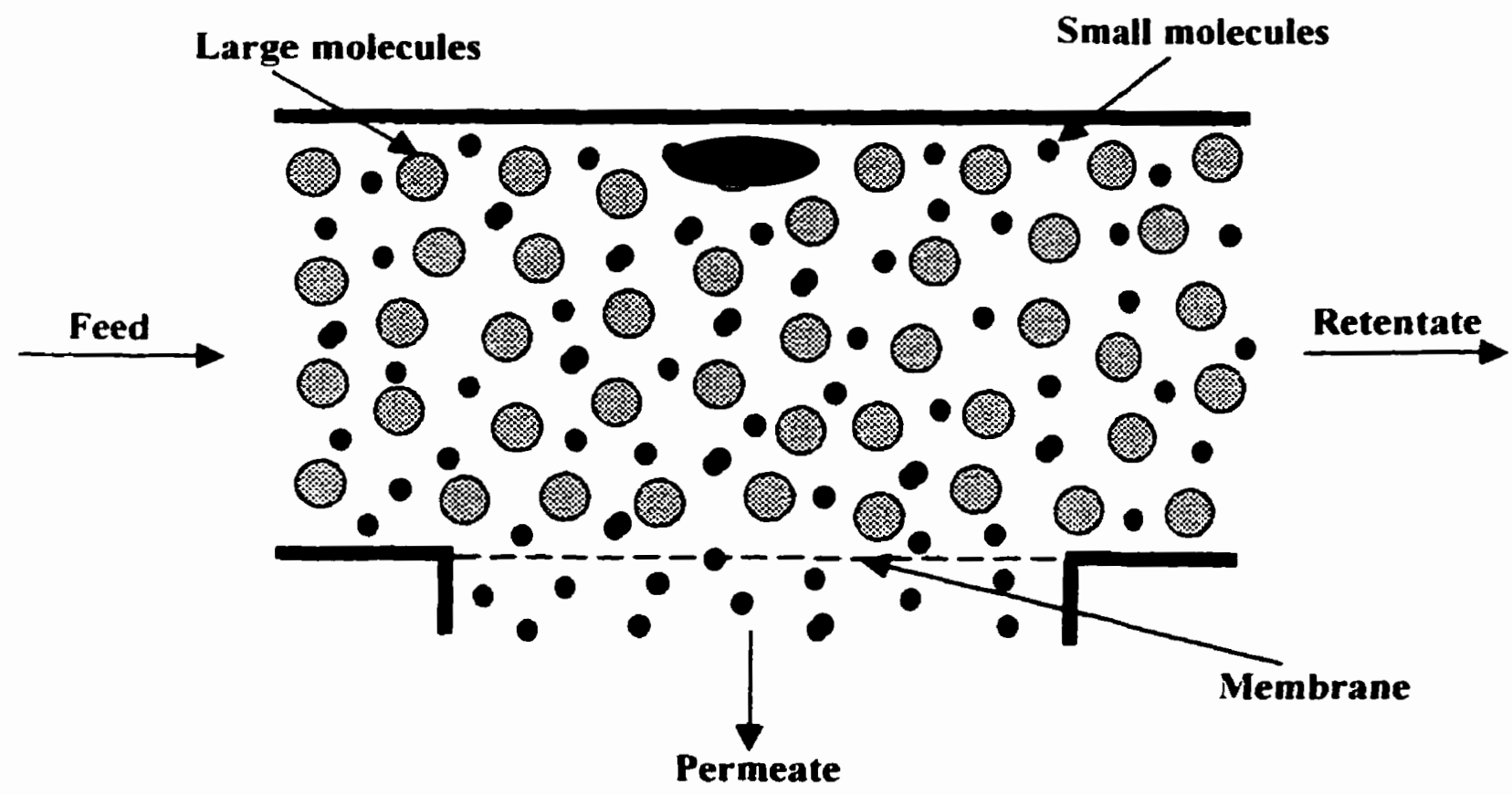


Figure 11. Schematic representation of gel layer formation and concentration in ultrafiltration

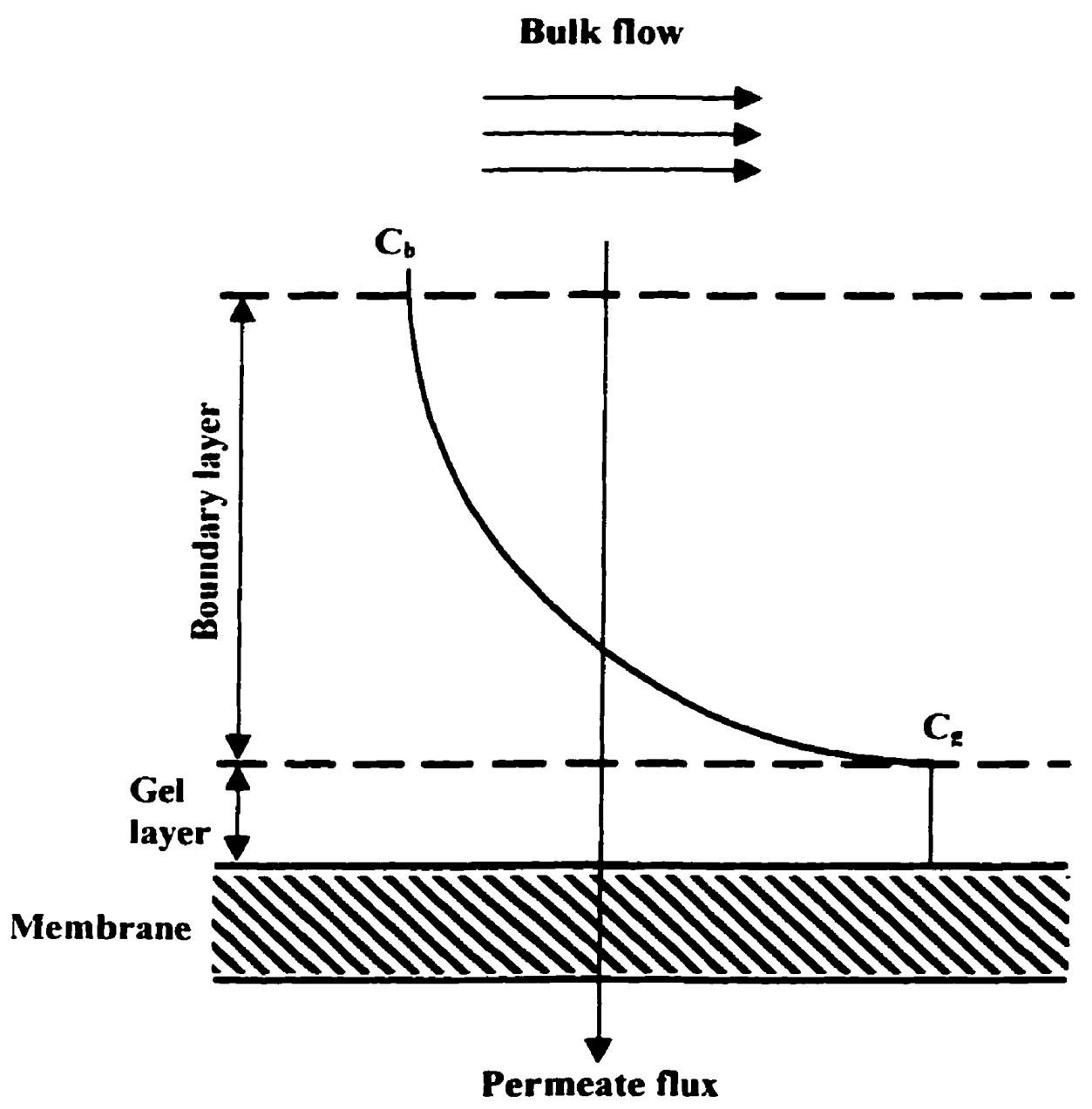

$\mathrm{C}_{\mathrm{b}}$ - bulk concentration of retained large solute molecules $\mathrm{C}_{\mathrm{g}}$ - gel concentration of retained large solute molecules 
this gel layer instead of the membrane itself (Goldsmith et al., 1971). In order to minimize the gel layer, membrane processing is usually conducted in a cross-flow manner. Cross-flow is able to maximize turbulence at the filter surface, thus flushing away the deposits and decreasing the gel layer.

Membrane processing is now a widely used and rapidly developing technology in the food industry for all its merits. In addition to its capability of separating substances of different molecular weights, other advantages of membrane processing include mild operating conditions, low energy consumption, generally no changes in $\mathrm{pH}$, and no phase change required to effect a separation. Thus, it is able to produce the food products with functional properties superior in many respects to those conventionally prepared.

\subsubsection{Ultrafiltration}

Ultrafiltration is a pressure-driven membrane process, thus able to produce a much greater flux of permeate than membrane separation processes driven by concentration difference such as dialysis, which makes it more suitable for large-scale industrial applications (Cheryan, 1986). The schematic diagram of batch ultrafiltration is shown in Figure 12. In ultrafiltration the feed solution is drawn from the container by a pump and pushed through a prefilter to remove all fine solids before the solution enters the membrane cartridge. Inside the membrane cartridge the low-molecular-weight solutes and some of the solvent are driven through the membrane as the permeate while the high-molecular-weight solutes are retained in the retentate and sent back to the container. As the feed solution is recirculated in the system, its volume gets reduced, and the high-molecular-weight 
Figure 12. Schematic diagram of an ultrafiltration process

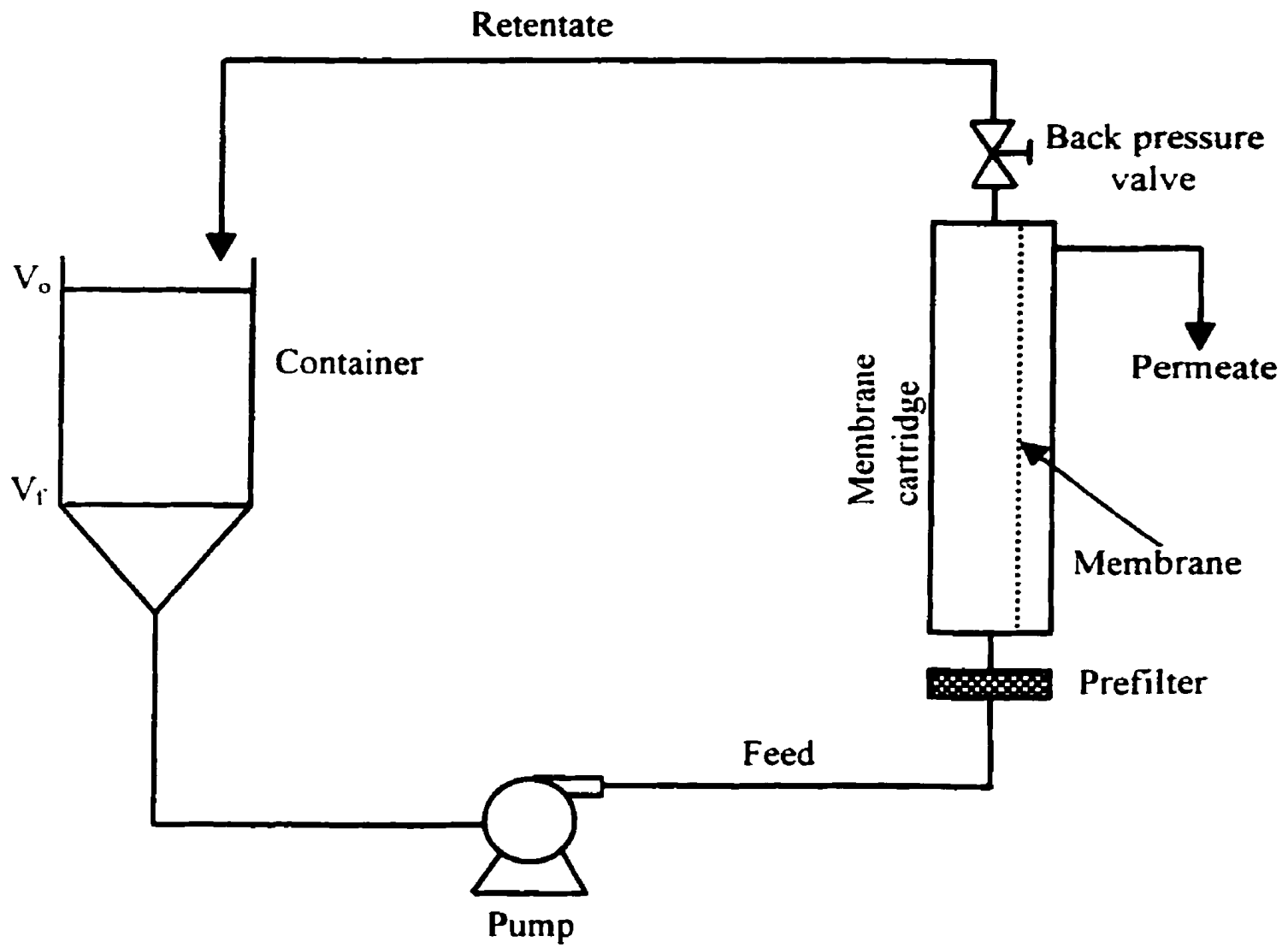


materials are thus being concentrated. Ultrafiltration can be characterized by the following equation (Cheryan, 1986):

$$
\frac{C_{f}}{C_{\text {o }}}=\left(\frac{V_{0}}{V_{f}}\right)^{R}=C F^{R}
$$

where

$$
\begin{aligned}
& C_{o}=\text { solute concentration in the original solution } \\
& C_{f}=\text { solute concentration in the final solution } \\
& V_{o}=\text { volume of the original solution } \\
& V_{f}=\text { volume of the final solution } \\
& C F=\text { concentration factor; } V_{o} / V_{f} \\
& R=\text { average rejection coefficient of the solute }
\end{aligned}
$$

The rejection coefficient at a certain instant during ultrafiltration $\left(R_{t}\right)$ is defined as:

$$
R_{t}=1-\frac{C_{P}}{C_{R}}
$$

where $C_{P}$ and $C_{R}$ are the solute concentrations in the permeate and retentate, respectively, at this instant.

If a solution contains a macromolecular compound, $A$, and a low-molecular-weight impurity, $B$, having rejection coefficients $R_{A}=1$ and $R_{B}=0$, respectively, the reduction of the volume to one tenth by ultrafiltration would result in a ten-fold increase in the concentration of compound $\mathrm{A}$. The concentration of $\mathrm{B}$ will remain constant during the entire process although its quantity will be reduced by $90 \%$ at the end, thus, achieving a ten-fold increase in the purity of $\mathrm{A}$.

Theoretically, the larger the concentration factor, the more low-molecular-weight components will be removed by ultrafiltration. However, it is not practical to run 
ultrafiltration with highly concentrated solutions, since high concentrations may cause the precipitation of the dissolved macromolecular solutes, the formation of an impermeable gel layer, and strong osmotic effects, which would all greatly increase the resistance to further permeation.

\subsubsection{Diafiltration}

Diafiltration is another form of membrane separation process. In diafiltration the permeate that leaves the system is replaced with fresh solvent as shown in Figure 13. Therefore, the volume of original solution is maintained throughout the whole process. It can be described by the following equation (Cheryan, 1986):

$$
\frac{C_{f}}{C_{0}}=e^{\frac{V_{w}}{V_{o}(R-1)}}=e^{D V(R-l)}
$$

where

$$
\begin{aligned}
& C_{o}=\text { solute concentration in the original solution } \\
& C_{t}=\text { solute concentration in the final solution } \\
& V_{o}=\text { volume of the original solution } \\
& V_{w}=\text { total volume of the fresh solvent added } \\
& R=\text { average rejection coefficient of the solute } \\
& D V=\text { diavolume; } V_{w} / V_{o}
\end{aligned}
$$

According to the above equation, when the solution discussed above is diafiltered at a diavolume of 4 , a $98.2 \%$ removal of the micromolecular solute B can be achieved, and the macromolecular solute $A$, on the other hand, is completely retained at an unchanged concentration. 
Figure 13. Schematic diagram of a diafiltration process

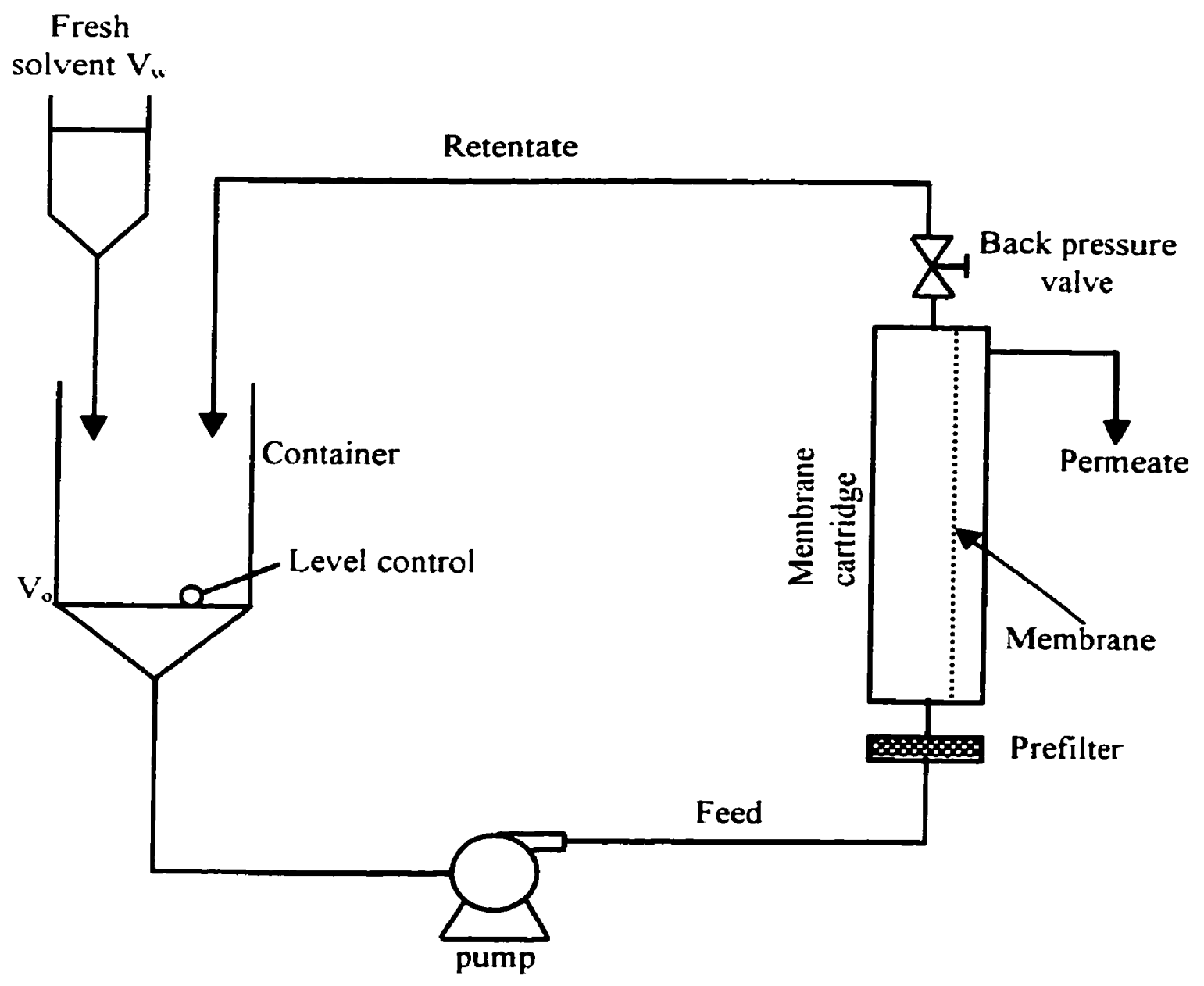


Therefore, diafiltration is an efficient complement to ultrafiltration. While ultrafiltration increases the concentration of high-molecular-weight solute, diafiltration reduces the concentration of small molecules. The combined use of both with an appropriate concentration factor and diavolume is able to minimize the low-molecular-weight impurities in the system, thus, producing macromolecular materials such as proteins of high purity.

\subsubsection{Production of rapeseed/canola protein isolates by membrane processing}

Membrane processes have been used commercially for many years in the dairy industry for the recovery of whey proteins while reducing pollution loads (Glover et al., 1978). The use of ultrafiltration for processing soy (Lawhon et al., 1977; Omosaiye and Cheryan, 1979) and cottonseed proteins (Lawhon et al., 1980) has also been reported.

The first attempt to produce rapeseed protein by ultrafiltration resulted in an isolate containing $76 \%$ protein, but the composition of the non-protein components was not reported (Maubois et al., 1976). Von Bockelmann et al. (1977) ultrafiltered the water extract of a rapeseed meal resulting in a $93 \%$ reduction in the glucosinolate content of the solution, however, the processed solution after drying contained only $30 \%$ protein.

Over the last fifteen years, in our laboratories, a series of membrane-based processes have been developed for the production of canola protein isolates. Diosady et al. (1984) applied a novel procedure based on water leaching and ultrafiltration to glucosinolate removal from rapeseed meal, producing a meal containing less than $1.77 \mu \mathrm{mol} / \mathrm{g}$ glucosinolates and a protein isolate with a glucosinolate content of $3.72 \mu \mathrm{mol} / \mathrm{g}$ and a protein content of $80.4 \%$. Further process development showed, that ultrafiltration alone, in either 
single-stage or multi-stage mode had little effect on the yield and quality of final products (Tzeng, 1987). Tzeng et al. (1988a) used a processing scheme which included protein extraction by aqueous sodium hexametaphosphate (SHMP) solution followed by ultrafiltration and diafiltration to produce a protein isolate with a protein content of about $90 \%$ and a protein recovery of $63 \%$. It was almost free of glucosinolates and low in phytates $(<2 \%)$. In the same year, another process for rapeseed protein isolation was developed in our laboratories (Tzeng et al., 1988b), comprising extraction with an aqueous SHMP or NaOH

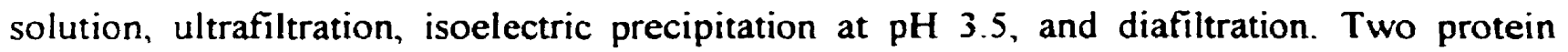
isolates were obtained with a protein recovery of up to $71.2 \%$ based on the protein content of the starting meal.

The disadvantages of the above processes, such as low protein recovery and poor quality of the products, led to the development of a novel approach for rapeseed/canola protein isolation (Tzeng et al., 1990a), which consisted of five main steps: alkaline extraction, isoelectric precipitation, ultrafiltration followed by diafiltration, and drying (Figure 14). Two rapeseed/canola protein isolates: precipitated and soluble, were produced with a combined protein recovery of over $70 \%$. Both products were of high protein content $(>90 \%)$, low in phytates $(<1 \%)$, essentially free of glucosinolates $(<2 \mu \mathrm{mol} / \mathrm{g})$, and with functional properties desirable for a variety of food applications (Igor et al., 1993: Xu and Diosady, 1994). This process was simple, economical, and thus had potential for commercial development.

However, the products from this process had some objectionable taste, and the soluble protein isolate produced solutions with dark brown colour, and developed offflavours. These problems are likely a result of phenolic compounds in the products. Hence, 
Figure 14: Flowsheet for the membrane-based canola protein isolation process developed by Tzeng et al. (1990a)

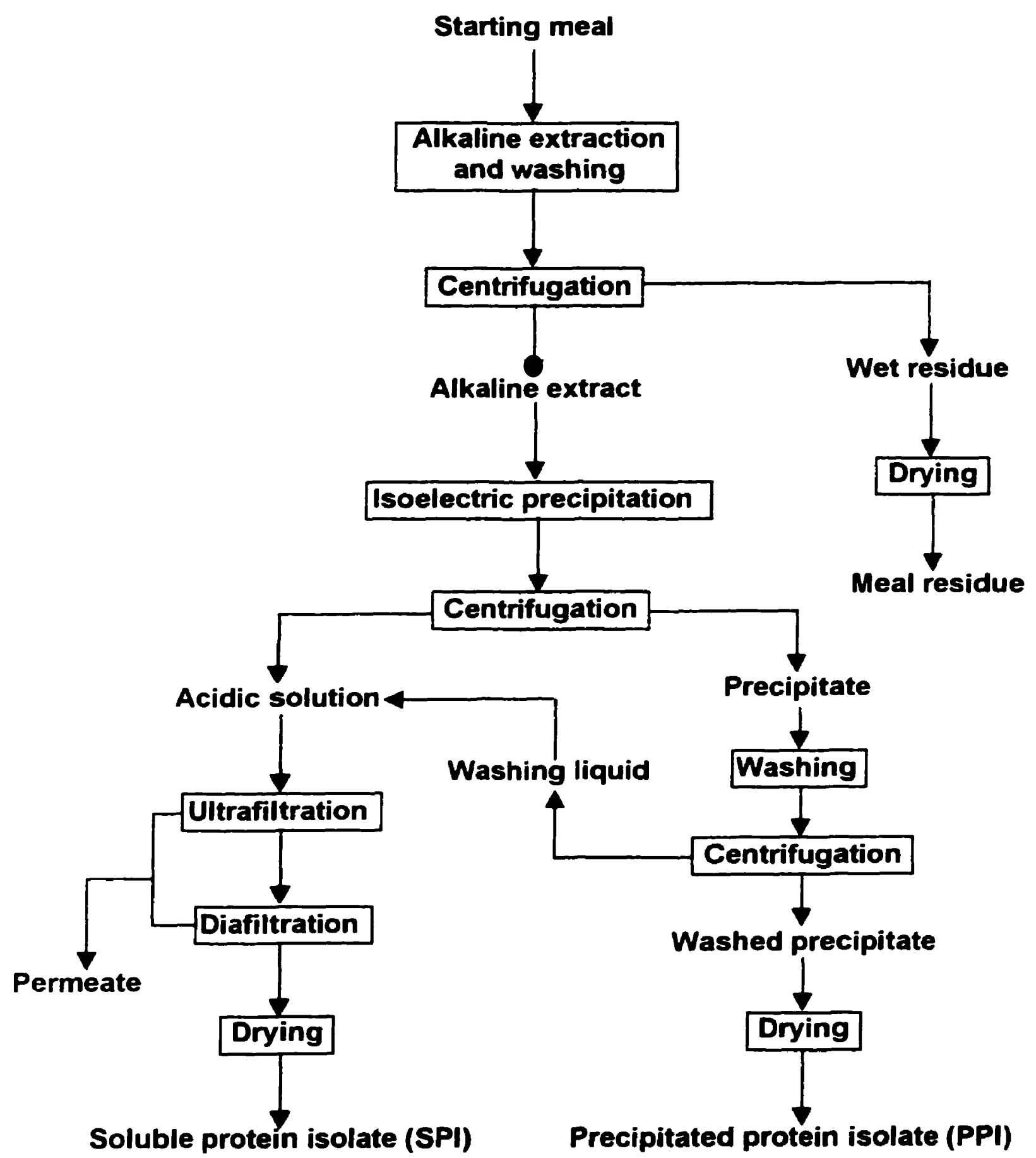


the present study was initiated with the objective of modifying the process of Tzeng et al. (1990a) - or developing a new process to minimize the phenolic content in the protein isolates so as to improve their taste and colour. The modifications initially involved the incorporation of phenolic-removal techniques reviewed earlier in Section 2.3.4.

\subsection{Colour Measurement}

Colour is both an indication of protein purity and a critical parameter in defining the uses of a protein product. Therefore, colour measurement is needed as an objective measure of the process modification or development. While the darkness of a coloured solution can be determined using a spectrophotometer in terms of absorbance or transmittance in a certain range of wavelengths, the measurement of surface colour of a solid sample is more complex. A colorimeter such as the Hunter L. a, b instrument must be used, which measures colour based on the opponent-colours theory.

In the opponent-colour theory, colour is considered to be a composite, threedimensional characteristic consisting of a lightness attribute, and two chromatic attributes indicating the shade and the concentration of colour, respectively (Hunter and Harold, 1987). Thus, it takes a solid-coordinate system to represent colour graphically. Many systems have been established for the specification of colours in three-dimensional space. Designed for the measurement of colour, there is a specific arrangement of attributes in colour space, which sees red, green, yellow, blue, white, and black as paired opposites; red-green, yellow-blue, and white-black. The dimensions of this system are shown in Figure 15. The black-to-white "axis" of this system is vertical to the horizontal plane where the red-to-green dimension runs 
Figure 15 . The $L, a, b$ colours system reflecting three-dimensional opponent-colour theory

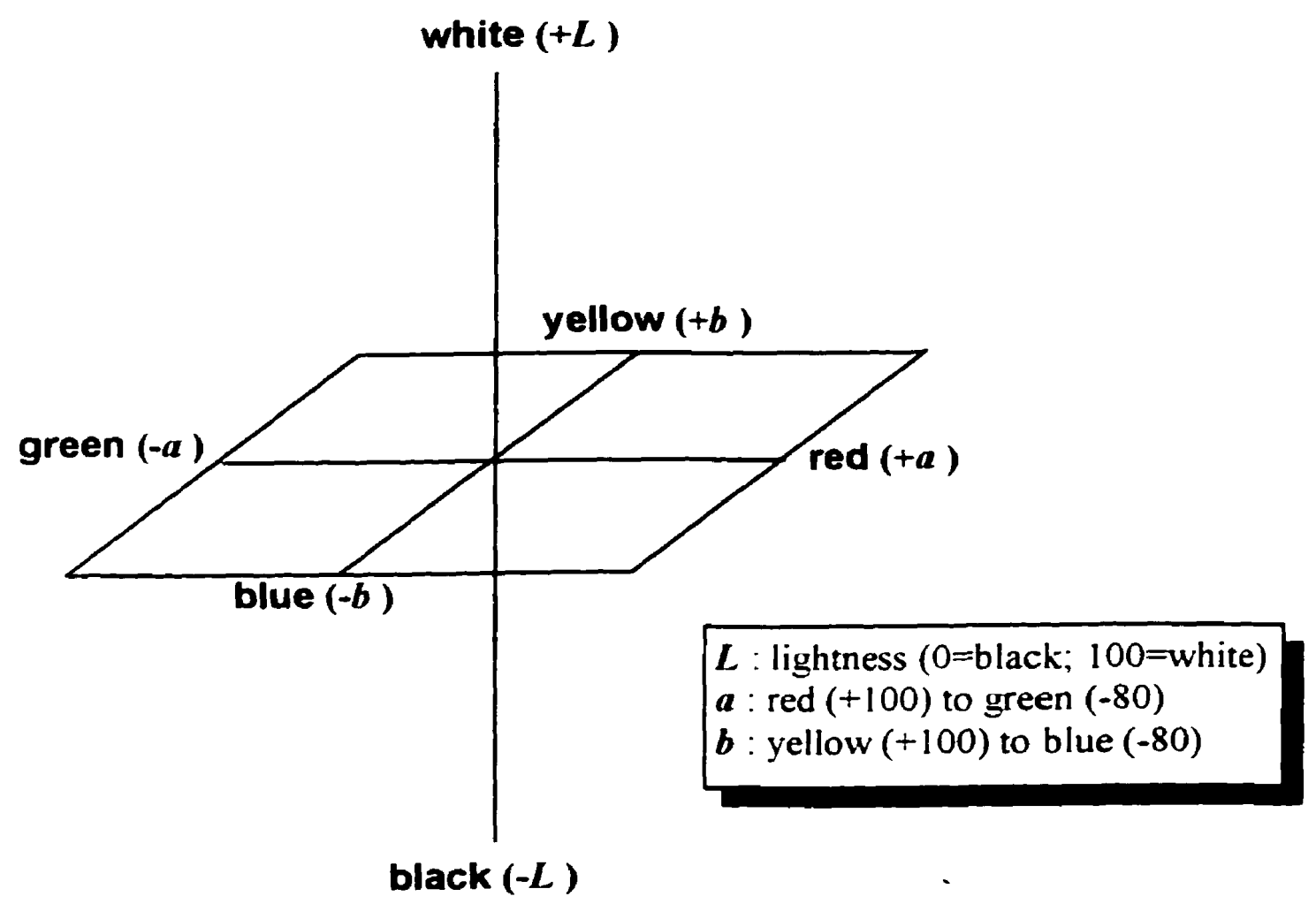


from right to left and the blue-to-yellow from front to back. The opponent-colours dimensions are considered today to correspond most closely to the actual visual signals going from eye to brain (deValois et al., 1966). In order to identify a colour by numbers, many scales were developed for colorimetry. Hunter (1942) proposed $L^{\prime}, \alpha^{\prime}, \beta^{\prime}$ colour scales and developed a trend toward surface colour scales with exactly or approximately 100 units between black and white. In the 1950's Hunter achieved the objective of uniform colour scales that could be computed and read directly from the dials of an instrument, the $L, a, b$ scales (Hunter, 1958). These scales reflect an opponent-colours system with the dimensions described as above (Figure 15), and such an instrument is called the Hunter colorimeter.

In this study, canola protein isolates (both PPI and SPI) were prepared by different processes with the treatments to remove phenolic compounds. Since the dark colour is likely caused by phenolic compounds in the products, as a result of the removal of them the colour of the products is expected to become lighter. Colour measurements were, therefore, carried out to examine the effects of different treatments for phenolic removal on the colour. All SPI's are soluble, so the colours of their solutions were measured using a spectrophotometer. For the PPI samples, a Hunter colorimeter was used.

\subsection{Sensory Evaluation}

Much like the colour, the taste of canola protein isolates also needs to be evaluated in order to make sure that the modified or newly developed processes are indeed able to improve the taste of the products. Taste is measured by sensory evaluation techniques. Sensory evaluation is the discipline to evoke, measure, analyze and interpret those 
characteristics of foods as perceived through the human senses (Institute of Food Technologists, 1975). Such an evaluation is usually carried out by panels of several to several hundred people. Since it uses people as a measuring instrument, the results of sensory evaluation are based on human judgment, and can be easily affected by many human factors, both psychological and physical. Thus, it is essential to control the testing methods and conditions to minimize the effects of these factors on human judgment (Poste et al., 1991). The value of each panel depends on the objectivity, precision, and reproducibility of the judgment of the panelists, hence these panelists need to be carefully selected. For different purposes, sensory analysis panel can be grouped into four types: highly trained experts, trained laboratory panels, laboratory acceptance panels, and large consumer panels. Panelists for laboratory testing are usually office, plant, or research staff.

Several sensory evaluation methods are available, each with its advantages and disadvantages (Meilgaard et al., 1987). None of the methods can be used universally. They should be chosen according to the purpose of the test and information required. The three fundamental types of sensory tests are discriminative, descriptive, and affective tests. Discriminative tests are used to determine whether a difference exists between samples whereas descriptive tests determine the nature and intensity of the differences. Information obtained from descriptive tests helps in identifying ingredient or process variables responsible for specific sensory characteristics of a food product, thus can be used to develop new products, to improve products or processes, and to provide process control. Affective tests are based on either a measure of preferences (or acceptance) or a measure from which relative preference can be determined, and they are mostly used for the hedonic attributes of a food product. 
In this study, the difference in taste among the canola protein isolates from different processes was examined to show the effects of phenolic removal on the taste. Descriptive tests were thus deemed to be suitable for this purpose. Different scaling methods are involved in this type of sensory tests, among which unstructured scaling was chosen for this study. Its details are given in Experimental Methods. 


\section{EXPERIMENTAL METHODS}

\subsection{Analytical Methods}

\subsubsection{Development of a rapid method for total phenolic acid determination in rapeseed/canola meals}

Based on the two wet chemical methods documented in the literature (Ismail and Eskin, 1979; Naczk et al., 1992), a new method was developed for the determination of total phenolic acids in canola meal. It combined the simple extraction technique of the method of Ismail and Eskin (1979) with the safer and more accurate colorimetric measurement of Naczk et al. (1992).

In the development of this technique, two canola varieties, Altex and Tower, obtained from Canola Council of Canada, and one commercially prepressed canola meal that was not hexane extracted (CanAmera Foods, Hamilton, ON) were used. All samples were first hexane-defatted in a Soxhlet apparatus for $24 \mathrm{~h}$ and air-desolventized overnight at room temperature. Casein was obtained from J. T. Baker (Toronto, ON). Sinapic acid, used as a standard, was purchased from Sigma Chemical Company (Oakville, ON). Sinapine bisulphate was obtained through the courtesy of Dr. S. Arntfield of the University of Manitoba.

To test the recovery of sinapic acid, a series of spiked samples of canola meal and casein were prepared by adding predetermined amounts of sinapic acid. Casein was used, as it was free of phenolic compounds, while the canola standards tested the effect of some trace components normally present in the seed, on the recovery of added sinapic acid.

With casein, a series of six samples were prepared by either adding the sinapic acid directly, or in solution, at levels which were equivalent to 5 to $1000 \mathrm{mg}$ sinapic acid/100 $\mathrm{g}$ 
sample. Since the esterified fraction could make up a considerable portion of the total phenolic acids, in two of the casein based samples, sinapine bisulphate, a choline ester of sinapic acid was added. All additions have been corrected for impurities in the chemical standards.

The processing scheme of the method is illustrated in Figure 16. A sample $(2 \mathrm{~g})$ was first refluxed three times with $50 \mathrm{~mL} 60 \%$ acetone (acidified to $\mathrm{pH} 3$ with trichloroacetic acid) for $0.5 \mathrm{hr}$ at the boiling point of the solvent, and then filtered using Whatman No. 41 filter paper. The filtered solutions were combined and evaporated at $50^{\circ} \mathrm{C}$ under vacuum to remove acetone. The acetone-free extract was then treated with $20 \mathrm{~mL}$ of $4 \mathrm{M} \mathrm{NaOH}$ under $\mathrm{N}_{2}$ for $4 \mathrm{~h}$ to hydrolyze the esterified phenolic acids. The resultant solution after alkaline hydrolysis was acidified to $\mathrm{pH} 2$ with concentrated $\mathrm{HCl}$. In order to extract the insoluble bound phenolic acids, the residual meal after acetone extractions was treated with $20 \mathrm{~mL}$ of $4 \mathrm{M} \mathrm{NaOH}$ under $\mathrm{N}_{2}$ for $4 \mathrm{~h}$. The mixture was also acidified with concentrated $\mathrm{HCl}$ to $\mathrm{pH} 2$ and centrifuged $(5000 \mathrm{rpm}, 10 \mathrm{~min})$. The supernatant was combined with the acidified extract obtained earlier. The combined extract was diluted to $100 \mathrm{~mL}$, from which an aliquot of 25 $m L$ was taken to be extracted six times with ethyl ether/ethyl acetate $(1: 1, v / v)$. The organic extracts were combined and evaporated to dryness at room temperature under vacuum. The extracted phenolic acids were then redissolved in a known amount of methanol selected so that the concentration of phenolic acids was in the range of 0 to $0.4 \mathrm{mg} / \mathrm{mL}$ methanol for the colormetric measurement. Finally, the phenolic acid content of the methanol was determined colormetrically using Folin-Denis reagent and by measuring the absorbance of the coloured complex formed at $725 \mathrm{~nm}$ (Naczk et al., 1992). The phenolic acids content in the sample was expressed as $\mathrm{mg}$ of sinapic acid equivalents per 100-g sample, in accordance with the 
Figure 16. A new analytical method for total phenolic acid determination of rapeseed/canola samples

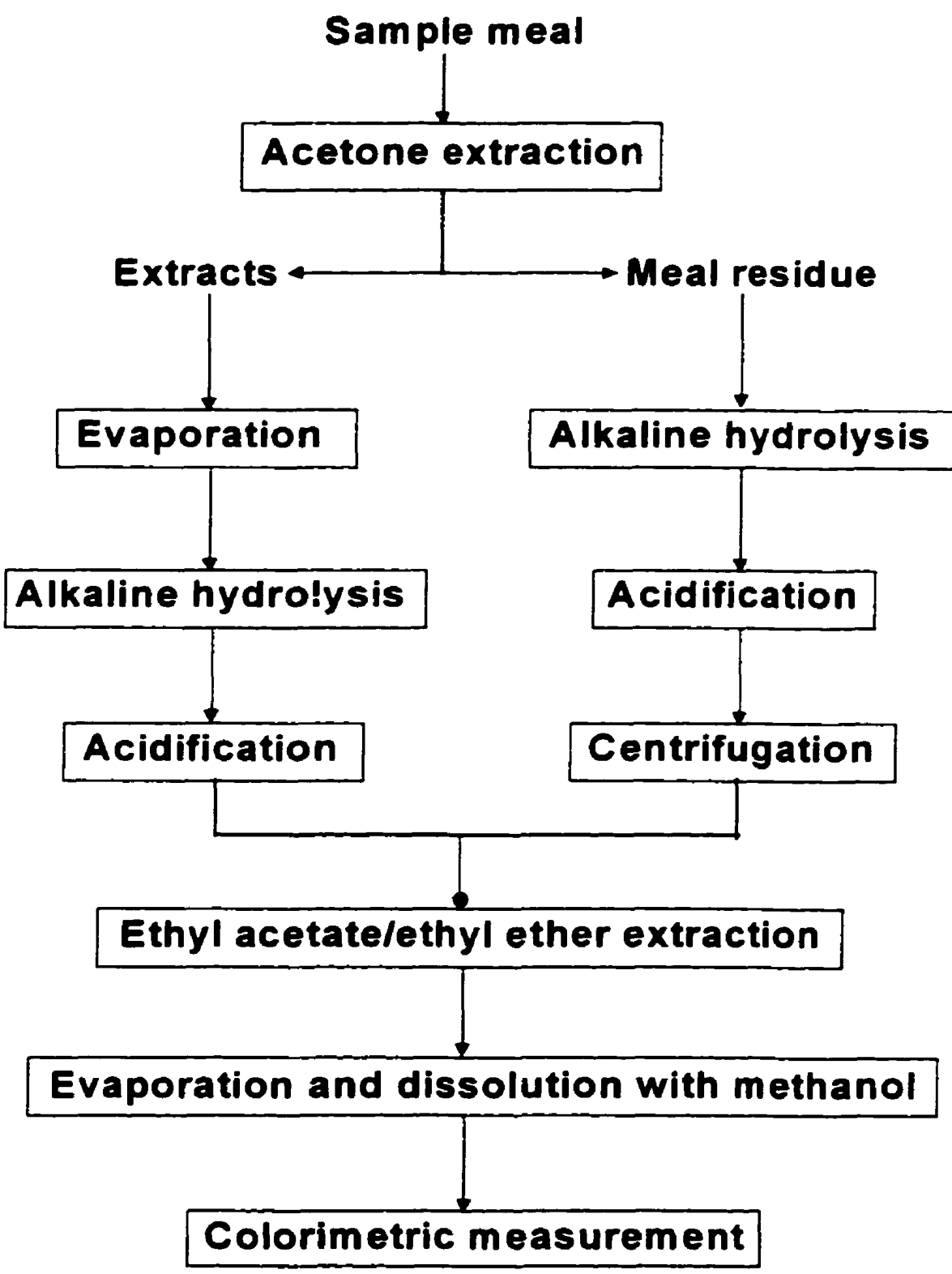


common practice in the literature.

All determinations were carried out in four replicates and the results obtained by each of the analytical methods were compared statistically using ANOVA (Microsoft Excel 97).

\subsubsection{Validation of the analytical method for condensed tannin determination}

Condensed tannins were determined using the method of Shahidi and Naczk (1989) in this study. In order to check its accuracy when used in a canola protein system, the method was validated as follows.

Again, casein as a tannin-free protein was used for the preparation of standard samples. Five standards were prepared by adding predetermined quantities of a catechin staridard to casein, which represented a range of tannin contents from $1000 \mathrm{mg}$ catechin equivalent $/ 00 \mathrm{~g}$ sample to $5 \mathrm{mg} / \mathrm{l} 00 \mathrm{~g}$. One sample was prepared by spiking hexane-defatted canola meal with the catechin standard (Sigma Chemical Company, Oakville, Ontario). For tannin determination, a lg sample was extracted twice with $20 \mathrm{~mL} 70 \%(\mathrm{v} / \mathrm{v})$ aqueous acetone for $15 \mathrm{~min}$ each time on a wrist shaker. After each centrifugation (5000 rpm, 10 $\mathrm{min})$, the supernatants were collected, combined and evaporated to dryness at $30^{\circ} \mathrm{C}$ under vacuum. The extracted tannins were dissolved in $10 \mathrm{~mL}$ methanol, and then assayed colorimetrically using vanillin reagent prepared by combining equal volumes of $8 \%$ concentrated $\mathrm{HCl}$ in methanol and $4 \%$ vanillin (Sigma Chemical Company, St. Louis, MO) in methanol (prepare daily). The absorbance was measured at $500 \mathrm{~nm}$. The tannin content in the sample was expressed as catechin equivalents ( $\mathrm{mg} / 100 \mathrm{~g}$ of sample), in accordance with the standard practice in the literature. 


\subsection{Study of Interactions between Canola Protein and Phenolic Compounds}

\subsubsection{Extractability of phenolic compounds from canola meal}

In order to find out the amount of phenolic compounds extractable from the meal into the solution along with the protein at different $\mathrm{pH}$ 's, the extraction procedure of rapeseed/canola protein was strictly followed with ten gram starting meal each time. During each extraction all operating parameters were carefully controlled. Those included a waterto-meal ratio of $18, \mathrm{pH}$, an extraction time of $30 \mathrm{~min}$, and twice washing of the meal residue each time with a water-to-meal ratio of 6 . The meal residue was separated by centrifugation (6000 rpm, 15min) with a B-22 centrifuge (International Equipment Company, Needham Heights, MA) and filtration with Whatman No. 41 filter paper. After the washings, the meal residue was freeze-dried, and both its residual phenolic acids and tannins contents were then determined. Therefore, the results of extractability of both phenolic acids and tannins could be calculated by the difference between the total amount before the extraction and the residual amount afterwards. The extractability of canola protein was obtained by the determination of protein concentration in the aqueous extracts using the Kjeldahl method (AACC, 1976).

\subsubsection{Membrane processing unit}

Membrane processing was used to separate low-molecular impurities from the protein so as to isolate and purify the protein. In this study it was performed with an Amicon hollowfibre concentrator, Model CH4 manufactured by Amicon Canada Ltd, Oakville, Ontario. It was operated in both ultrafiltration and diafiltration modes (Figures 12 and 13). A built-in peristaltic pump drew feed solution from a container, pumped it through a prefilter to remove 
fine solids, and then through an Amicon DIAFLO H1P10-20 hollow-fibre membrane cartridge which was characterized by a nominal molecular weight cut-off of 10,000 Dalton and a membrane area of approximately $0.06 \mathrm{~m}^{2}$. Pressure in the cartridge was contrclled by a back-pressure valve at the outlet. Water and those dissolved species with molecular weights below the molecular weight cut-off of the membrane were driven through the fibre walls as the permeate while the retentate containing the solutes with molecular weights higher than that was pumped back to the original container. At the end of each process, the unit was immediately drained of the solution and flushed with distilled water, and then a $5 \mathrm{~g} / \mathrm{L} \mathrm{Terg-}$ A-Zyme solution (Alconox Inc., New York, U.S.A) was recycled through the unit for about an hour to clean it. Upon the draining of the detergent solution, the system was flushed again with a large quantity of distilled water until the initial permeate flux was restored. The cleaned membrane cartridge was stored in $1 \%$ formaldehyde solution when not in use. One day before use it was rinsed with distilled water and soaked in distilled water overnight.

\subsubsection{Determination of rejection coefricients of phenolic compounds for membrane processing}

In order to show whether phenolic compounds can permeate the membrane, their rejection coefficients were determined. The samples of both phenolic acids and tannins used for this study were extracted directly from hexane-defatted prepress canola meal using the extraction techniques described in the analytical methods for the determination of phenolic acids and tannins in Sections 3.1.1. and 3.1.2.

Ten and twenty grams of the meal were used for phenolic acids and tannins extraction, respectively. After the removal of acetone by evaporation under vacuum at $50^{\circ} \mathrm{C}$, 
both extracts of phenolic acids and tannins were centrifuged ( $15 \mathrm{~min}, 5000 \mathrm{rpm}$ ), filtered, and diluted to $500 \mathrm{~mL}$ with water for ultrafiltration, during which the retentate was circulated in the system with its volume reduced by different concentration factors. The volume of retentate was noted when each time a sample was taken out of the retentate for phenolic acid or tannin analysis. A series of initial and final phenolic concentrations, and initial and final volumes of the retentate were thus obtained.

\subsubsection{Fractionation of phenolic compounds in alkaline extract and acidic solution of canola protein}

The literature reveals that phenolic compounds bind to protein by several different mechanisms: ionic bonding, hydrophobic interaction, hydrcgen bonding, and covalent bonding. For the removal of phenolic compounds from canola protein, it was of vital importance to study their interactions, especially in aqueous media as canola protein was processed primarily with water. Based on the chemistry of these interactions, a novel approach was proposed for the quantification of each of these binding modes, which combines a series of chemical treatments with membrane processing (Figure 17). Each chemical treatment was expected to break one type of phenolic-canola protein complex, therefore, by this approach total extractable phenolic compounds were fractionated in terms of different interactions with rapeseed/canola protein.

The alkaline extract of canola protein was prepared by extracting defatted prepressed canola meal at pH 12.0 and a water-to-meal ratio of 18 for $30 \mathrm{~min}$. After extraction the meal residue was separated by centrifugation (6000 rpm, $15 \mathrm{~min})$ with a B-22 centrifuge (International Equipment Company, Needham Heights, MA) and filtration with Whatman 


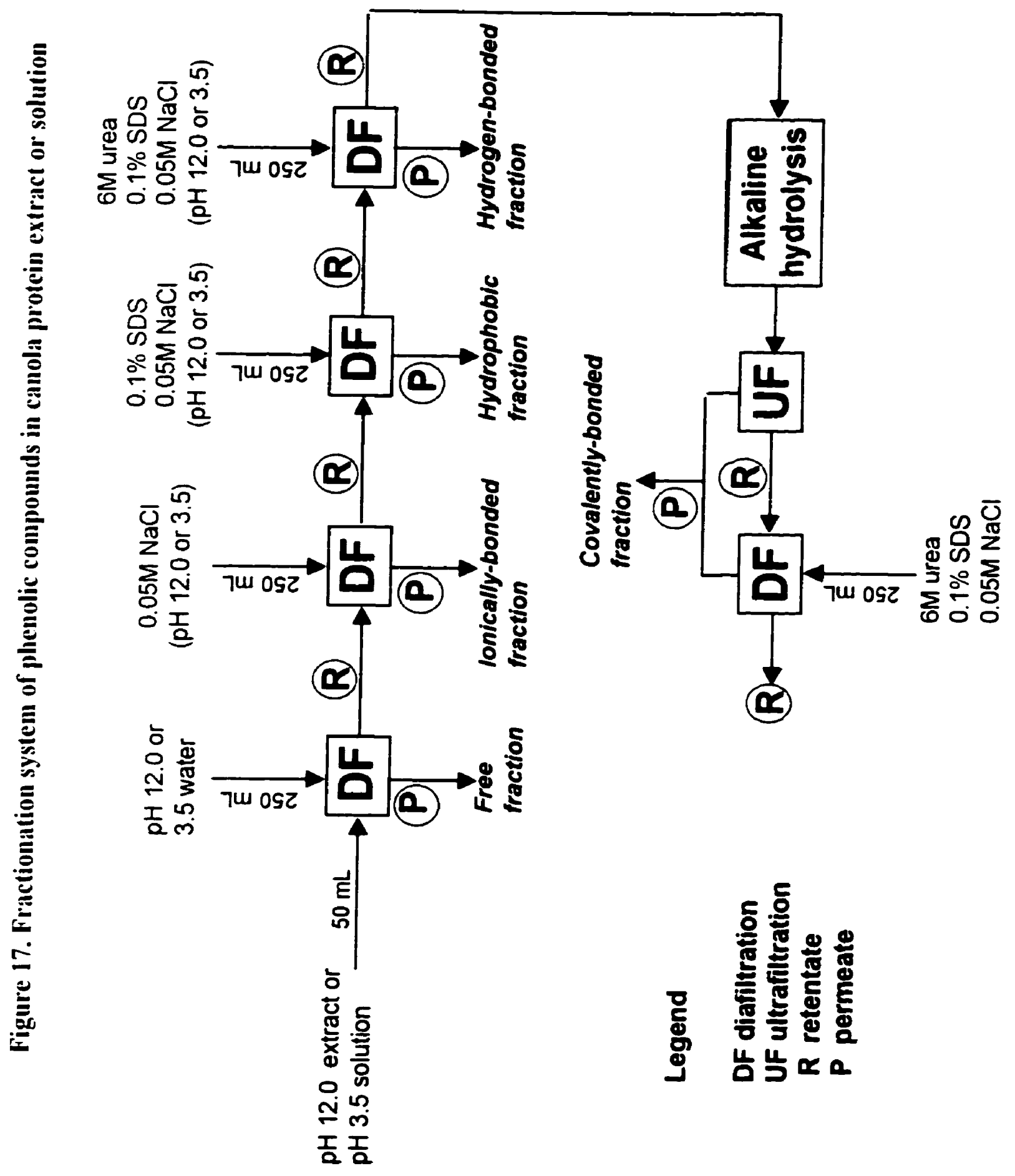


No. 41 filter paper. To obtain the acidic solution of canola protein, the alkaline extract was acidified to $\mathrm{pH} 3.5$ for isoelectric precipitation of proteins. It was maintained at $\mathrm{pH} 3.5$ for 15 min before it was centrifuged $(6000 \mathrm{rpm}, 15 \mathrm{~min}))$ to separate the canola protein precipitated at $\mathrm{pH} 3.5$, and the supernatant was polished filtered with Whatman No. 41 filter paper to yield the acidic solution.

As shown in Figure 17, to run this fractionation system an aliquot of $50 \mathrm{~mL}$ was first taken from $\mathrm{pH} 12.0$ alkaline extract of canola protein. After the removal of the free fraction by diafiltration, the chemical treatments were carried out in an order from $0.05 \mathrm{M} \mathrm{NaCl}$ (BDH Inc., Toronto, ON), 0.1\% sodium lauryl sulphate (BDH Inc., Toronto, ON), 6M urea (BDH Inc., Toronto, ON), to alkaline hydrolysis with 4M NaOH (ACP Chemicals Inc., Montreal, QC). The first three treatments were actually conducted in the diafiltration mode, in which the retentate was diafiltered against 5 times $(250 \mathrm{~mL})$ as much washing liquid containing the chemicals, i.e., each of these treatments was carried out simultaneously with the separation of the released phenolics. The last treatment, four hour alkaline hydrolysis was completed before diafiltration. In each treatment, in order to prevent the reformation of the bonds already broken in the previous treatments, the chemicals used in the previous treatments were still added, e.g., in the treatment of hydrophobic fraction with $0.1 \%$ sodium lauryl sulphate (SDS), $\mathrm{NaCl}$ was still added to make sure that the residual free phenolic compounds do not re-form ionic bonds with the proteins. Samples were taken out of the permeates from diafiltration, and stored in a refrigerator at $5^{\circ} \mathrm{C}$ before the analyses of phenolic acids and tannins. The volume of the permeate from each diafiltration was noted to permit the calculation of the amount of phenolic acids and tannins. 
With the acidic solution of canola protein, the same process was repeated, keeping each diafiltration step at $\mathrm{pH} 3.5$.

In order to confirm the effects of $\mathrm{NaCl}$ treatment on ionic bonding, a control run with no salt addition was performed at both pH's for comparison. And another run was performed using $0.10 \mathrm{M} \mathrm{NaCl}$ instead of $0.05 \mathrm{M}$ to ensure that the addition level of $\mathrm{NaCl}$ was adequate.

\subsection{Process Development for Production of High-Quality Canola Protein Isolates by Removing Phenolic Compounds}

The information obtained from the results of the above phenolic fractionation was useful in the process development for the removal of phenolic compounds. Some of the treatments could be incorporated into the processing scheme, e.g., the free fraction of the extractable phenolic acids and tannins was expected to be removed simply by diafiltration with no treatment; with the help of $0.05 \mathrm{M} \mathrm{NaCl}$ the ionically-bonded phenolic acids and tannins could be removed. Further treatment with $0.1 \%$ SDS would remove the phenolic acids and tannins recognized as the hydrophobic fraction.

\subsubsection{Removal of phenolic compounds by treatments prior to isoelectric precipitation}

An experimental scheme has been thus designed to achieve partial removal of phenolic compounds by treating and diafiltering the alkaline extract prior to isoelectric precipitation (Figure 18). Each run in the scheme started with 50 gram defatted prepress canola meal. The protein was extracted at $\mathrm{pH} 12.0$ for $30 \mathrm{~min}$ and the meal residue was separated by centrifugation $(6000 \mathrm{rpm}, 15 \mathrm{~min})$ with a B-22 centrifuge (International 


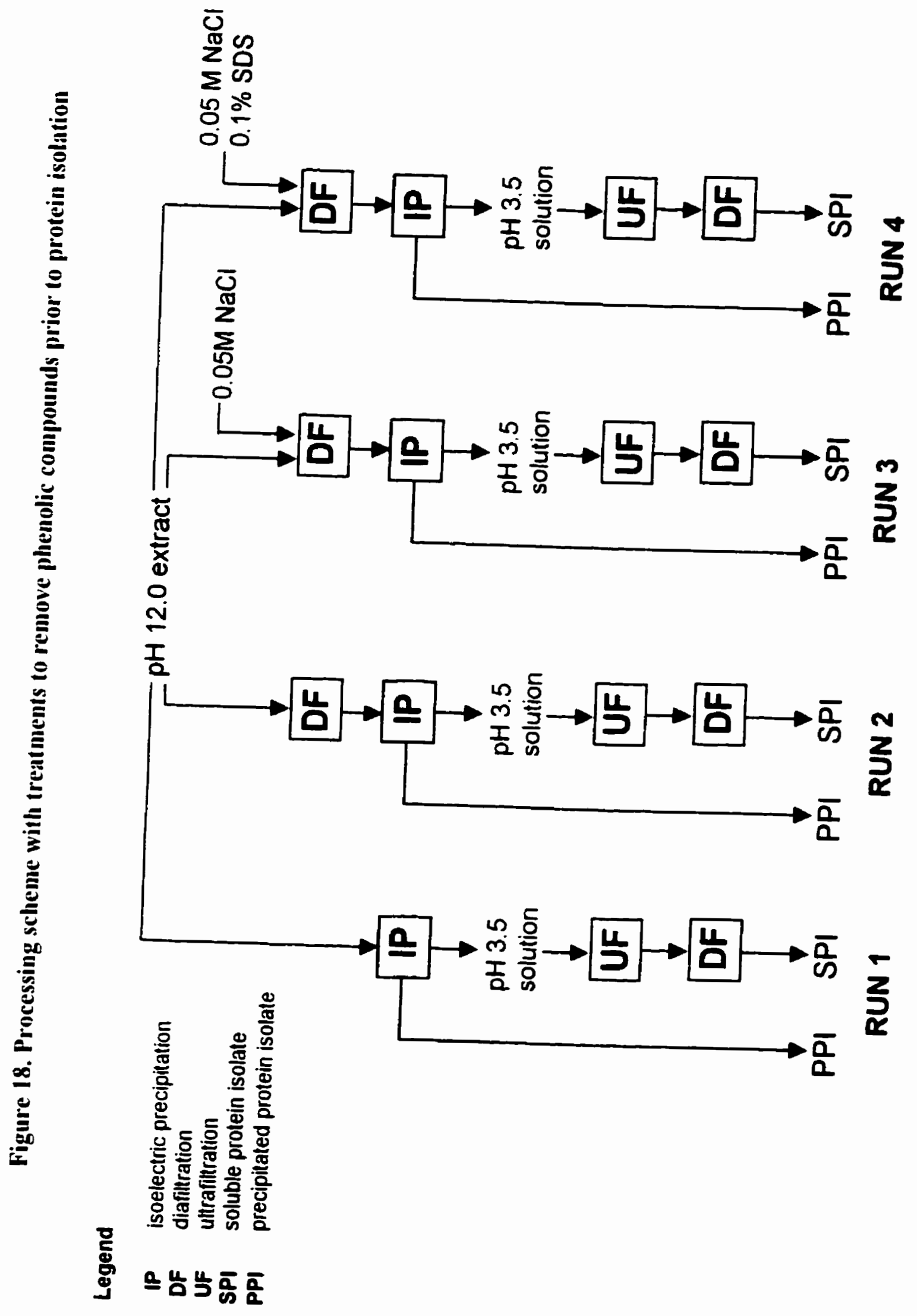


Equipment Company, Needham Heights, MA). The meal residue was washed twice with distilled water each time at a ratio of 6 . The washing liquids were combined with the original extract.

A control run (Run 1) was performed with no treatment prior to isoelectric precipitation. In other runs, the resulting alkaline extracts were diafiltered at a diavolume of 5 in Run 2, treated with $0.05 \mathrm{M} \mathrm{NaCl}$ before diafiltration in Run 3, and with $0.05 \mathrm{M} \mathrm{NaCl}$ and $0.1 \%$ SDS before diafiltration in Run 4. Each diafiltration was conducted with the treatment reagent solution at $\mathrm{pH} 12.0$.

The treated alkaline extracts were then further processed to produce two protein products, soluble and precipitated protein isolates. The $\mathrm{pH}$ of the extract was reduced to 3.5 to precipitate some protein (PPI), which was separated by centrifugation (6000 rpm, $15 \mathrm{~min})$. The precipitate was washed with 5 times its weight of distilled water (on wet basis) and centrifuged again for separation. The precipitate was freeze-dried. The acidic protein solution from the isoelectric precipitation and washing liquid were combined, uitrafiltered at a concentration factor of 10 , and diafiltered at a diavolume of 5 to concentrate and purify the soluble proteins (SPI). These proteins were also recovered by freeze-drying. All final protein products were analyzed for phenolic acids, tannins, and protein.

\subsubsection{Treatment with reduced amount of SDS and elimination of the second diafiltration}

In Run 4 an excess amount of SDS was used since the alkaline extract already treated with $0.1 \%$ SDS was then diafiltered against five-fold $0.1 \%$ SDS solution. This level of SDS addition may lead to a substantial SDS content in the final products as a result of SDS binding to canola protein, thus rendering these products useless. Therefore, an extra run was 
performed with a reduced quantity of SDS used, in which SDS was only added to the alkaline extract but not to the water added during diafiltration.

During protein isolation, after isoelectric precipitation the acidic solution was further membrane processed (ultrafiltration and diafiltration) to concentrate and purify the soluble proteins (Figure 18). However, since the a!kaline extract was already diafiltered prior to isoelectric precipitation in this case, a second diafiltration in the process seemed redundant, and could be eliminated to make the process more efficient. Hence, another run was done without the diafiltration for the acidic solution after isoelectric precipitation. The effects of this modification on the products were investigated in terms of protein, phenolic, and residual SDS contents.

\subsubsection{Study of the effects of PVP on removal of phenolic acids}

The extracts and solutions of canola protein were contacted with insoluble polyvinylpyrrolidone (PVP) to remove hydrogen-bonded phenolic acids. As shown in Figure 19, aliquots of $100 \mathrm{~mL}$ were taken from either $\mathrm{pH} 12.0$ alkaline extract or $\mathrm{pH} 3.5$ acidic solution after isoelectric precipitation. The free, ionically-bonded, and hydrophobic fractions of phenolic acids were first removed by diafiltration with water containing $0.05 \mathrm{M} \mathrm{NaCl}$ and $0.1 \%$ SDS at a diavolume of 5 . The retentate from the diafiltration was collected, and presoaked insoluble PVP (Sigma Chemical Company, St. Louis, MO) was added to it at 10 or $20 \%$, as of the starting meal proportioned to $100 \mathrm{~mL}$ sample. The mixture was stirred for 1 hour at room temperature on a hot plate stirrer. After the separation of PVP by filtration with Whatman No. 42 filter paper, the treated retentate was diafiltered with water containing $6 \mathrm{M}$ 
Figure 19. Study of the effects of PVP on removal of phenolic acids

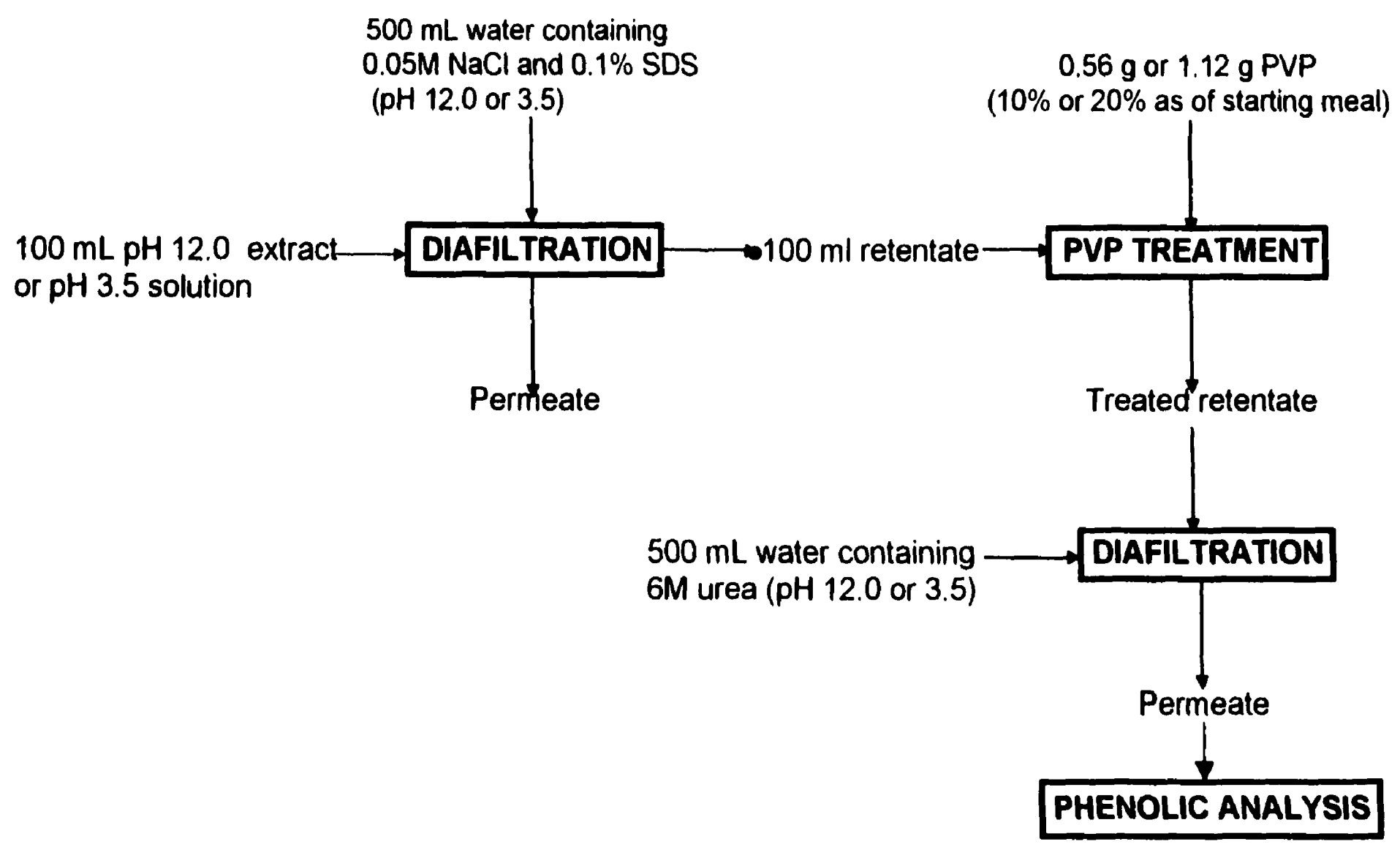


urea to remove phenolic acids that were not adsorbed by the PVP. The permeate from the diafiltration was collected with its volume noted, and analyzed for phenolic acids.

\subsubsection{Study of the effects of $\mathrm{Na}_{2} \mathrm{SO}_{3}$ on removal of phenolic acids}

The scheme for the study of $\mathrm{Na}_{2} \mathrm{SO}_{3}$ was similar to that for PVP (Figure 20), except that, in this case aliquots were only taken from $\mathrm{pH} 3.5$ solution of canola protein after isoelectric precipitation. In the first diafiltration urea $(6 \mathrm{M})$ was used in addition to $\mathrm{NaCl}$ and SDS to help remove hydrogen-bonded phenolic acids. The retentate was then collected. and 0.10 or $0.50 \% \mathrm{Na}_{2} \mathrm{SO}_{3}$ by weight was added. It was stirred for 4 hours under $\mathrm{N}_{2}$ blanketing when $\mathrm{pH}$ was maintained at 3.5. The treated solution was then diafiltered again. The permeate from the diafiltration was collected with its volume noted, and analyzed for phenolic acid.

\subsubsection{The further modified process to produce high-quality canola protein isolates by removing phenolic compounds}

Based on the effects of various treatments studied earlier, the original protein isolation process was tailored to produce protein isolates of low phenolic contents (Figure 21). To start, fifty grams of defatted prepressed canola meal was mixed with water containing $0.1 \% \mathrm{Na}_{2} \mathrm{SO}_{3}$ at a ratio of 18 , and stirred at $\mathrm{pH} 12.0$ for 30 minutes. The alkaline extract was collected by centrifugation ( $6000 \mathrm{rpm}, 15 \mathrm{~min})$ using a B-22 centrifuge (International Equipment Company, Needham Heights, MA) and polished by filtration. The meal residue was then washed twice with distilled water in total of $600 \mathrm{~mL}$, and the washing liquids were combined with the alkaline extract. Both $\mathrm{NaCl}$ and SDS were added to the combined extract 
Figure 20. Study of the effects of $\mathrm{Na}_{2} \mathrm{SO}_{3}$ on removal of phenolic acids

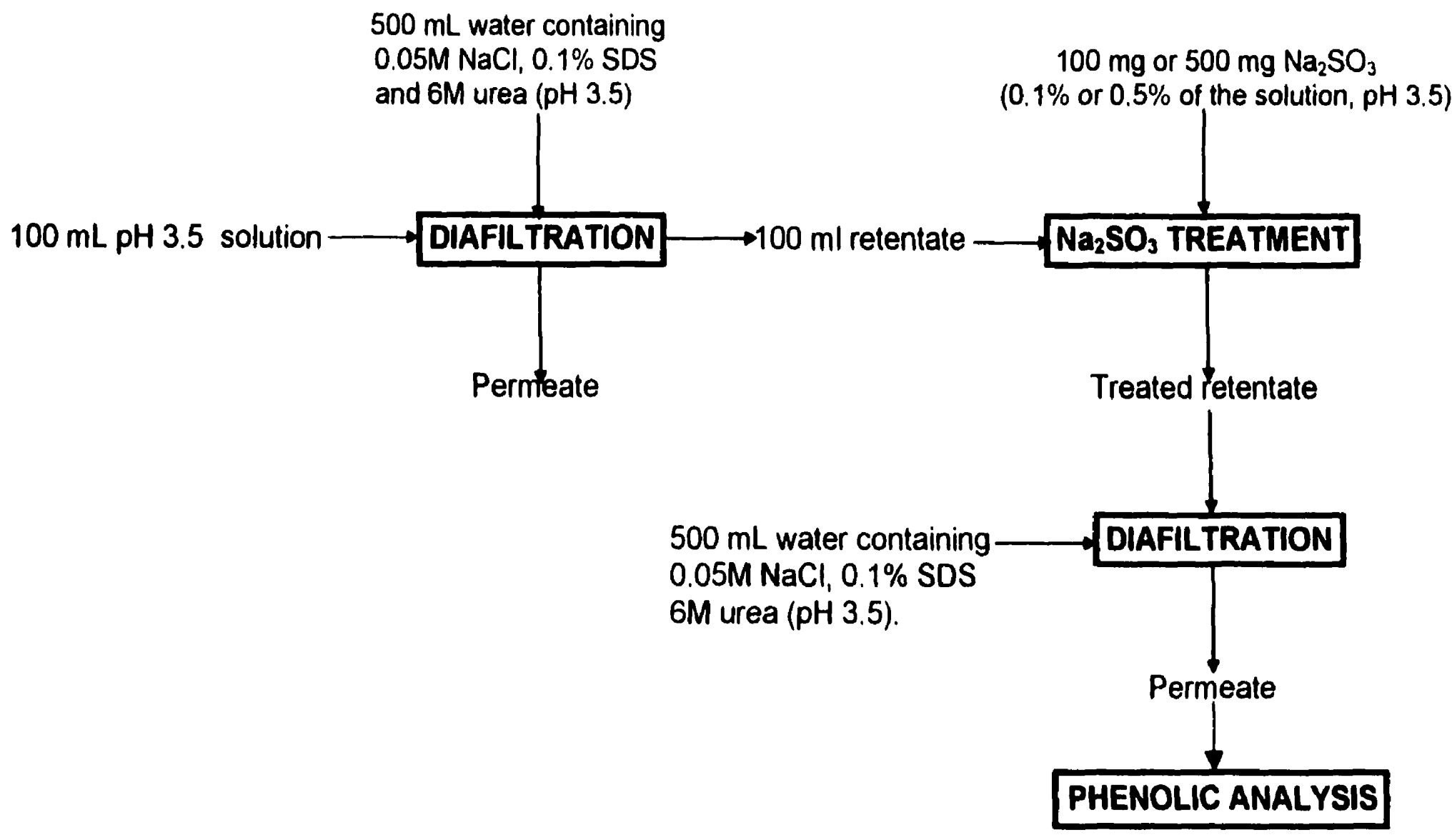


Figure 21. The further modified process for the production high-quality canola protein isolates

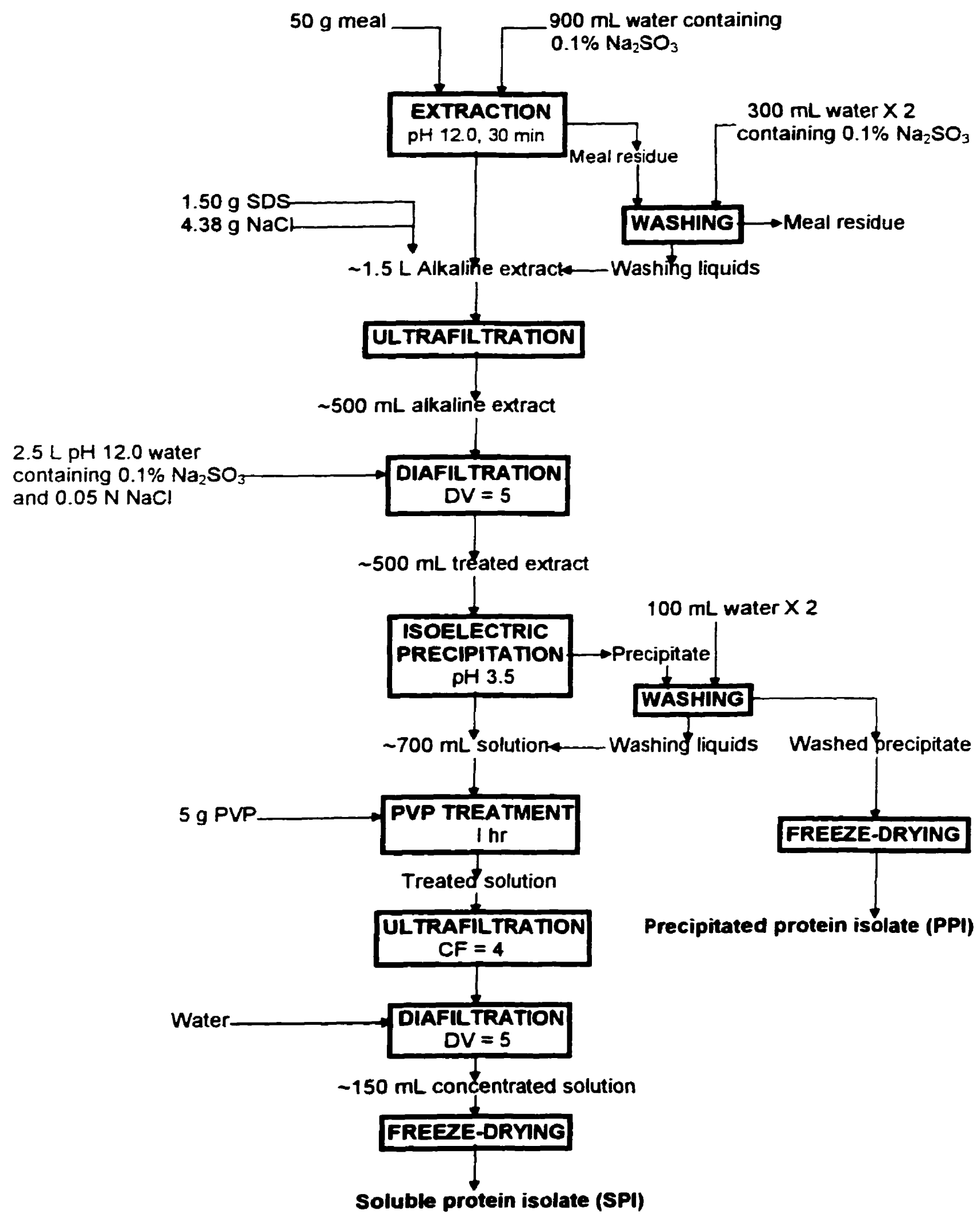


at concentrations of $0.05 \mathrm{M}$ and $0.1 \%$, respectively. Its volume was then reduced by uitrafiltration by a factor of 3 before it was diafiltered at a diavolume of 5 with pH 12.0 water containing $0.1 \% \mathrm{Na}_{2} \mathrm{SO}_{3}$ and $0.05 \mathrm{M} \mathrm{NaCl}$ (but without $\mathrm{SDS}$ ).

The diafiltered alkaline extract was acidified with $6 \mathrm{M} \mathrm{HCl}$ to $\mathrm{pH} 3.5$ for isoelectric precipitation, and this $\mathrm{pH}$ was maintained for $15 \mathrm{~min}$ for protein aggregation. The precipitate formed was separated from the supernatant by centrifugation $(6000 \mathrm{rpm}, 15 \mathrm{~min})$, the supernatant was decanted and polish-filtered using Whatman No. 41 filter paper. The precipitate was washed in the centrifuge tubes with $100 \mathrm{~mL}$ distilled water, and then centrifuged again for separation.

The washing liquid was combined with the supernatant. The resulting acidic solution was treated with 5 gram PVP for one hour before it was ultrafiltered at a concentration factor of 4 and then diafiltered at a diavolume of 5 with distilled water.

Both the washed precipitate and the membrane-processed solution were eventually freeze-dried for 72 hr using a Labconco Freeze Dryer-18 (Labconco Corp., Kansas City, MO) to obtain two protein isolates (PPI and SPI).

\subsection{Colorimetric and Sensory Characterization of the Final Products}

\subsubsection{Colour measurement}

In order to examine the effects of removal of phenolic compounds on the colour of the products, colour measurements were carried out for the PPI and SPI samples from the processes with different treatments.

The colour of all PPI's was measured using a D25A-9 Hunter Colorimeter. It was built in two sections - the optical sensor and the signal processor. The optical sensor used the 
light from the quartz halogen cycle lamp, which was filtered to closely approximate CIE illuminant D65. The light was directed upward to the sample port at an angle of $45^{\circ}$ from the perpendicular. The light receptor was placed directly below the sample port. Electrical signals were directed by cable to the signal processor where they were converted into the standard Hunter L, a, b scale. For each measurement approximately four grams of sample were used.

For all SPI samples the colour measurement was performed on their aqueous solutions using a Beckman DU-7 UV-visible spectrophotometer (Beckman Instruments Inc., Irvine, CA). The sample was first dissolved in distilled water at concentration of $1 \%$, and centrifuged (5000 rpm, $15 \mathrm{~min}$ ) with a Centra 4 centrifuge (International Equipment Company, Needham Heights, MA). The supernatant was decanted into a quartz cuvette and scanned in a UV-visible range from 385 to $700 \mathrm{~nm}$ against distilled water as blank.

\subsubsection{Sensory evaluation}

Like the colour, the taste of the products also needed to be quantitatively evaluated to show the improvement of taste as a result of the removal of phenolic compounds by different treatments. The information sought in this case was the degree or intensity of the differences in taste of the products. Therefore, unstructured scaling, also known as line or visual analogue scaling, was chosen for the sensory test. It is a descriptive methods (Poste et al., 1991).

A panel was set up consisting of 13-14 people, including the staff, graduate, and undergraduate students in food engineering. The samples were contained in jars wrapped with aluminum foil to mask colour differences to avoid stimulus error. The order of 
presentation of the samples was randomized to minimize central tendency error. Drinking water was offered for mouth rinsing between samples to control contrast effect. Talking or commenting was not permitted during the test to eliminate suggestion effect. To minimize expectation error, all panelists were given only enough information for them to conduct the test, and the person directly involved in making the products was not included on the panel.

The most commonly used unstructured scale consists of a horizontal line $15 \mathrm{~cm}$ long with two anchor points on both ends and a mid point. Each anchor point is labeled with a word or expression. A separate line is used for each sensory attribute to be evaluated. In this study two attributes were investigated, taste intensity and pleasantness of the products, and the latter one was a hedonic attribute. Panelists recorded each evaluation by making a vertical line across the horizontal line at the point that best reflects their perception of the magnitude of that property. Numerical scores were then given to the ratings by measuring the distance of the marks from the left end of the line in units of $0.1 \mathrm{~cm}$. One score was an equivalent of 1 $\mathrm{cm}$ on graphical scale.

\subsection{Chemical Analyses}

The analytical method for determination of total phenclic acid content was developed in this study, and its procedure was described in detail in Section 3.1.1. Tannin content was determined by the method of Shahidi and Naczk (1989), which was validated in Section 3.1.2.

Crude protein $(\mathrm{N} \times 6.25)$ was determined by the Kjeldahl method, AACC Method 4612 (AACC, 1976), using a Büchi 425 digester and Büchi 315 distillation unit. Details of this analysis are given in Appendix 8.1. 
The residual sodium dodecyl sulphate (SDS) was determined using a method developed by Igor (1992) in our laboratories based on dissociation and precipitation of the sulphate, and the total sulphate was determined gravimetrically using AACC Method 40-66 (AACC, 1976), the details of which are given in Appendix 8.2. 


\section{RESULTS AND DISCUSSION}

\subsection{Analytical Methods}

\subsubsection{Development of a rapid method for total phenolic acid determination in rapeseed/canola meals}

As mentioned earlier, there was a need for a rapid, accurate, and simple analytical technique for the phenolic compounds of rapeseed/canola meal. Two literature methods were. therefore, investigated in an attempt to adapt them to this study (Figures 8 and 9).

With the method of Naczk et al. (1992), low results (Table 1) were obtained compared to the literature values (Shahidi, 1992). This was likely due to losses incurred during the many steps involved in the fractionation of total phenolic acids. The method was long and tedious as the entire procedure took more than 24 hours for duplicates in parallel, and some of the information it provided was not really needed when only the total phenolic acid content of the sample of concern.

By contrast the method of Ismail and Eskin (1979) took only 7 hours, and it gave much higher phenolic acid contents than the method of Naczk et al. (Table I). The results were even higher than any reported in the literature. This was probably because some of the tannins, also present in the aqueous extracts, interfered with the colorimetric measurement, thus leading to a substantial overestimation of total phenolic acids.

Since both methods have drawbacks, a modified procedure was developed by combining their best features (Figure 16). This new procedure was tested and validated in terms of the number of extraction steps, length of time for alkaline hydrolysis, and phenolic acid recoveries of the spiked samples.

To assure that refluxing the sample three times with $70 \%$ acetone was adequate for 
Table 1. Total phenolic acid content in canola determined by the new method (expressed as $\mathrm{mg}$ sinapic acid equivalents $/ 100 \mathrm{~g}$ defatted meal)'.

\begin{tabular}{l|ccc}
\hline \multicolumn{1}{c|}{ Methods/Samples } & Altex & Tower & $\begin{array}{c}\text { Commercial prepress } \\
\text { canola meal }\end{array}$ \\
\hline New method & $1683 \pm 47$ & $1773 \pm 84$ & $1819 \pm 146$ \\
Naczk et al. (1992) & $1383 \pm 112$ & $1293 \pm 141$ & $1429 \pm 127$ \\
Ismail and Eskin(1979) & $2481 \pm 178$ & $2514 \pm 92$ & $2283 \pm 145$ \\
\hline
\end{tabular}

1. All values are presented as means \pm standard deviations of four replicates. The means in the same column are significantly different from one another $(P \leq 0.01)$. 
extracting essentially all phenolic acids, a series of samples were extracted four times. No phenolic acids were detected in the fourth extracts.

According to Naczk et al. (1992), both the esterified and the insoluble bound phenolic acids were hydrolyzed with $4 \mathrm{M} \mathrm{NaOH}$ before they were recovered in ethyl ether/ethyl acetate upon acidification. In order to ensure that the hydrolysis was completed in $4 \mathrm{hr}$, the remaining aqueous extract and the residual meal after ethyl acetate/ethyl ether extraction were both treated again with $4 \mathrm{M} \mathrm{NaOH}$ under $\mathrm{N}_{2}$ for another $4 \mathrm{~h}$. Since no further phenolic acids were released from either, it is safe to assume that the reaction was completed well within the $4 \mathrm{hr}$ period.

Most results from the sample series prepared with the additions of sinapic acid and sinapine standards to casein are reproducible with relative standard deviations of less than $10 \%$. The sample with the lowest addition level of only $0.100 \mathrm{mg}$ sinapic acid standard, equivalent to $5 \mathrm{mg}$ sinapic acid/100 $\mathrm{g}$ meal, was determined with a relative standard deviation of about $17 \%$ (Table 2). The recoveries in all other samples varied between 95 and $106 \%$. The relatively high standard deviation at the lowest addition level indicates that $5 \mathrm{mg}$ sinapic acid equivalents per $100 \mathrm{~g}$ sample is the lower limit of reliable quantitative analysis by this method although the actual detection limit is less than $5 \mathrm{mg}$ sinapic acid/100 $\mathrm{g}$ meal.

In two samples sinapine bisulphate was used to spike the matrix, in an effort to test if esterified phenolic acids are accurately quantified by the method. The four-hour alkaline hydrolysis with $4 \mathrm{M} \mathrm{NaOH}$ under $\mathrm{N}_{2}$ step in the method cleaved the sinapine bisulphate, and the released sinapic acid was then detected (Table 2). For the casein samples spiked with sinapic acid the alkaline hydrolysis was not required for the recovery of the standard, 


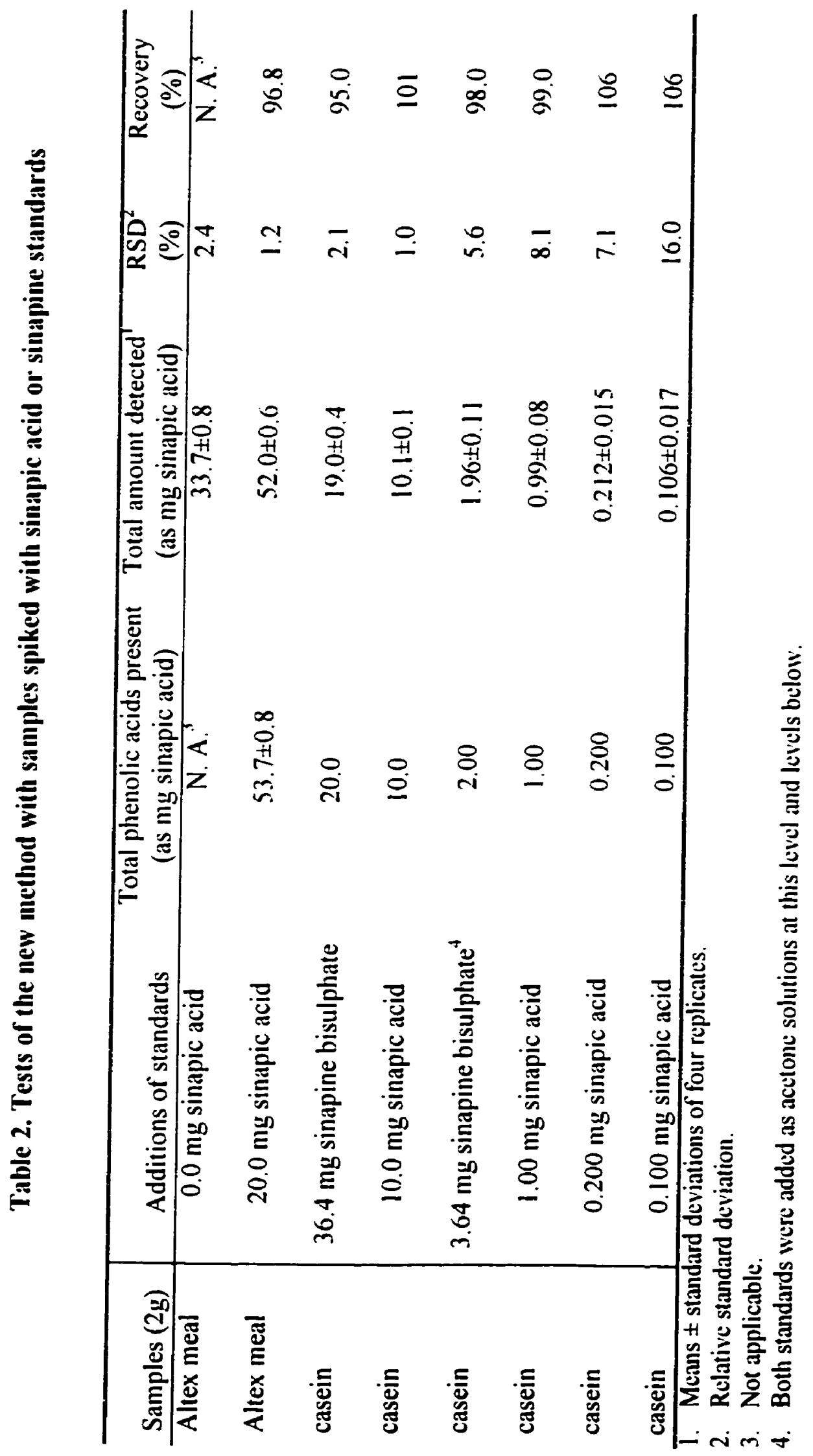


however, this step was still followed so as to validate the entire procedure. In both standards recoveries of $100 \pm 7 \%$ were obtained.

It is shown that the analytical method developed in this study is a compromise, as it gives accurate quantification of total phenolic acids in a reasonable time (approximately 16 hr). The simplification of the method of Naczk et al. (1992) results in an improved recovery, and a significant time saving, but the details of the distribution of the forms of phenolic compounds are not determined by this modification. The modified procedure is simpler and more efficient. It is safer to use than that of Ismail and Eskin (1979), and gives more accurate, lower values of phenolic acid content. The accuracy of the modified method extends to low levels of phenolic acids in the samples $(<5 \mathrm{mg} / 100 \mathrm{~g})$, and has been shown to be suitable for the determination of total phenolic acid content in a wide variety of rapeseed and canola protein products including meals, protein concentrates and isolates.

\subsubsection{Validation of the analytical method for condensed tannins}

The accuracy and reproducibility of the method of Shahidi and Naczk (1989) was determined. A sample of hexane-defatted canola meal (Tower variety), was extracted twice with $70 \%$ acetone. To assure that treating the sample twice with $70 \%$ acetone was adequate to achieve total removal of tannins present in the sample, a third and fourth extraction were also carried out. The amount of tannins in the third extract was determined to be over $5 \%$ of that in the first two extracts combined (Table 3), indicating that a third extraction was desirable for accurate analysis. In the fourth extract little tannin was found, making the fourth extraction step superfluous. The procedure was, therefore, standardized on three extractions. 
Table 3. Effects of number of $70 \%$ acetone extractions on condensed tannin removal from Tower meal

\begin{tabular}{c|ccc}
\hline Sample & $\begin{array}{c}\text { First two extracts combined } \\
(\text { mg catechin/100 g) }\end{array}$ & $\begin{array}{c}\text { Third extract } \\
\text { (mg catechin/100 g) }\end{array}$ & $\begin{array}{c}\text { Fourth extract } \\
\text { (mg catechin/100 g) }\end{array}$ \\
\hline I $(\mathrm{lg})$ & 815 & 44 & $<10$ \\
$2(\mathrm{lg})$ & 807 & 54 & $<10$ \\
\hline
\end{tabular}

1. Expressed as $\mathrm{mg}$ catechin equivalents. 
In the analyses of phenolic acids in rapeseed/canola, it was found that some phenolic acids were always covalently bound to protein (Naczk et al., 1992). It was thus suspected that tannins could also form covalent bonds with protein. To test for the presence of the covalently-bound complexes of tannins and canola protein, the sample was hydrolyzed with $4 \mathrm{M} \mathrm{NaOH}$ for $4 \mathrm{hr}$ after the acetone extractions, as in the analyses of phenolic acids. After neutralization with $\mathrm{HCl}$, the rest of the tannin analytical procedure was followed. The result showed that, unlike phenolic acids, there was no covalent bonding between canola protein and condensed tannins.

The results from the sample series prepared with the additions of catechin standard to casein were reproducible with most relative standard deviations of less than $10 \%$ (Table 4). The recoveries of added catechin ranged from 74 to $103 \%$. Even when only $0.100 \mathrm{mg}$ was added to $\mathrm{g}$ samples (equivalent to $10 \mathrm{mg} / 100 \mathrm{~g}$ sample), a recovery of $103 \%$ was attained with a relative standard deviation of about $15 \%$ of the average. However, when the level of added catechin was reduced to $5 \mathrm{mg} / 100 \mathrm{~g}$ sample, a somewhat low recovery (74\%) was obtained with a high relative standard deviation of approximately $23 \%$, indicating that the useful detection limit of this method is $5-10 \mathrm{mg} / 100 \mathrm{~g}$ sample. At the tannin levels encountered in this study the method is reproducible with low standard errors. 


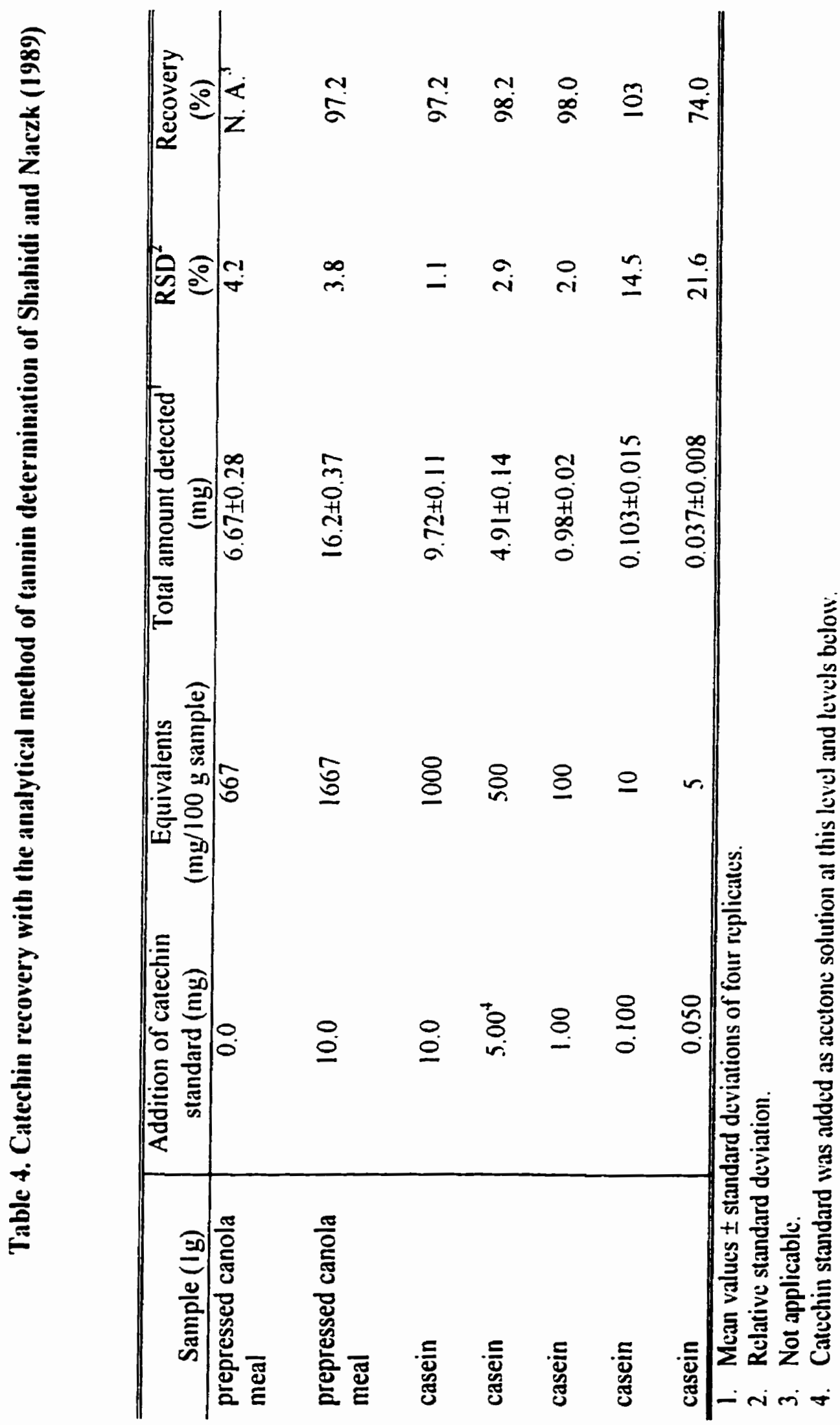




\subsection{Study of Interactions between Canola Protein and Phenolic Compounds}

\subsubsection{Extractability of protein and phenolic compounds from canola meal}

Although some other reagents such as sodium hexametaphosphate (SHMP) and $\mathrm{NaCl}$ were tested for rapeseed/canola protein extraction from the meal (Thompson et al., 1976; Tzeng et al., 1988a; Bhatty et al., 1968; Lo and Hill, 1971; Finnigan and Lewis, 1985), many reports indicated that high $\mathrm{pH}(>11)$ considerably increased the protein solubility from the meal (Gillberg and Tomell, 1976; Tzeng et al., 1988a, b and 1990a). Thus, NaOH solution was recommended by previous researchers for the production of rapeseed/canola protein isolates. In the $\mathrm{pH}$ range investigated in this study $(8-12)$, the protein extractability increased with $\mathrm{pH}$ (Figure 22), confirming the trend reported in literature. At pH 12.0, approximately $70 \%$ of protein in the meal was extracted. This protein extractability was lower than that of other hexane-defatted canola meals prepared in our laboratories, which was up to $90 \%$ (Tzeng, et al., 1990a). Since the starting material used in this study was hexane-defatted prepressed canola meal, the heating effect of the prepressing could have denatured some protein in the meal, thus lowering its extractability. Nevertheless, most of the protein was extractable at high $\mathrm{pH}$. No extraction at $\mathrm{pH}$ higher than 12 was investigated due to the concern for the formation of lysinolalanine, which is toxic. Although Deng et al. (1990) demonstrated that rapeseed/canola protein products prepared by the process developed in our laboratories contained too low levels of lysinolalanine to represent a health hazard, extreme $\mathrm{pH}$ values (>12) should still be avoided during the production of canola protein isolates.

In this study the extractability of phenolic compounds was studied by following the extraction procedure of canola protein from the meal with $\mathrm{NaOH}$ at different $\mathrm{pH}$ values. The phenolic contents were determined in the meal residue after protein extraction, and the 
Figure 22. Extractability of protein, phenolic acids and tannins of canola meal at different pH's*

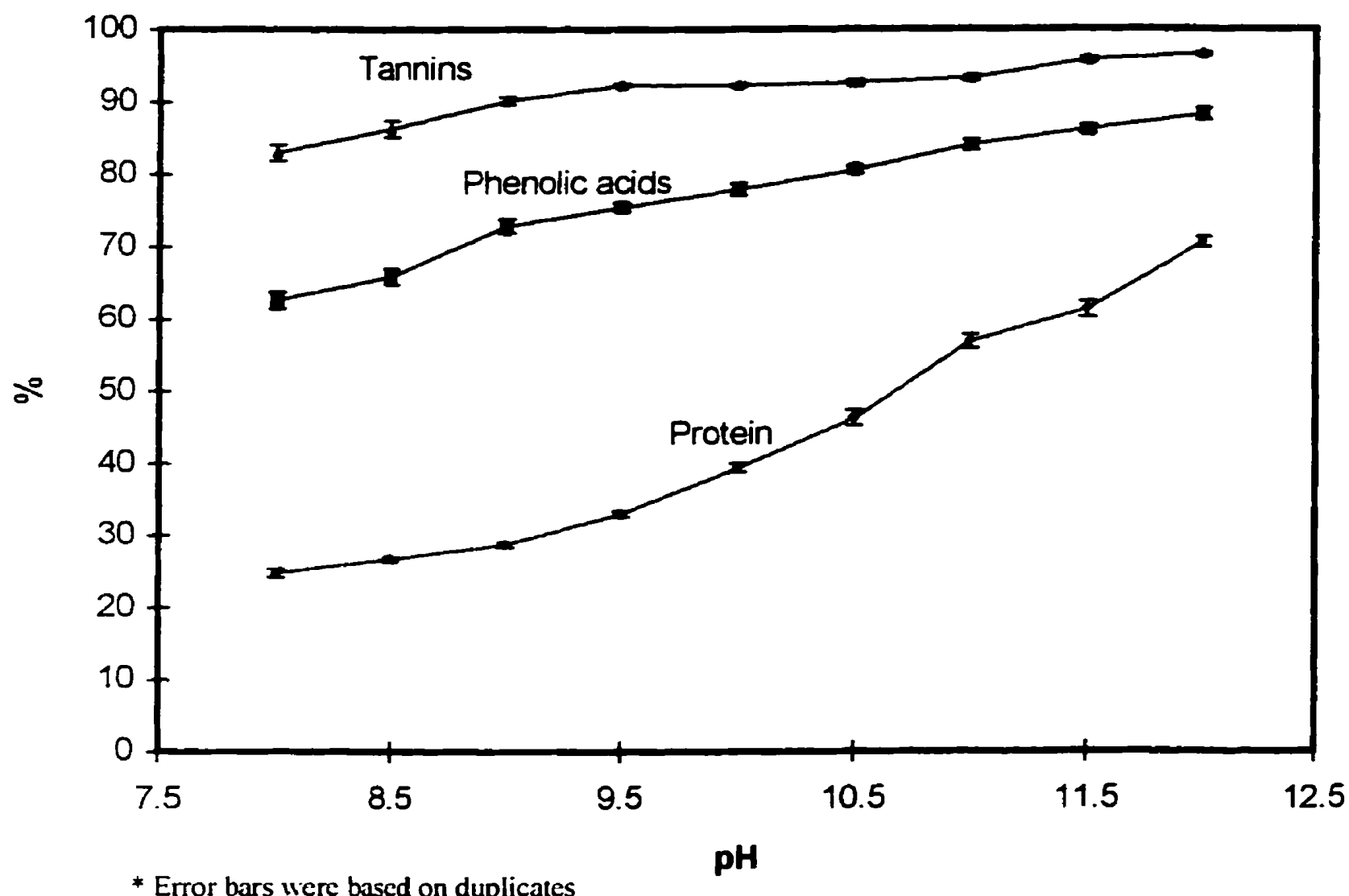


amounts extracted were calculated by difference. As shown by Figure 22, in the alkaline $\mathrm{pH}$ range most of phenolic acids and tannins present in the meal were extracted. This high extractability was likely a result of the interactions of these phenolic compounds with water and extractable canola proteins through ionic bonding, hydrogen bonding, etc.. The tannin extractability curve started to level off at pH 9.5 as they were mostly extracted (>90\%), whereas the extractability of phenolic acids rose steadily as $\mathrm{pH}$ went from 8.0 up to 12.0, indicating that $\mathrm{pH}$ had a considerable effect on the extractability of phenolic acids. This $\mathrm{pH}$ effect was probably due to the ionic bonding between esterified phenolic acids and rapeseed proteins. As the $\mathrm{pH}$ went up, the protein became increasingly negatively charged, and the ionic bonding could thus be enhanced between the negatively charged protein and the positively charged phenolic acids such as sinapine. Condensed tannins, on the other hand, are generally not so ionizable as phenolic acids, therefore, their interactions with either canola proteins or water were thought to be through hydrophobic interactions and hydrogen bonding (Loomis and Battaile, 1965; Hagerman and Butler, 1978; Martin et al., 1985; Haslam, 1988), and could be less affected by $\mathrm{pH}$ change within the alkaline range than the ionic bonding of phenolic acids.

The error bars on the curves in Figure 22 were based on duplicate runs. They were within $5 \%$ at all $\mathrm{pH}$ 's tested, showing that results were essentially reproducible. At $\mathrm{pH} 12.0$ where about $70 \%$ of rapeseed protein was in solution, over $80 \%$ of the phenolic acids and more than $90 \%$ of tannins were also extracted and could bind to the extracted canola protein by different mechanisms. 


\subsubsection{Rejection coefficients of phenolic compounds}

As. compared to canola protein, phenolic compounds are relatively small molecules, membrane processing was considered for the separation of these compounds from canola proteins in solution. In the scheme developed for the study of interactions between canola proteins and phenolic compounds, diafiltration was used to separate the free phenolic compounds released from phenolic-protein complexes by the chemical treatments. To show that the phenolic compounds were actually permeable, the rejection coefficients of both free phenolic acids and condensed tannins were determined using the membrane chosen for the study of phenolic-canola protein interactions.

The effect of membrane processes on a component in solution can be best described by its rejection coefficient $R$. $R$ varies between 0 and 1 , where zero indicates perfect permeation while one means total rejection by the membrane. In order for a component to be removable, it must have a relatively low rejection coefficient. Tzeng et al. (1990b) studied ultrafiltration rejection coefficients of canola meal components, and found that glucosinolates had an overall rejection coefficient close to zero whereas that of protein nitrogen was almost unity. They concluded that ultrafiltration is an effective technique for producing canola protein products low, or essentially free of glucosinolates, without loss of proteins. Phytic acid had an average rejection coefficient between 0.6 and 1.0 , due to the formation of binary and ternary complexes with proteins, which did not permeate through the membrane. Thus all phytates cannot be separated from canola proteins by a simple membrane process, and chemical treatments were necessary to break the phytate-protein complexes.

In this study the rejection coefficients of both phenolic acids and tannins were also determined by ultrafiltration. However, instead of concentrating the original solution ten fold 
all at once to get an overall rejection coefficient, as reported by Tzeng et al. (1990b), a series of $C_{o}, C_{f}, V_{o}$, and $V_{f}$ values were determined. When $\ln \left(C_{f} / C_{o}\right)$ was plotted against $\ln \left(V_{o} / V_{f}\right)$, a straight line was obtained by linear regression, the slope of which was the rejection coefficient $\mathbf{R}$ according to the characteristic equation of ultrafiltration. The values of $\mathbf{R}$ for phenolic acids and tannins were thus determined to be 0.12 and 0.27 , respectively (Figure 23). In both cases, the samples of phenolic acids or tannins were isolated from the meal using the extraction techniques for their analyses, hence essentially free of protein, therefore, these rejection coefficients were close approximations of those of free phenolic compounds that were not bound to the protein in aqueous extracts of canola meal. As expected, tannins had a greater rejection coefficient than phenolic acids as they had higher molecular weights. The correlation coefficients $\left(r^{2}\right)$ for linear regression were 0.97 for phenolic acids and 0.96 for tannins. The rejection coefficient of a small molecular component may be affected considerably by the build-up of a gel layer made of large molecules such as protein during ultrafiltration, in which case a straight line could not be obtained. In this case, the extracts of phenolic acids or tannins contained very little canola protein as these phenolic compounds were extracted following the analytical procedures to isolate them. Therefore, there was not a substantial gel layer of protein formed on the membrane, and the rejection coefficients obtained for phenolic acids and tannins were relatively constant over a range of concentration factors $\left(V_{o} / V_{f}\right)$. However, both groups of phenolic compounds have a complex composition of a variety of components differing in molecular weights, hence the divergence in rejection coefficients within each group, which, together with experimental errors, may have caused the data to deviate from perfect linearity.

The low rejection coefficients of phenolic acids and tannins suggested that these 
Figure 23. Determination of rejection coefficients for phenolic acids and tannins

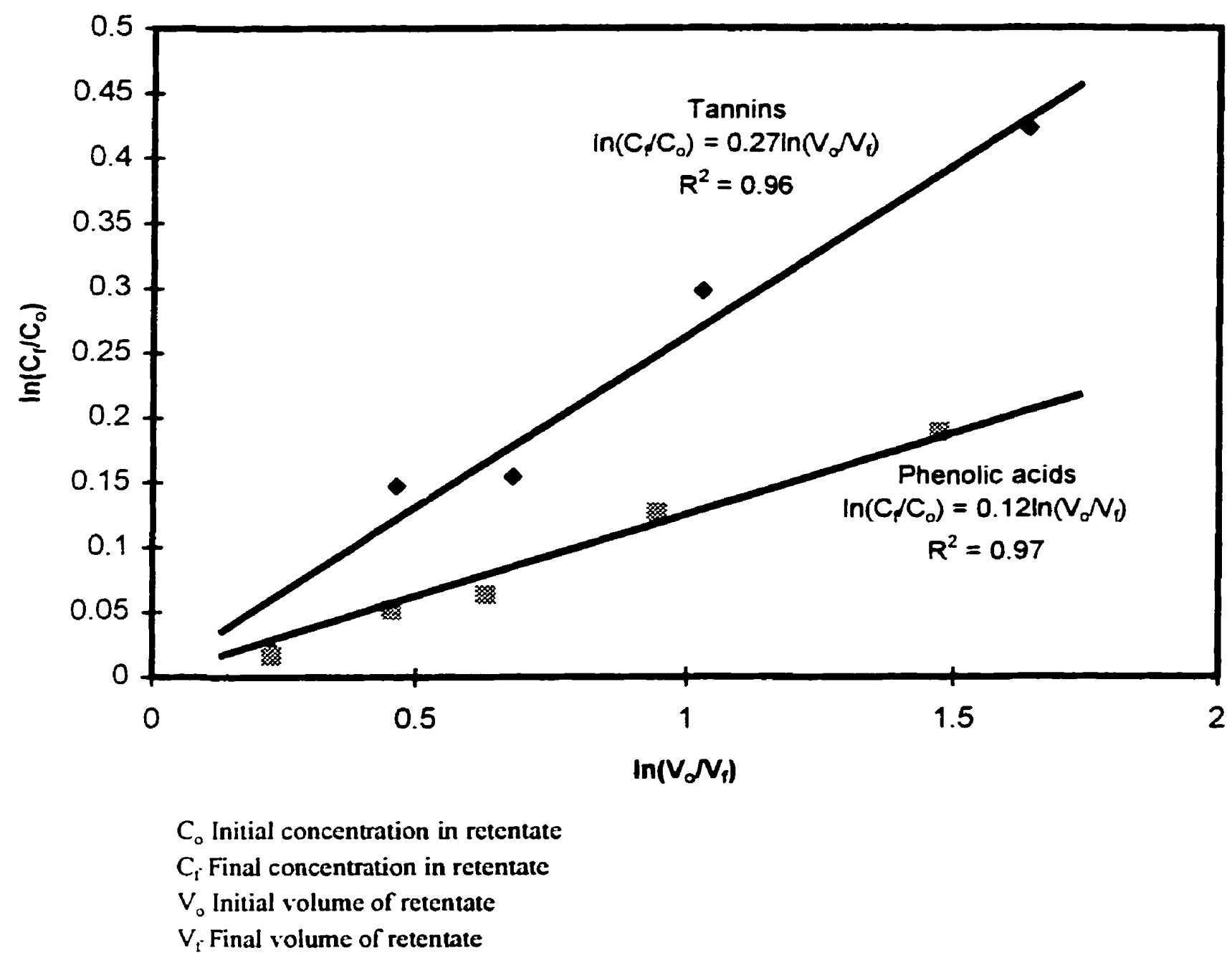


compounds in free form were essentially able to permeate the membrane, and the separation of them from canola proteins could, therefore, be achieved by diafiltration. Diafiltration could reduce the concentration of free phenolic compounds to minimal levels by replacing the permeate with fresh water to maintain the initial volume, thus continuously diluting the phenolic compounds while maintaining the concentration of proteins. According to the characteristic equation of a diafiltration process shown in Section 2.4.3., with the rejection coefficients determined for phenolic acids and tannins in this case, it was estimated that five times as much washing liquid as the initial feed volume would be enough to bring down the concentration of either phenolic group to about only $2 \%$ of the initial value. For $99.9 \%$ removal of phenolic compounds, almost 100 times as much washing liquid was required. However, in reality a large amount of phenolic compounds formed complexes with the proteins through different types of interactions in aqueous extract of canola meal, thus could not be separated from canola protein by a simple membrane process. Therefore, certain chemical manipulations were necessary in order to break the phenolic-protein complexes before membrane processing effected separation.

\subsubsection{Fractionation of phenolic compounds in alkaline extract and acidic solution of canola protein}

In order to remove phenolic compounds from canola protein, it is essential to understand their interactions, for which a unique approach was proposed as shown in Figure 17. It combined a series of chemical treatments with membrane processing. All the treatments were chosen based on the chemistry of different types of interactions between canola protein and phenolic compounds; each could break one specific type of phenolic- 
protein bonding, thus releasing only one phenolic fraction from the proteins. They were run in the order of $0.05 \mathrm{M} \mathrm{NaCl}, 0.1 \% \mathrm{SDS}, 6 \mathrm{M}$ urea, and $4 \mathrm{M} \mathrm{NaOH}$, so as to successively displace ionically, hydrophobically, hydrogen, and covalently bonded phenolic compounds from the proteins. Since the strength associated with different types of bonds involved in protein conformation differed greatly, indicating different amounts of activation energy required to break them, the time taken to complete the reaction with the proper reagents also varied. While the other three types of bonding had bond strength of $4-40 \mathrm{~kJ} / \mathrm{mol}$, covalent bonds could have bond energies of up to $400 \mathrm{~kJ} / \mathrm{mol}$ (Schnepf, 1992). Hence, it took $4 \mathrm{M}$ $\mathrm{NaOH}$ four hours to ensure complete hydrolysis of covalent bonds between phenolic acids and canola protein (Krygier et al., 1982b). On the other hand, the other three treatments released phenolics almost instantaneously. The released phenolic compounds were then passed through the membrane. Thus, this system was able to fractionate the extracted phenolic compounds in terms of their interactions with canola proteins.

The results of the fractionation of phenolic compounds for both the alkaline extract and the acidic solution are shown in Figures 24 and 25 , and each phenolic fraction is expressed as percentage based on the total amount of phenolic compounds extracted at $\mathrm{pH}$ 12.0 as only the extractable phenolics could have an adverse effect on the protein isolates. As can be seen from the graphs, for phenolic acids all five fractions were identified (including free fraction) in both aqueous media. Although the free fraction of phenolic acids was the largest of all in the alkaline extracts, still about half of the extractable phenolic acids were bound to the protein by different mechanisms, amongst which ionic bonding was predominant (about 30\%). The other three fractions each contained less than $10 \%$ of the total 
Figure 24. Fractionation of phenolic compounds in pH 12.0 canola protein extracts*

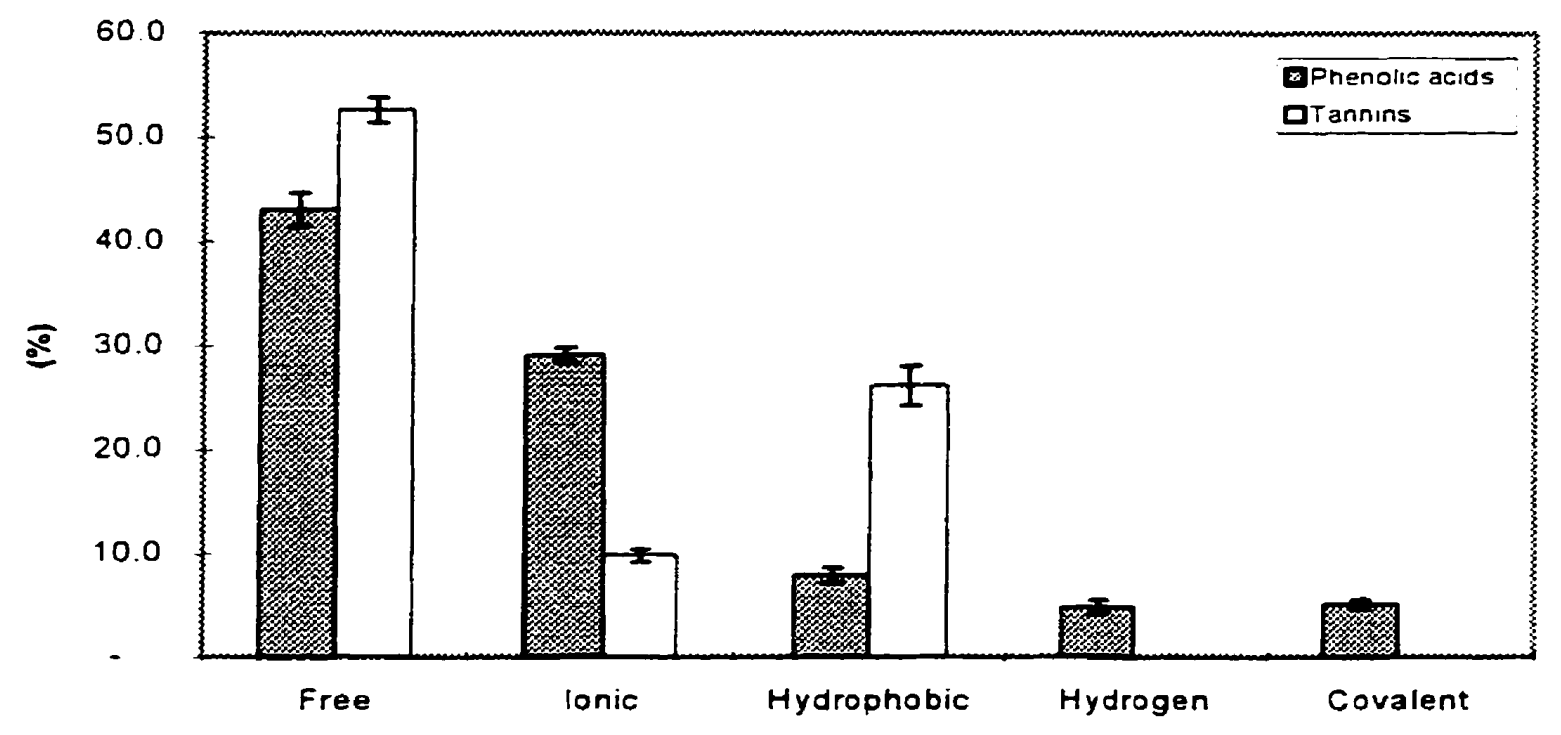

Figure 25. Fractionation of phenolic compounds in pH 3.5 canola protein solutions*

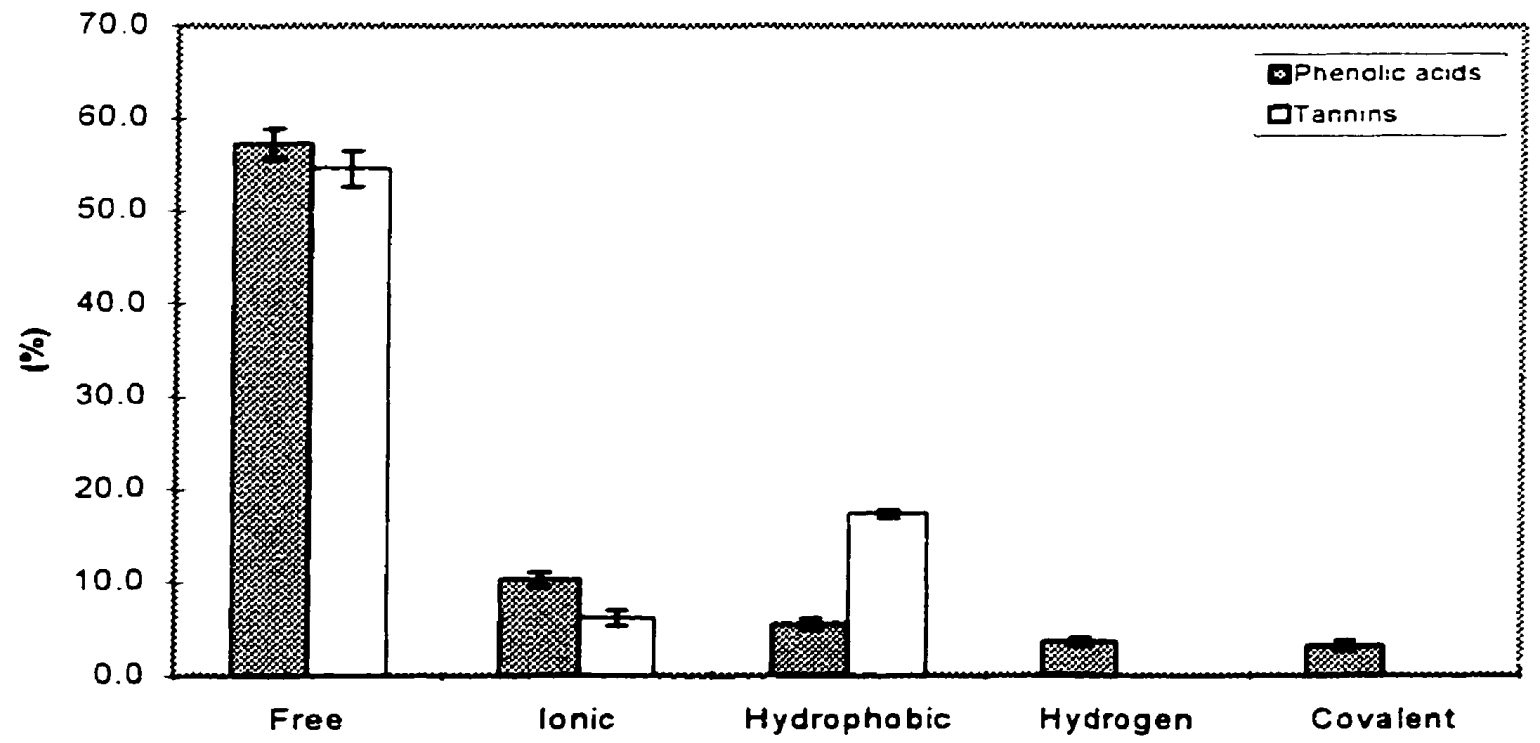

* The results are presented as percentage of the amount of phenolic acids or tannins extractable at $\mathrm{pH}$ 12.0. It was calculated that $50 \mathrm{~mL}$ pH 12.0 canola protein extract contained $38.9 \mathrm{mg}$ extractable phenolic acids and $18.2 \mathrm{mg}$ extractable tannins. 
extractable phenolic acids. Although these may seem minor, if not removed, they could lead to high phenolic acids contents in the final products, since the mass yields of the products are low.

As previous researchers have found that the $0.10 \mathrm{M} \mathrm{NaCl}$ was able to significantly reduce the level of binding of sinapic acid to canola protein at $\mathrm{pH} 4.5$ (Rubino et al., 1996), $\mathrm{NaCl}$ was chosen to break ionic bonding in this study. To show that the concentration of $0.05 \mathrm{M}$ was adequate, another test was run with $0.10 \mathrm{M} \mathrm{NaCl}$. In both cases approximately the same amount of phenolic acids was released into the permeate (Figure 26), indicating that the treatment with $0.05 \mathrm{M} \mathrm{NaCl}$ was sufficient for breaking ionic bonding between canola protein and phenolic acids. In a control run with no salt added, very little phenolic acids was detected in the permeate from diafiltration (Figure 26). This confirmed that ionic bonding was indeed broken by the salt. This concentration of $\mathrm{NaCl}$ was, however, too low to affect hydrophobic interactions between phenolic compounds and proteins according to Hagerman and Butler (1978).

Lowering the $\mathrm{pH}$ of the extracts from 12.0 to 3.5 substantially reduced the ionicallybonded fraction of phenolic acids, while increasing the free fraction considerably. This was primarily due to the change of electric charge of the protein molecules as a result of $\mathrm{pH}$ change. At high pH most protein molecules possessed a net negative charge, thus electrostatically attracting the phenolic acids essentially in form of sinapine, a choline ester of sinapic acid, which had a positively charged end. Hence a large ionically-bonded fraction of phenolic acids was detected in the $\mathrm{pH} 12.0$ extracts. When the $\mathrm{pH}$ was brought down to 3.5, the electrostatic interaction between the proteins and sinapine was much weakened as the proteins became far less negatively charged, which thus released a large quantity of phenolic 
Figure 26. Comparis on of ionically-bonded fraction of phe nolic acids with different concentrations of $\mathrm{NaCl}^{*}$

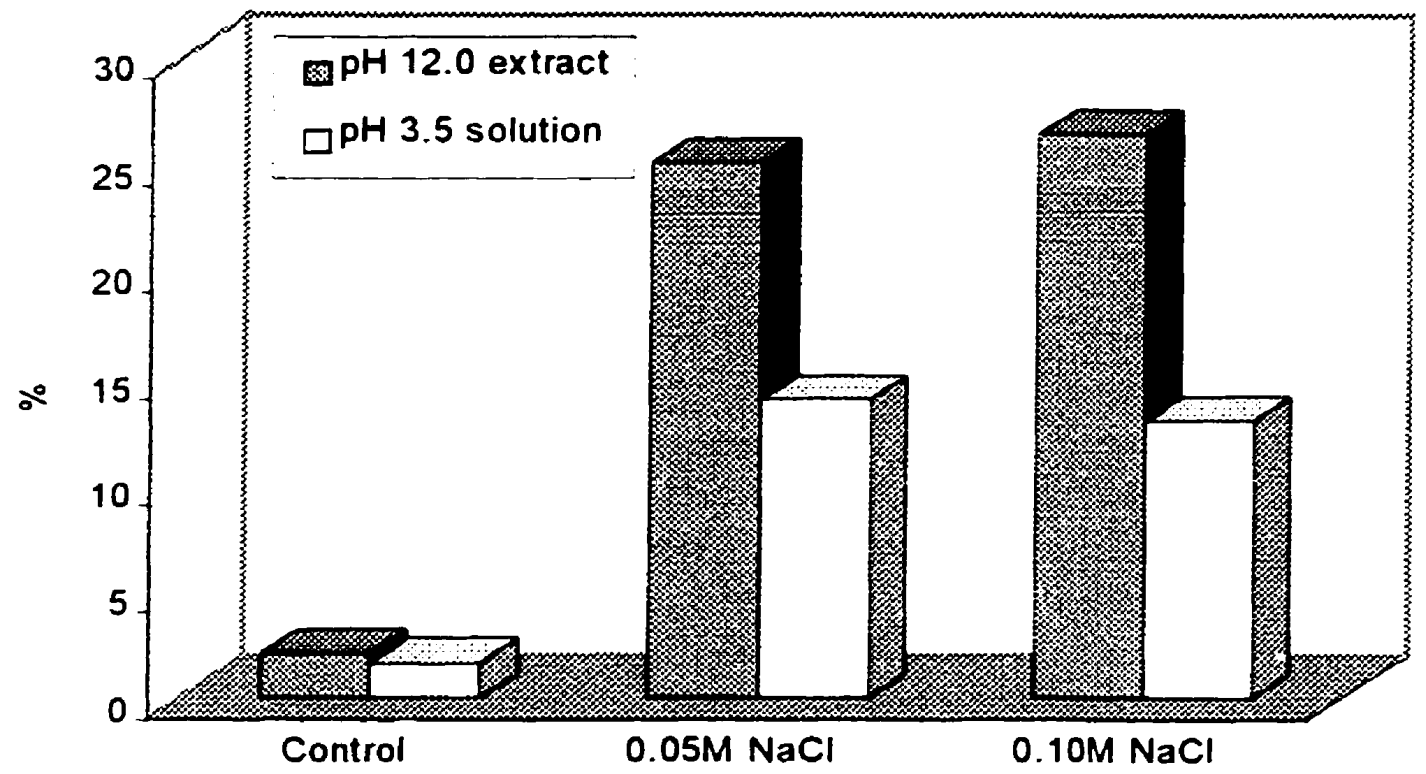

- The results are presented as percentage of the amount of phenolic acids extractable at pH 12.0 . 
acids, and resulted in a larger free fraction and a much smaller ionically-bonded fraction of phenolic acids.

Like phenolic acids, about $50 \%$ of the total extractable amount of tannins was unbound or free. Due to the hydrophobicity of tannins, a significant hydrophobic fractionwas seen (Figures 24 and 25$)$ among the tannins (25\% in the alkaline extracts and about $18 \%$ in the acidic solutions) whereas among phenolic acids hydrophobic fraction was much smaller. This observation confirms the conclusion in the literature that hydrophobic forces were mainly involved in tannin-protein interactions (Hagerman and Butler, 1978; Oh et al., 1980; Martin et al., 1985). Since it was reported earlier that SDS at low concentration (0.1\%) was able to inhibit the hydrophobic interactions between tannins and protein (Hagerman and Butler, 1978), the detergent was also chosen in this case. Although condensed tannins were known to be less ionizable than phenolic acids, an appreciable fraction of ionically-bound tannins (about $10 \%$ in the alkaline extracts) was still found by $0.05 \mathrm{M} \mathrm{NaCl}$ treatment. These tannins were likely bound to phenolic acids through hydrophobic interactions such as the stacking of aromatic rings. So when the phenolic acids were released by the treatment with $0.05 \mathrm{M} \mathrm{NaCl}$, the tannins attached to them were also released, and detected as ionicallybonded. The free and ionically-bonded fractions of tannins were, however, not affected as much by $\mathrm{pH}$ change as the phenolic acids. This was probably due to the fact that, unlike phenolic acids, condensed tannins were essentially non-ionizable. Having identified both a large free and hydrophobic fractions of tannins in the alkaline and acidic media, it was confirmed that tannins were indeed amphipathic.

No hydrogen-bonded or covalently-bonded tannins were detected. In fact, covalent bonding was never found in this study between tannins and rapeseed/canola protein, even 
during the tannin analyses of the starting meal. The absence of hydrogen-bonded fraction could be due to the fact that some other species in the extraction solution such as $\mathrm{H}_{2} \mathrm{O}, \mathrm{OH}^{-}$, $\mathrm{H}^{-}$were also capable of hydrogen bonding with tannins or canola protein so that they (both tannins and the protein) became unavailable to each other for this specific type of interaction.

The error bars shown in both Figures 24 and 25 were based on the measurements of the duplicate runs. The results were reproducible. Although the differences between the duplicates were relatively large for the small fractions, for those major fractions of both phenolic acids and tannins the errors were well below $5 \%$ of the averages. In the alkaline extracts, all fractions added up to about $90 \%$ of the total extractable phenolic acids or tannins (Figure 24). The unaccountable 10\% could be attributed to experimental errors. The results also showed that after isoelectric precipitation only about $80 \%$ of the total extractable phenolic compounds in the original alkaline extract was recovered as different fractions in the $\mathrm{pH} 3.5$ solution (Figure 25), indicating that some of phenolic compounds were precipitated with the protein at $\mathrm{pH} 3.5$.

Thus, by this fractionation system different types of interactions were identified in two aqueous media encountered in canola protein isolation, $\mathrm{pH} 12.0$ extract and $\mathrm{pH} 3.5$ solution, and the total amount of extracted phenolic compounds was broken down into fractions according to their modes of binding to canola protein. The information obtained through the fractionation was of vital importance to the following work in an attempt to develop a process for the removal of phenolic compounds in the production of high-quality canola protein isolates. 


\subsection{Process Development for Production of High-Quality Canola Protein Isolates by Removing Phenolic Compounds}

\subsubsection{Removal of phenolic compounds by treatments in combination with diafiltration prior to isoelectric precipitation}

As mentioned earlier, the knowledge obtained from the fractionation of phenolic compounds was used for process development to remove phenolic compounds. The fractionation showed that about half of the extractable phenolic acids and tannins were actually unbound, so they could be removed simply by diafiltration without any treatment. Treatment with $0.05 \mathrm{M} \mathrm{NaCl}$ was able to break phenolic-protein complexes bonded ionically, and the phenolic acids and tannins thus released could then be removed by diafiltration. Further treatment with $0.1 \%$ SDS would help remove more phenolic acids and tannins recognized by the fractionation as the hydrophobic fraction. Therefore, an experimental scheme was developed to test these treatments in terms of phenolic removal (Figure 18).

All the processes in the scheme illustrated in Figure 18 were run to produce four sets of samples, each set including a precipitated protein isolate (PPI) and a soluble protein isolate (SPI). The mass yields and protein recoveries of all the products are shown in Table 5, and their protein, phenolic acid, and tannin contents were determined (Table 6).

Mass recoveries for the first three runs were almost the same, about $15 \%$ for PPI and $9 \%$ for SPI. The total mass yields of the protein isolates were lower than what was previously reported by our laboratories on canola protein preparation. Tzeng et al. (1990a) obtained a isolate yield of $32.5 \%$ with hexane-defatted canola meal. Apparently the inferior mass recoveries in this case were the direct result of the low protein extractability of hexanedefatted prepressed canola meal. With $0.1 \%$ SDS treatment an increase in both PPI yield and total mass recovery was experienced (Table 5). This was due to SDS residue in the products, 
Table 5. Mass and protein recoveries in the protein products

\begin{tabular}{|c|c|c|c|c|c|}
\hline \multirow[b]{2}{*}{ Treatments } & \multirow[b]{2}{*}{ Products } & \multicolumn{2}{|c|}{ Mass recovery } & \multicolumn{2}{|c|}{ Protein recovery } \\
\hline & & (g) & $(\%)$ & (g) & $\left(\%^{2}\right)$ \\
\hline \multirow{2}{*}{$\begin{array}{l}\text { 1. Control run } \\
\text { (No treatment) }\end{array}$} & $\overline{\text { PPI }}$ & 7.58 & 15.2 & 6.42 & 47.7 \\
\hline & SPI & $\frac{5.02}{12.60}$ & $\frac{10.0}{25.2}$ & $\frac{4.57}{10.99}$ & $\begin{array}{l}34.0 \\
81.7\end{array}$ \\
\hline \multirow[t]{3}{*}{ 2. Diafiltration } & PPI & 7.47 & 14.9 & 6.55 & 48.7 \\
\hline & SPI & 4.68 & 9.36 & 4.33 & 32.1 \\
\hline & & 12.12 & 24.3 & 10.88 & 80.8 \\
\hline \multirow[t]{3}{*}{ 3. $0.05 \mathrm{M} \mathrm{NaCl}$} & PPI & 7.53 & 15.1 & 6.66 & 49.4 \\
\hline & SPI & 4.03 & 8.06 & 3.82 & 28.5 \\
\hline & & 11.56 & 23.2 & 10.48 & 79.9 \\
\hline 4. $0.1 \%$ SDS with & PPI & 12.55 & 25.1 & 9.24 & 68.8 \\
\hline \multirow{2}{*}{$0.05 \mathrm{M} \mathrm{NaCl}$} & SPI & 1.88 & 3.76 & 1.57 & 11.7 \\
\hline & & 14.43 & 28.9 & 10.81 & 80.8 \\
\hline
\end{tabular}

1. The percentage values were based on 50.0 gram starting meal.

2. The percentage values were based on the amount of protein extractable at $\mathrm{pH} 12.0$. deternined to be 13.4 grams. 
Table 6. Effects of the treatments on composition of the products

\begin{tabular}{|c|c|c|c|c|c|c|}
\hline \multirow[b]{2}{*}{ Treatments } & \multicolumn{2}{|c|}{$\begin{array}{c}\text { Protein } \\
(\%) \\
\end{array}$} & \multicolumn{2}{|c|}{$\begin{array}{c}\text { Phenolic acids } \\
\text { (mg/100 g sample) }\end{array}$} & \multicolumn{2}{|c|}{$\begin{array}{c}\text { Tannins } \\
\text { (mg/100 g sample) }\end{array}$} \\
\hline & PPI & SPI & PPI & $\overline{\text { SPI }}$ & PPI & $\overline{\text { SPI }}$ \\
\hline $\begin{array}{l}\text { 1. Control run } \\
\text { (No treatment) }\end{array}$ & 84.7 & 91.1 & 1094 & 1053 & 675 & 852 \\
\hline 2. Diafiltration & 87.7 & 92.6 & 917 & 823 & 457 & 648 \\
\hline 3. $0.05 \mathrm{M} \mathrm{NaCl}$ & 88.5 & 94.9 & 451 & 470 & 347 & 562 \\
\hline $\begin{array}{l}\text { 4. } 0.1 \% \text { SDS with } \\
0.05 \mathrm{M} \mathrm{NaCl}\end{array}$ & 73.7 & 83.5 & 210 & 240 & 30.2 & 25.1 \\
\hline $\operatorname{ACV}^{2}(\%)$ & 0.44 & 0.34 & 9.9 & 6.3 & $8.0^{3}$ & $5.8^{3}$ \\
\hline
\end{tabular}

1. All results are mean values of duplicates.

2. Average coefficient of variations (see Appendix 8.3.2).

3. ACV for tannin analyses does not include the last run (Run 4). 
which resulted in lower protein content (Table 6). Since the alkaline extract was diafiltered against $0.1 \%$ SDS solution, a large quantity of SDS $(5.4 \mathrm{~g})$ was used. This amount was not entirely removed by diafiltration, and during the subsequent protein isolation some of SDS may bind to the protein, thus ending up in the products. Although the formation of micelles could also cause SDS to be retained by the membrane due to the large size of some micelles, this was unlikely at the concentration of $0.1 \%$ since the critical micelle concentration (CMC) of SDS was reported to be $0.24 \%$ (Porter, 1994). The binding of SDS as well as other surfactants to protein was demonstrated by previous researchers in the study of tannin-protein interactions (Hagerman and Butler, 1978; Martin et al., 1985; Igor et al., 1993). The residual SDS lowered the protein content in both products from Run 4 (Table 6). The results of the work on SDS removal are discussed in the next subsection. The products from other runs had a protein content ranging from 85 to $95 \%$. The remaining 5 to $15 \%$ were likely a variety of polysaccharides. Previous researchers have reported glycoprotein for rapeseed/canola (Jones, 1979). It seemed that unlike SDS. the treatment with diafiltration and $0.05 \mathrm{M} \mathrm{NaCl}$ before isoelectric precipitation increased the protein content of the products perhaps by the removal of some low-molecular-weight impurities during the treatment. In all cases, the SPI's were higher in protein than the PPI's. This was consistent with the results reported for canola protein previously (Tzeng, et al., 1990a).

The total protein recoveries did not vary by much. The similar total protein recoveries of different runs indicated that the treatments used did not incur significant protein losses. The treatment with $0.1 \%$ SDS gave an SPI yield of less than half of that in other runs, thus significantly changing the recovery ratio of PPI to SPI from approximately 1.5 to 5.9 (Table 5). In each run some $20 \%$ of the extractable protein was lost during the processing. Most of 
this was likely non-protein nitrogen of low molecular weights, and thus able to pass through the membrane and end up in the permeate (Tzeng, et al., 1990b). Experimental errors were also believed to contribute to this "loss".

The phenolic acid and tannin contents showed a distinct descending trend with increased number of treatments, confirming that each treatment indeed removed some phenolic compounds (Table 6). From the control run (Run 1) where no treatment was employed, both protein isolates obtained were high in both phenolic groups. Their phenolic acid contents were over $1000 \mathrm{mg}$ per $100 \mathrm{~g}$ sample (Table 6), approximately $65 \%$ of the value of the starting meal ( $1596 \mathrm{mg} / 100 \mathrm{~g}$ ), and the tannin contents even exceeded that of starting meal $(676 \mathrm{mg} / 100 \mathrm{~g})$. Since no treatment was used in the control run, only those phenolic compounds not bound to canola protein in the $\mathrm{pH} 3.5$ solution were eventually removed by the membrane-processing (uitrafiltration followed by diafiltration). Although the free phenolic compounds made up more than half of the total amount in the solution as shown earlier by the fractionation, the remaining phenolic compounds that bound to the proteins could still give rise to high values of phenolic contents in the final products. As a result of the high phenolic contents, the protein products still exhibited undesired organoleptic properties such as dark colour and bitter taste.

The high phenolic acid and tannin contents in the protein isolates confirmed that the further treatments were necessary in order to improve the quality of the products. Accordingly the original process was modified based on the results of the phenolic fractionation. First, diafiltration prior to isoelectric precipitation was tested to remove the free fractions of both phenolic acids and tannins. It was shown in Table 6 that, with this treatment, the phenolic acid contents in PPI and SPI were brought down by $17 \%$ and $22 \%$, 
respectively; while tannin contents were reduced by $32 \%$ and $24 \%$, respectively (Table 6 ). Apparently more free phenolic compounds were removed by this additional diafiltration step.

In Run 2 , the treatment with $0.05 \mathrm{M} \mathrm{NaCl}$ was tested since it was shown by the fractionation to be able to break ionic bonding between canola protein and phenolic compounds. The phenolics released by this treatment were then removed by diafiltration prior to isoelectric precipitation (Run 3). As a result of the removal of the ionically-bonded fraction of phenolic acids, both protein isolates contained only about half as much phenolic acids as those from Run 2 (Table 6). This represented a major decrease in phenolic acid retention from 15.2 to $7.5 \%$ in the final products as shown in Table 7 . The treatment resulted in a less dramatic decrease in tannins in PPI and SPI of only $24 \%$ and $13 \%$, respectively (Table 6). It was shown earlier by the fractionation results that there was only a small ionically-bonded fraction of tannins.

The treatment with $0.1 \%$ sodium dodecyl sulphate (SDS) in Run 4 had a great effect on the tannins. Again this was expected since for the tannins, the hydrophobic fraction responding to SDS was one of the major fractions. Hence with the addition of SDS, the tannin contents in both protein products were further slashed by over $90 \%$ as compared to those from Run 3 (Table 6), corresponding to the largest decrease in the tannin recovery from 14.9 to $1.3 \%$ among all the treatments (Table 7 ).

The phenolic acid and tannin retention in Table 7 was calculated based on the mass yields and contents of these compounds in the products, and it was shown by their retention that all the treatments were effective in terms of removing some phenolic acids and tannins. After the treatment involving a combination of $0.05 \mathrm{M} \mathrm{NaCl}$ and $0.1 \% \mathrm{SDS}$ in the last run, only about $4 \%$ of the extractable phenolic acids and $1 \%$ of the extractable tannins were left in 
Table 7. Retention of phenolic acids and tannins in the products

\begin{tabular}{|c|c|c|c|c|c|}
\hline \multirow[b]{2}{*}{ Treatments } & \multirow[b]{2}{*}{ Products } & \multicolumn{2}{|c|}{ Phenolic acid retention } & \multicolumn{2}{|c|}{ Tannin retention } \\
\hline & & $(\mathrm{mg})$ & $\left.(\%)^{1}\right)$ & $\overline{(\mathrm{mg})}$ & $\left(\%^{2}\right)$ \\
\hline \multirow{3}{*}{$\begin{array}{l}\text { I. Control run } \\
\text { (No treatment) }\end{array}$} & $\overline{\mathbf{P P I}}$ & 82.9 & 11.8 & 51.2 & 15.6 \\
\hline & SPI & 52.9 & 7.50 & 42.7 & 13.0 \\
\hline & & & 19.3 & & 28.6 \\
\hline \multirow[t]{2}{*}{ 2. Diafiltration } & PPI & 68.5 & 9.72 & 34.1 & 10.5 \\
\hline & SPI & 38.5 & $\frac{5.47}{15.2}$ & 30.3 & $\frac{9.27}{19.8}$ \\
\hline \multirow[t]{2}{*}{$3.0 .05 \mathrm{M} \mathrm{NaCl}$} & PPI & 34.0 & 4.82 & 26.1 & 7.99 \\
\hline & SPI & 18.9 & $\begin{array}{r}2.69 \\
7.31\end{array}$ & 22.6 & $\frac{6.92}{14.9}$ \\
\hline \multirow{2}{*}{$\begin{array}{l}\text { 4. } 0.1 \% \text { SDS with } \\
0.05 \mathrm{M} \mathrm{NaCl}\end{array}$} & PPI & 26.3 & 3.74 & 3.79 & 1.16 \\
\hline & SPI & 4.51 & $\frac{0.63}{4.37}$ & 0.47 & $\frac{0.13}{1.26}$ \\
\hline
\end{tabular}

1. The percentage values were based on the amount of phenolic acids extractable at $\mathrm{pH}$ 12.0. determined to be $705 \mathrm{mg}$.

2. The percentage values were as of the amount of tannins extractable at $\mathrm{pH} 12.0$. determined to be $327 \mathrm{mg}$. 
the final products as compared to almost $20 \%$ and $30 \%$, respectively, in the untreated control run.

As mentioned earlier an excess of SDS was added during the treatment in the last run, and was not completely removed, thus both the PPI and SPI from this run contained SDS residues, which rendered them practically useless due to the sensory and health effects of the chemical. This was consistent with the results reported by Igor (1992) of our laboratories, who used SDS for the deamidation of canola proteins. He eventually removed the residual SDS from the canola protein isolates by extraction with ethanol solutions. To make the products useful in this case, it was essential that the residual SDS be removed or reduced to an acceptable level. The treatment was, therefore, modified to reduce the amount of SDS used.

\subsubsection{Modification of SDS treatment and elimination of the second diafiltration}

In order to reduce the residual SDS levels in the final products, the amount of SDS used was decreased by modifying the treatment. After the addition of SDS to the alkaline extract at a concentration of $0.1 \%$, the alkaline extract was then diafiltered against $\mathrm{pH} 12.0$ $\mathrm{NaOH}$ solution containing no SDS. This reduced quantity of SDS required from $5.4 \mathrm{~g}$, when the alkaline extract was diafiltered against the solution containing $0.1 \%$ SDS, to less than $1 \mathrm{~g}$. When diafiltered with excess SDS, the PPI and SPI contained $12 \%$ and $8 \%$ SDS, respectively, and both had a lower protein content (Table 8). By reducing the amount of SDS, the protein content in both protein isolates rose back to the level obtained without SDS treatment, while SDS levels in these products were detected to be much below $0.5 \%$, which 


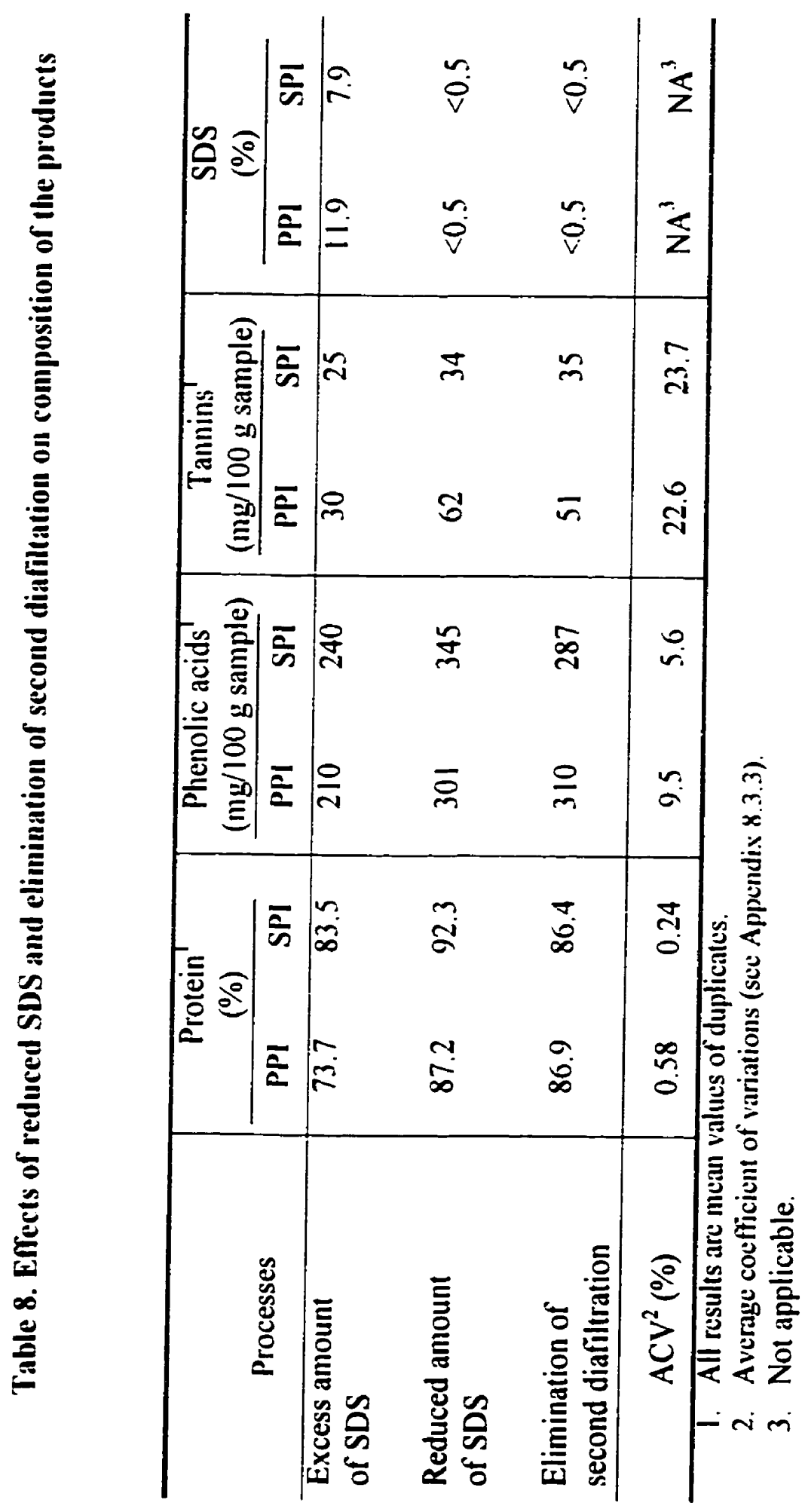


were acceptable on the basis of health safety alone (Health Canada, 1994). This showed that by eliminating SDS in the diafiltration, the amount originally added to the alkaline could be mostly removed during the processing. It was postulated that at a high $\mathrm{pH}$ such as 12 the binding of SDS to canola protein became much weaker than in the acidic range since both were negatively charged at the high $\mathrm{pH}$, and the electrostatic repulsion was able to keep them apart to a certain extent, allowing the removal of SDS by diafiltration. Although both phenolic acid and tannin contents in the products appeared slightly higher than those treated with excess SDS (Table 8), a compromise has been reached between low content of phenolic compounds and residual SDS amount well below maximum acceptable level.

In the original process, the acidic solution after isoelectric precipitation was again membrane processed (ultrafiltration followed by diafiltration) to concentrate and purify the protein remaining in the solution (SPI). Since in the modified process the alkaline extract of canola protein was already diafiltered prior to isoelectric precipitation, another diafiltration step in the process seemed superfluous, and eliminating it would obviously make the process more economical. However, one result of elimination of this step was the drop of the protein content of SPI to below $90 \%$ (Table 8), indicating that this diafiltration was not to be skipped because it indeed removed some further impurities to make the SPI purer. Neither phenolic acid nor tannin content in the products was, however, significantly affected by this elimination (Table 8). 


\subsubsection{Effects of PVP on the removal of phenolic acids}

Although the afore-mentioned processing was indeed able to remove over $90 \%$ of the phenolic compounds in rapeseed/canola extracts, in both protein isolates there was still an appreciable amount of residual phenolic acids (200 to $300 \mathrm{mg} / 100 \mathrm{~g}$ ) which was most likely bound to the proteins through hydrogen and covalent bonding according to the fractionation tests. They may also need to be removed so as to produce high quality canola protein isolates. To release these residual phenolic acids, two further treatments were proposed: insoluble polyvinylpyrrolidone (PVP) adsorption and $\mathrm{Na}_{2} \mathrm{SO}_{3}$ reduction. They could be applied after the treatment with $\mathrm{NaCl}$ and SDS.

PVP is an adsorbent, which binds through hydrogen bonding, owing to its chemical structure:

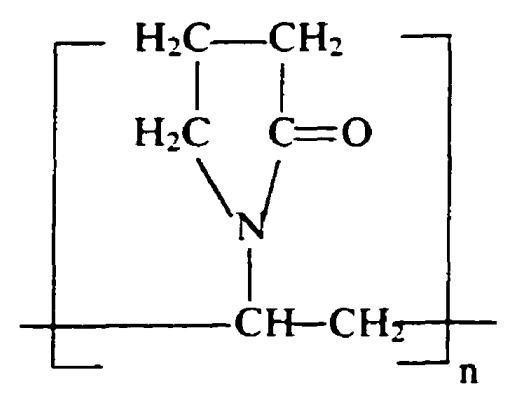

Thus it was expected to be able to break the hydrogen bonding between rapeseed/canola protein and phenolic acids. Insoluble PVP was used in relatively large quantities (10\% of the starting materials and up) for the removal of phenolics to purify certain enzyme preparations (Loomis and Battaile, 1966).

In this study PVP was tested on both $\mathrm{pH} 12.0$ alkaline extract and $\mathrm{pH} 3.5$ solution of canola protein. After each PVP treatment, the phenolic acids that were not adsorbed by PVP were removed by a diafiltration with $6 \mathrm{M}$ urea since urea is an even stronger $\mathrm{H}$ donor than PVP, able to break most H-bonds. It was used to define the hydrogen-bonded fraction of 
phenolic acids in the fractionation system discussed in Section 4.2.3. Accordingly, the results of this study were reported as the concentrations of the phenolic acids that were not adsorbed by PVP and thus remained in the extracts or solutions until removed by $6 \mathrm{M}$ urea (Figure 27). Hence, the higher concentration of phenolic acids remaining in the solution after PVP treatment indicated a smaller amount of them removed by PVP adsorption.

As shown by the graph in Figure 27, PVP behaved differently at $\mathrm{pH} 12.0$ and 3.5 . There were virtually no phenolic acids adsorbed by PVP at $\mathrm{pH} 12.0$ at either addition level of $10 \%$ or $20 \%$, hence the concentrations of the phenolic acids remaining in the extract were as high as in case of no PVP added at all (Figure 27). However, at pH $3.510 \%$ addition of PVP was able to remove approximately half of the phenolic acids present in the solution. Increasing PVP addition to $20 \%$ resulted in no further removal of phenolic acids (Figure 27), indicating that $10 \%$ addition as of the starting meal was adequate for PVP treatment. Although the kinetics of PVP adsorption were unknown, time was never reported to be a significant factor according to literature (Gustavson, 1956; Loomis and Battaile, 1966). One hour was chosen in this case for the treatment, and any longer duration would be considered uneconomical. Since the purpose of the work discussed in this section was to show effects of PVP on removing hydrogen bonded phenolic acids, the treatment was not optimized in terms of the amount of PVP added or the time.

The pH effects on PVP treatments in this study confirmed the work of Gustavson (1956) with PVP and the hydrolysable tannins. He found that at high pH much less tannins were bound to PVP, and suggested that with hydrolysable tannins the H-bonds were formed by un-ionized carboxyl groups rather than hydroxyl groups, therefore they tended to be broken when the carboxyl groups dissociated at high $\mathrm{pH}$ values. Since all hydrolysable 
Figure 27. Effects of PVP on removal of phenolic acids in pH 12.0 canola protein extract or $\mathrm{pH} 3.5$ solution

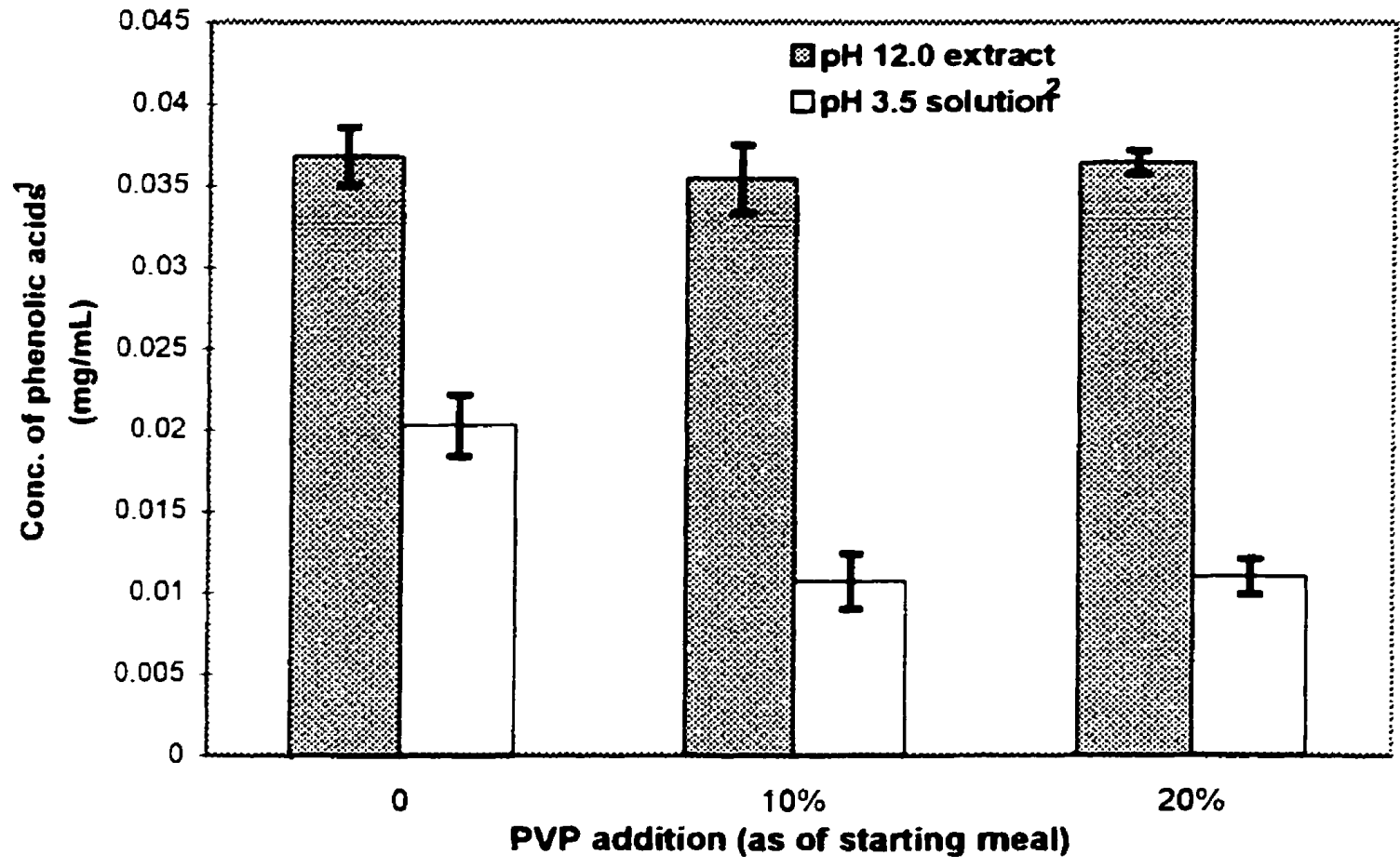

1. The results are presented as concentrations of phenolic acids not removed by PVP.

2. In pH 3.5 solution. concentration values at 0 PVP level are significantly different from those at $10 \%$ or $20 \%$ levels $(P \leq 0.05)$. 
tannins are polymers of phenolic acids, which actually provide the carboxyl groups, this theory was believed to be also applicable to the phenolic acids investigated in this case.

Another possible reason for weak hydrogen bonding between phenolic acids and protein at high $\mathrm{pH}$ could be the abundance of $\mathrm{OH}^{-}$in the solution, which was able to compete with either protein or phenolic acids to form hydrogen bonds.

For each treatment, at least duplicate runs were performed to define the error bars in Figure 27.

\subsubsection{Effects of $\mathrm{Na}_{2} \mathrm{SO}_{3}$ on removal of phenolic acids}

It was found earlier that in both alkaline extract and acidic solution of canola proteins, $4-5 \%$ of the extractable phenolic acids were bound to protein by covalent bonding. These phenolic acids were released by 4 -hour alkaline hydrolysis with $4 \mathrm{M} \mathrm{NaOH}$. For canola protein production it was obviously impossible to use these conditions to remove covalentlybonded phenolic acids due to their detrimental effects on the nutritional value of the protein. Hence, milder alternatives were considered, among which $\mathrm{Na}_{2} \mathrm{SO}_{3}$ was investigated for the task. $\mathrm{Na}_{2} \mathrm{SO}_{3}$ was a reducing agent. Upon acidification by $\mathrm{HCl}$, it remained in the solution as sulfurous acid, which, according to literature, was able to break weak covalent bonds such as S-S bond (Torchinskii and Dixon, 1974), and disrupt certain conjugated double bonds to bleach some vegetable pigments (Ellis, 1959; Gheyasuddin, et al., 1970; Keshavarz et al., 1976). Covalent bonding between phenolic acids and protein was the result of oxidation of phenolic acid to quinone and subsequent attachment of SH-containing amino acids to the ring either by addition or substitution (Mason, 1955; Torchinskii and Dixon, 1974). The final 
products of these reactions were, in fact, thioethers. Therefore, $\mathrm{Na}_{2} \mathrm{SO}_{3}$ was examined for its possible effect on breaking these covalent bonds between the protein and phenolic acids. Since, as mentioned earlier, the reactions took place under acidic conditions, $\mathrm{Na}_{2} \mathrm{SO}_{\text {; }}$ was tested only at $\mathrm{pH} 3.5$. In the tests, the $\mathrm{pH} 3.5$ solutions of canola proteins were first treated with $\mathrm{NaCl}, \mathrm{SDS}$, and urea, followed by diafiltration to remove the phenolic acids bound to the protein by the other mechanisms. $\mathrm{Na}_{2} \mathrm{SO}_{3}$ was then added at two different levels and the $\mathrm{pH}$ was maintained throughout the treatment. Any phenolic acids released were again separated by diafiltration.

The results were expressed by the concentrations of phenolic acids released by the $\mathrm{Na}_{2} \mathrm{SO}_{3}$ treatments (Figure 28). It could be seen that, compared to the amount of covalentlybonded phenolic acids identified by alkaline hydrolysis with $4 \mathrm{M} \mathrm{NaOH}$, very little phenolic acids were released by $\mathrm{Na}_{\Sigma} \mathrm{SO}_{\xi}$ at either addition level. The duration for this treatment was 4 hours, which was selected based on the time for alkaline hydrolysis in phenolic acid analyses. Although it was not optimized, any time longer would be uneconomical for the process. Besides. the fact that increasing the amount of $\mathrm{Na}_{2} \mathrm{SO}_{3}$ resulted in no more phenolic acids released also indicated that much as with PVP, the quantity of the chemical as well as the time did not affect the treatment in this case.

The failure of $\mathrm{Na}_{2} \mathrm{SO}_{3}$ to break covalent bonding between phenolic acids and canola protein could be the consequence of a variety of factors. The low acidity of $\mathrm{pH} 3.5$ may have contributed to the outcome. It was known that sulfurous acid $\left(\mathrm{H}_{2} \mathrm{SO}_{3}\right)$ had a pK $\mathrm{K}_{\mathrm{al}}$ of 1.81 and $\mathrm{pK}_{\mathrm{L2}} 6.91$, hence at $\mathrm{pH} 3.5, \mathrm{Na}_{2} \mathrm{SO}_{3}$ essentially assumed the form of sodium bisulphite $\left(\mathrm{NaHSO}_{3}\right)$ instead of sulfurous acid per se, which may not be able to break the covalent 
Figure 28. Effects of $\mathrm{Na}_{2} \mathrm{SO}_{3}$ on covalently bonded phenolic acids

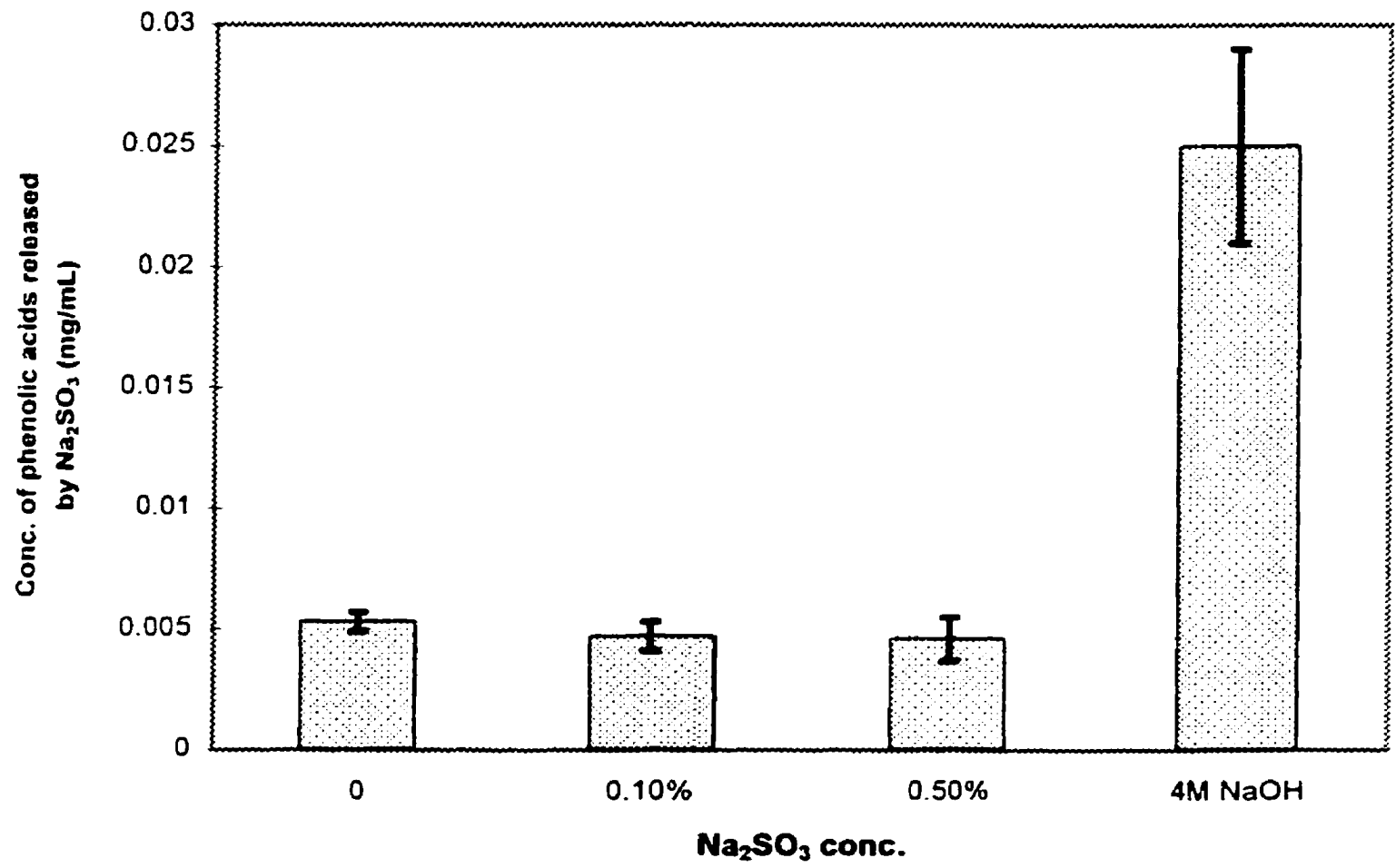

* $\mathrm{Na}_{2} \mathrm{SO}_{3}$ treatment did not have a significant effect on the release of phenolic acids $(\mathrm{P} \leq 0.05)$. 
bonds of concern as expected. It could be calculated that in order to convert most of $\mathrm{Na}_{2} \mathrm{SO}_{3}$ to $\mathrm{H}_{z} \mathrm{SO}_{3}$, a pH below 1.0 was needed. However, even though it would probably be helpful to further lower the $\mathrm{pH}$ in terms of phenolic acid removal, it was undesirable for the protein to experience such extreme conditions for an extended period of time. Another possible reason for $\mathrm{Na}_{2} \mathrm{SO}_{3}$ failure was that even sulfurous acid itself was not able to break these thioether bonds as they were different from S-S bonds after all. Although it is now clear that $\mathrm{Na}_{2} \mathrm{SO}_{3}$ does not help remove phenolic acids, it has been reported that it can lighten the colour and prevent the oxidation of phenolic acids (Ellis, 1959; Gheyasuddin, et al., 1970; Keshavarz et al., 1976). Therefore, it may still be useful in the processing of canola proteins.

\subsubsection{The further modified process to remove phenolic compound for production of high-quality canola protein isolates}

The earlier modified process discussed in Section 4.3.2., which included a treatment with $0.05 \mathrm{M} \mathrm{NaCl}$ and $0.1 \%$ SDS followed by a diafiltration before isoelectric precipitation, was further modified by incorporating a few new steps to remove more phenolic acids.

First, $\mathrm{Na}_{2} \mathrm{SO}_{3}$ was added at a low concentration of $0.1 \%$ at the beginning of alkaline extraction of canola protein from the meal and during the diafiltration of the alkaline extract, although earlier $\mathrm{Na}_{2} \mathrm{SO}_{3}$ treatment did not prove effective in removing phenolic acids. It was hoped that $\mathrm{Na}_{2} \mathrm{SO}_{3}$ would prevent the extractable phenolic compounds from being oxidized at high $\mathrm{pH}$ as well as other "base shifts" from taking place. The oxidation of phenolic compounds would increase covalent-binding to the protein, hence darkening the colour of the protein extracts or solutions (Gheyasuddin, et al., 1970). 
An ultrafiltration step was included prior to the diafiltration of the alkaline extract simply to reduce the volume processed so that the amount of water for the diafiltration could be greatly reduced, and the time shortened.

After isoelectric precipitation 5g PVP was added to treat the $\mathrm{pH} 3.5$ solution $(10 \%$ of the starting meal) since it was demonstrated earlier that PVP was able to further remove phenolic acids in the acidic solution. The results presented in Table 9 showed that the soluble protein isolate (SPI) obtained from the PVP treated solution had a phenolic acid content less than half that of non-PVP treated one. The protein content in the SPI was not affected at all by PVP. The tannin contents in both products were not determined simply because even with the earlier process the products were almost tannin-free. Despite the noticeable effects of PVP on phenolic acid removal, $10 \%$ addition was not really economical as it was an expensive reagent. The treatment was then tested with $1 \%$ PVP addition. The phenolic acid content of SPI obtained with reduced amount of PVP was as low as with $10 \%$ addition (Table $10)$, suggesting that $1 \%$ addition was adequate. For commercial production of canola protein isolates, the reuse and regeneration of PVP also needed to be studied for cost reduction, this was, however, beyond the scope of this program.

Another modification notable in this case was that the second ultrafiltration in the process, which was applied for the acidic solution, was carried out at a concentration factor of 4 instead of the usual 10. This change was justified by the fact that the solution at this point had already been concentrated 3 fold during the ultrafiltration of the alkaline extract. It was elaborated in the literature (Michaels et al., 1971; Goldsmith et al., 1971) that over concentration would only increase the viscosity of feed, enhance the formation of gel layer 


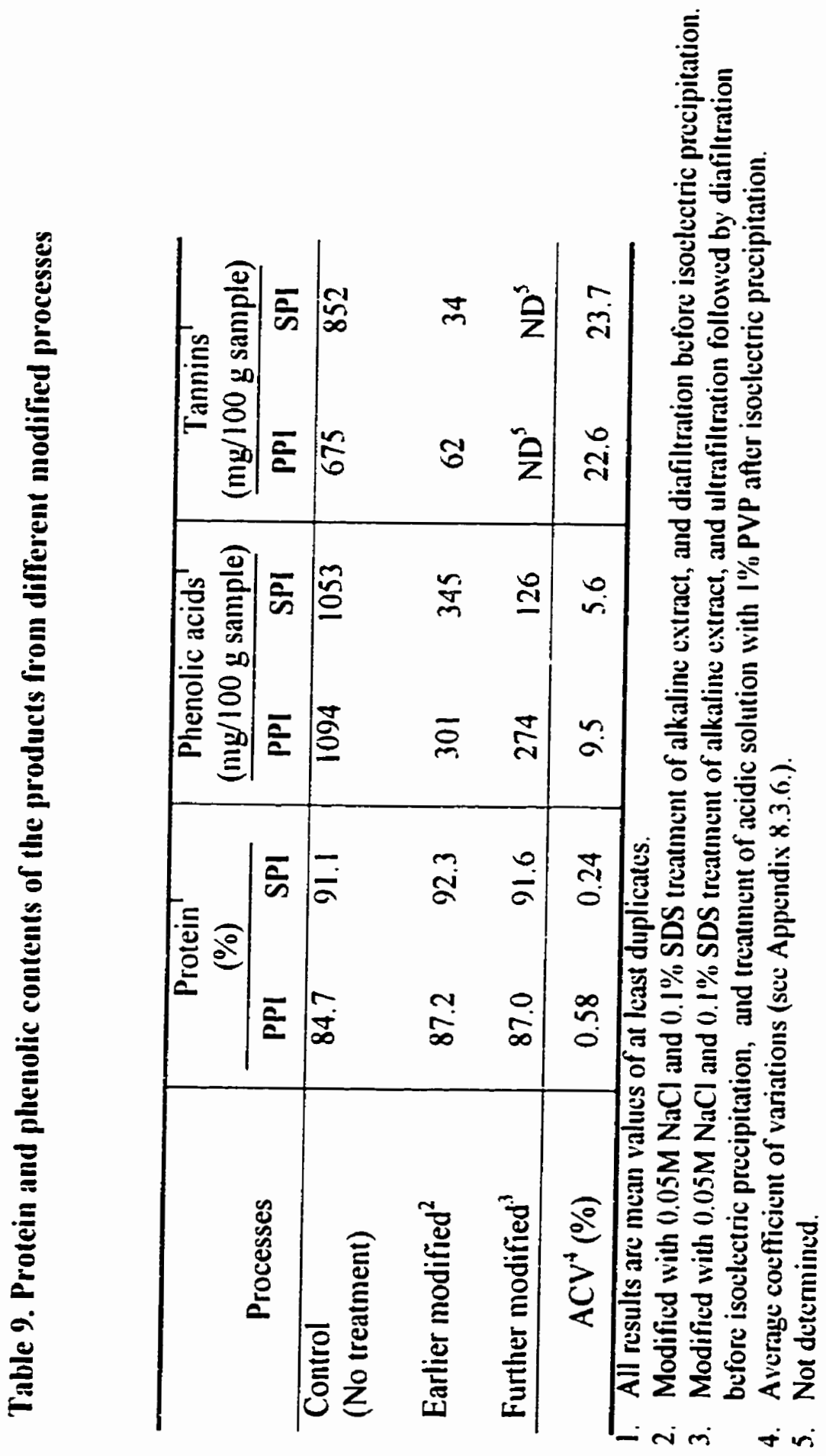


Table 10. Comparison between $10 \%$ and $1 \%$ PVP treatment on soluble protein isolate (SPI)

\begin{tabular}{c|cc}
\hline PVP treatments & $\begin{array}{c}\text { Protein } \\
(\%)\end{array}$ & $\begin{array}{c}\text { Phenolic acids } \\
\text { (mg/100 g sample) }\end{array}$ \\
\hline $10 \%$ addition & 91.6 & 126 \\
$1 \%$ addition & 91.0 & 114 \\
\hline $\mathrm{ACV}^{2}(\%)$ & 0.7 & 7.0 \\
\hline
\end{tabular}

1. All results are mean values of at least duplicates.

2. Average coefficient of variations (see Appendix 8.3.7.). 
on the membrane, and decrease the permeability of the membrane, thus making the processing even more difficult.

The mass or protein recoveries of both PPI and SPI from the further modified process remained the same as compared to the earlier one (Table 11). However, both modified processes gave slightly lower total mass and protein recoveries than the original process. This was likely due to the membrane processing of the alkaline extract, which removed more impurities, thus leading to a slightly higher mass loss. To show the overall yields and losses of both mass and protein from the further modified process, a mass and protein distribution was determined among major process streams (Table 12). While more than half of meal protein was recovered in the protein isolates, about $60 \%$ meal solids (mass) ended up in the meal residue. The discrepancies in amount between the starting meal and the products were referred to as "loss". A significant mass "loss" of $17.9 \%$ was experienced in this case, as a resuit of the intensive membrane processing. This "loss" was, however, close to what previous researchers reported for the original membrane-based process starting with hexanedefatted canola meal (Tzeng et al., 1990a). The approximate 10\% protein "loss" was likely due to the non-protein nitrogen-containing compounds such as amino acids and short peptides which have relatively low molecular weights, thus passing through the membrane in the permeate.

From the above results, it could be concluded in general that with all the modifications oriented toward removing phenolic compounds from the extracted canola proteins, the further modified process was able to produce two canola protein isolates, PPI and SPI at combined mass and protein yields of about $24 \%$ and $55 \%$ of the starting meal, respectively. Both protein isolates were of high protein content $(87-92 \%)$, essentially free of tannins, and low in phenolic acids. 
Table 11. Comparison of different modified processes in mass and protein recoveries

\begin{tabular}{|c|c|c|c|c|c|}
\hline \multirow[b]{2}{*}{ Process } & \multirow[b]{2}{*}{ Products } & \multicolumn{2}{|c|}{ Mass } & \multicolumn{2}{|c|}{ Protein } \\
\hline & & (g) & $\left(\%^{1}\right)$ & (g) & $\left(\%^{2}\right)$ \\
\hline \multirow{2}{*}{$\begin{array}{l}\text { Control } \\
\text { (No treatment) }\end{array}$} & PPI & 7.58 & 15.2 & 6.42 & 33.7 \\
\hline & SPI & $\frac{5.02}{1260}$ & $\frac{10.0}{252}$ & $\frac{4.57}{1099}$ & $\frac{24.0}{577}$ \\
\hline \multirow[t]{3}{*}{ Earlier modified ${ }^{3}$} & PPI & 7.74 & 15.5 & 6.75 & 35.4 \\
\hline & SPI & 4.01 & 8.0 & 3.70 & 19.4 \\
\hline & & 11.75 & 23.5 & 10.45 & 54.8 \\
\hline \multirow{3}{*}{ Further modified ${ }^{4}$} & PPI & 7.67 & 15.3 & 6.67 & 35.0 \\
\hline & SPI & 4.23 & 8.5 & 3.89 & 20.4 \\
\hline & & 11.90 & 23.8 & 10.56 & 55.4 \\
\hline
\end{tabular}

1. The percentage values are based on $50.0 \mathrm{~g}$ starting meal.

2. The percentage values are based on the total amount of protein in the starting meal, determined to be 19.05 grams.

3. Modified with $0.05 \mathrm{M} \mathrm{NaCl}$ and $0.1 \%$ SDS treatment of alkaline extract, and diafiltration before isoclectric precipitation.

4. Modified with $0.05 \mathrm{M} \mathrm{NaCl}$ and $0.1 \%$ SDS treatment of alkaline extract. and ultrafiltration followed by diafiltration before isoelectric precipitation, and treatment of acidic solution with $1 \%$ PVP after isoelectric precipitation. 
Table 12. Mass and protein distribution among major process streams of further modified process

\begin{tabular}{|c|c|c|c|}
\hline \multirow[b]{2}{*}{ Process streams } & \multirow{2}{*}{$\begin{array}{l}\text { Mass } \\
(\%)\end{array}$} & \multicolumn{2}{|c|}{ Protein } \\
\hline & & Yield (\%) & Content (\%) \\
\hline Starting meal & 100 & 100 & 38.1 \\
\hline $\begin{array}{l}\text { Precipitated protein } \\
\text { Isolate (PPI) }\end{array}$ & 15.3 & 35.0 & 87.0 \\
\hline $\begin{array}{l}\text { Soluble protein } \\
\text { Isolate (SPI) }\end{array}$ & 8.5 & 20.4 & 91.6 \\
\hline Meal residue (MR) & 58.3 & 33.8 & 22.1 \\
\hline Loss $^{1}$ & 17.9 & 10.8 & - \\
\hline
\end{tabular}

1. The "loss" of mass and protein was calculated by substraction:

Starting meal (100) - Products 


\subsection{Colorimetric and Sensory Evaluation}

\subsubsection{Colour measurement}

The colours of the PPI's from different processes (Figure 18) were measured and compared using a Hunter colorimeter to study the effect of the treatments on the colour. For each measurement a $4 \mathrm{~g}$ sample was needed, which was actually more than half of the amount of each sample produced in a single run. Since a Hunter colorimeter measures the colour in the three-dimensional opponent-colour system as introduced earlier in Section 2.5 , all L values in Table 13 indicated sample lightness with 100 being white and 0 black. All a values were indicative of redness varying between +100 and -80 as sample colour changed from red to green, whereas yellowness was read by $b$ values from +100 (yellow) to -80 (blue). It could be seen that the colour darkness of the samples decreased with more intensive treatments applied to further remove phenolic compounds except for the treatment with $0.05 \mathrm{M} \mathrm{NaCl}$, which did not make much difference in the colour of its PPI. Although both PPI samples prepared by the original process and the further modified process were yellow in colour, the former was much darker than the latter, likely due to the substantial difference in their phenolic content.

The colours of the SPI's were evaluated by measuring their absorbance in aqueous solutions in the UV-visible range. The absorbance curves are presented in Figure 29. Like any other protein soluble in water, all SPI's in solutions had high aborbance in the UV range, hence their absorbance curves rose sharply as the wavelength approached the UV range. The colour of each SPI solution may be a result of the presence of phenolic compounds bound to canola proteins by different mechanisms. Therefore, when those treatments aimed at removing phenolic compounds were applied in the processing, the colours of the solutions 
Table 13. Colour measurement of precipitated protein isolates (PPI)

\begin{tabular}{|c|c|c|c|}
\hline $\begin{array}{c}\text { PPI samples } \\
\text { From different processes }\end{array}$ & $\begin{array}{c}\mathrm{L} \\
\text { (Lightness) }\end{array}$ & $\begin{array}{c}\mathrm{a} \\
\text { (Redness) }\end{array}$ & $\begin{array}{c}\mathrm{b} \\
\text { (Yellowness) }\end{array}$ \\
\hline $\begin{array}{l}\text { Control } \\
\text { (No treatment) }\end{array}$ & 52.1 & 3.1 & 21.4 \\
\hline Diafiltration & 61.5 & 3.4 & 14.2 \\
\hline $0.05 \mathrm{M} \mathrm{NaCl}$ & 60.2 & 3.8 & 14.3 \\
\hline Earlier modified' & 66.9 & 2.7 & 12.9 \\
\hline Further modified ${ }^{2}$ & 69.3 & 0.8 & 17.5 \\
\hline $\begin{array}{l}\text { 1. Modified with } 0.05 \mathrm{M} \mathrm{NaC} \\
\text { isoelectric precipitation. } \\
\text { 2. Modified with } 0.05 \mathrm{M} \mathrm{NaC} \\
\text { followed by diafiltration be } \\
\text { PVP after isoclectric precip }\end{array}$ & $\begin{array}{l}\text { SDS of } t \\
\text { tric precipi }\end{array}$ & $\begin{array}{l}\text { of alkaline } \\
\text { nd treatmen }\end{array}$ & $\begin{array}{l}\text { id diafiltration } \\
\text { ct. and ultrafi } \\
\text { idic solution w }\end{array}$ \\
\hline
\end{tabular}


Figure 29. Spectra of solutions of soluble protein isolates (SPI) from different processes

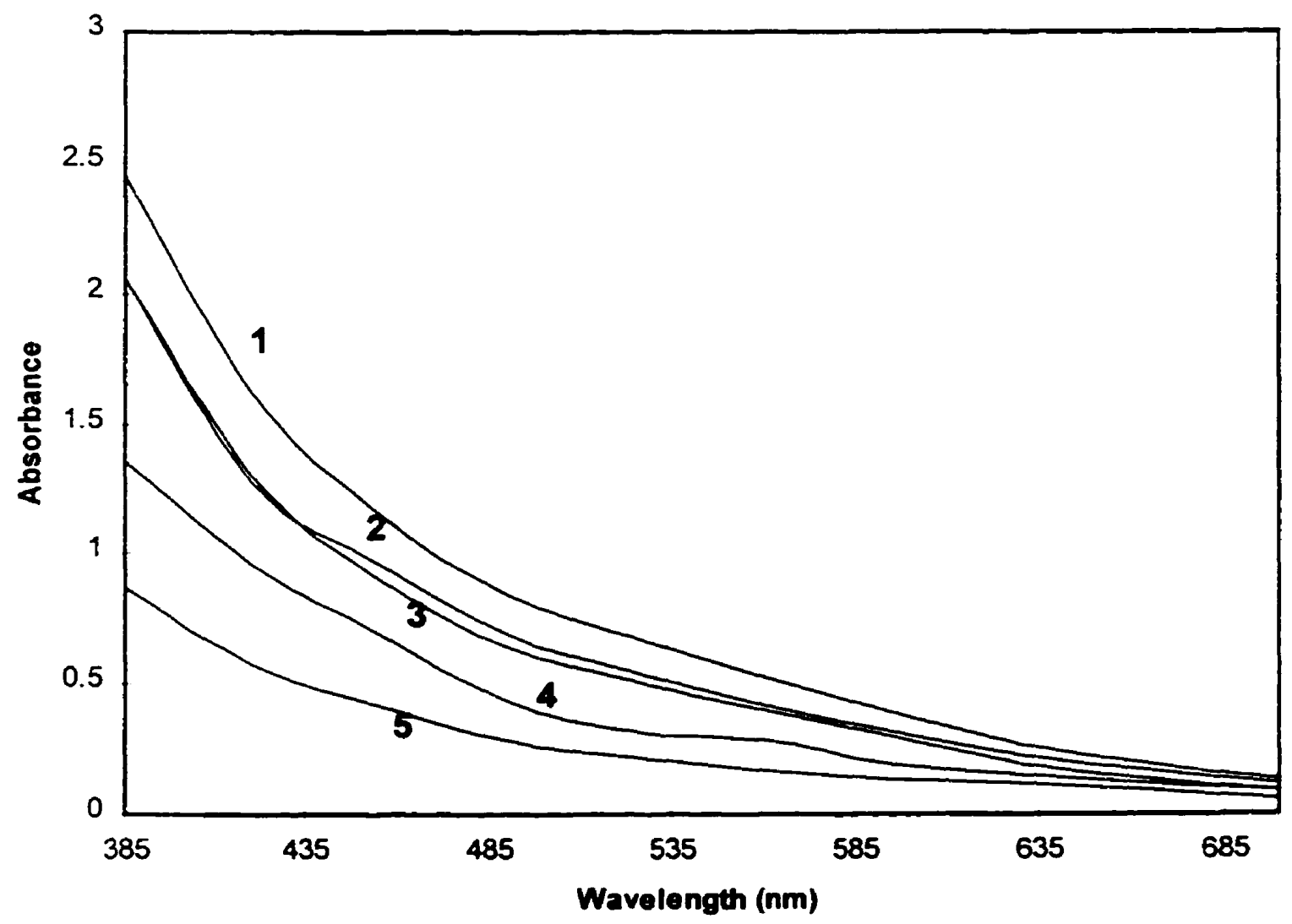

1. Prepapred by the original process with no treatment.

2. Prepared by the process with a diafiltration before isoelectric precipitation.

3. Prepared by the process with $0.05 \mathrm{M} \mathrm{NaCl}$ treatment of alkaline extract and difiltration before isoelectric precipitation.

4. Prepared by the earlier modified process with $0.05 \mathrm{M} \mathrm{NaCl}$ and $0.1 \% \mathrm{SDS}$ treatment of alkaline extract, and diafiltration before isoelectric precipitation.

5. Prepared by the further modified process with $0.05 \mathrm{M} \mathrm{NaCl}$ and $0.1 \%$ SDS treatment of akaline extract, and ultrafitration followed by difitration before isoelectric precipitation, and $1 \%$ PVP treatment of acidic solution after iscelectric precipitation. 
became lighter. However, even with the treatments no process developed in this study was able to remove the colour completely. The solution of SPI from the further modified process still had a light brownish colour. This was probably because of the phenolic compounds bonded to canola protein covalently, which could not be removed by any treatment. According to the mechanism proposed by Torchinskii and Dixon (1974), the covalent bonds could be formed through the reaction of SH-containing amino acids such as cysteine with quinones that were derived from phenolic compounds. The products of this reaction were, in fact thioethers, which had absorption maxima at $420-430 \mathrm{~nm}$. The colour of SPI solution from the last process (further modified) corresponded to the absorbance at wavelengths in this visible range (Figure 29).

As shown by the colour measurements, the treatments employed in the processes to remove phenolic compounds were effective in improving the colours of both canola protein isolates. A descending trend in sample colour darkness was observed as more phenolic compounds were removed. The products with the best colour improvement of all were obtained from the further modified process where the additional treatments were applied. 


\subsubsection{Sensory evaluation}

Sensory evaluation uses people as sensors to measure food quality in programs such as quality control and new product development since many sensory characteristics of food can only be measured well, completely, and meaningfully by human subjects. In the present study, it was applied to evaluate the taste of canola protein isolates prepared by different processes. Since protein isolates are used as functional ingredients in food, it is desirable that they do not contribute to flavour, or provide only minimal, complementary flavour to food products. Accordingly, canola protein isolates were examined for both the strength and acceptability of their taste. In the meantime, as PPI and SPI samples are likely useful in different food systems, they were evaluated and compared separately for sensory tests. The method chosen was one of the descriptive tests, known as unstructured scaling, as it was able to provide information on the degree or intensity of the sensory characteristics of concern, thus helping to identify treatments or process variables responsible for these characteristics of a product. Therefore, it was often used to develop new products, improve products or processes, and provide quality control (Poste et al., 1991). In this method, the panelists recorded each evaluation by marking a $15-\mathrm{cm}$ long horizontal line at the point that best reflected their perception of the magnitude of the property of concern. Numerical values were then given to the ratings by measuring the distance of the panelists' marks from the left end of the line in units of $0.1 \mathrm{~cm}$ (Tables 14, 15, 16, and 17). The numerical values for taste intensity indicated the strength of taste; the higher the value was, the stronger the product tasted. Pleasantness was a hedonic measurement, the values of which represented the degree of acceptability of taste. 
Table 14. Comparison in taste intensity of precipitated protein isolates (PPI)

\begin{tabular}{|c|c|c|c|c|c|c|}
\hline Panelist & $\begin{array}{c}\text { Control with } \\
\text { no treatment } \\
\left(337^{3}\right)\end{array}$ & $\begin{array}{c}\text { Diafiltration } \\
(346)\end{array}$ & $\begin{array}{c}0.05 \mathrm{M} \mathrm{NaCl} \\
(378)\end{array}$ & $\begin{array}{c}\text { Earlier modified } \\
\text { (NaCl \& SDS) } \\
(353)\end{array}$ & $\begin{array}{l}\text { Further modified } \\
\qquad(333)\end{array}$ & $\begin{array}{c}\text { Soy Protein } \\
(362)\end{array}$ \\
\hline 1 & 15.0 & 15.0 & 8.7 & 11.8 & 2.4 & 1.1 \\
\hline 2 & 10.9 & 9.8 & 8.0 & 6.9 & 2.9 & 2.2 \\
\hline 3 & 11.6 & 10.3 & 5.5 & 7.4 & 3.4 & 4.0 \\
\hline 4 & 12.6 & 14.3 & 9.0 & 7.1 & 4.6 & 1.0 \\
\hline 5 & 11.0 & 12.3 & 8.4 & 7.4 & 6.2 & 4.8 \\
\hline 6 & 9.2 & 3.6 & 7.7 & 6.9 & 4.8 & 8.4 \\
\hline 7 & 12.8 & 13.8 & 14.6 & 7.2 & 9.4 & 1.9 \\
\hline 8 & 10.7 & 13.0 & 6.5 & 7.5 & 4.3 & 5.6 \\
\hline 9 & 7.1 & 9.7 & 3.5 & 5.0 & 6.3 & 12.3 \\
\hline 10 & 15.0 & 13.0 & 1.9 & 7.1 & 4.4 & 2.6 \\
\hline 11 & 8.6 & 13.6 & 12.1 & 6.5 & 1.0 & 2.5 \\
\hline 12 & 14.5 & 13.9 & 6.1 & 7.3 & 6.1 & 4.5 \\
\hline 13 & 11.3 & 14.6 & 13.5 & 6.2 & 8.2 & 7.5 \\
\hline 14 & 10.9 & 12.4 & 9.9 & 7.4 & 3.9 & 3.0 \\
\hline Total & 161.2 & 169.3 & 115.4 & 101.7 & 67.9 & 61.4 \\
\hline Average & 11.5 & 12.1 & 8.2 & 7.3 & 4.9 & 4.4 \\
\hline
\end{tabular}

Table 15. Comparison in taste pleasantness of precipitated protein isolates (PPI)

\begin{tabular}{|c|c|c|c|c|c|c|}
\hline Processes & $\begin{array}{c}\text { Control with } \\
\text { no treatment } \\
\left(337^{3}\right)\end{array}$ & $\begin{array}{c}\text { Diafiltration } \\
(346)\end{array}$ & $\begin{array}{c}0.05 \mathrm{M} \mathrm{NaCl} \\
(378)\end{array}$ & $\begin{array}{c}\text { Earlier modified } \\
(\mathrm{NaCl} \& \mathrm{SDS}) \\
(353)\end{array}$ & $\begin{array}{c}\text { Further modified }{ }^{2} \\
\text { (333) }\end{array}$ & $\begin{array}{c}\text { Soy Protein } \\
(362)\end{array}$ \\
\hline l & 0.0 & 0.0 & 6.2 & 3.3 & 12.5 & 13.9 \\
\hline 2 & 12.5 & 11.6 & 5.0 & 8.0 & 6.4 & 3.5 \\
\hline 3 & 2.5 & 4.0 & 5.5 & 7.6 & 9.0 & 10.5 \\
\hline 4 & 1.3 & 0.3 & 2.9 & 8.1 & 7.0 & 9.5 \\
\hline 5 & 5.2 & 3.9 & 8.5 & 6.6 & 7.7 & 9.5 \\
\hline 6 & 6.8 & 9.9 & 5.6 & 8.1 & 8.9 & 7.6 \\
\hline 7 & 7.8 & 9.3 & 1.5 & 4.7 & 2.8 & 8.7 \\
\hline 8 & 5.7 & 4.9 & 7.2 & 7.5 & 10.5 & 9.3 \\
\hline 9 & 4.3 & 6.4 & 10.8 & 12.8 & 8.6 & 1.6 \\
\hline 10 & 4.5 & 2.8 & 12.7 & 6.7 & 8.8 & 11.7 \\
\hline 11 & 7.4 & 1.5 & 3.4 & 8.4 & 11.6 & 13.7 \\
\hline 12 & 0.5 & 1.9 & 7.0 & 10.2 & 3.9 & 9.6 \\
\hline 13 & 4.9 & 0.6 & 1.5 & 8.7 & 3.0 & 6.7 \\
\hline 14 & 4.8 & 0.4 & 5.7 & 7.7 & 9.6 & 11.7 \\
\hline $\begin{array}{c}\text { Total } \\
\text { Average }\end{array}$ & $\begin{array}{c}68.2 \\
4.9 \\
\end{array}$ & $\begin{array}{c}57.5 \\
4.1 \\
\end{array}$ & $\begin{array}{c}83.5 \\
6.0\end{array}$ & $\begin{array}{c}108.4 \\
7.7\end{array}$ & $\begin{array}{c}110.3 \\
7.9 \\
\end{array}$ & $\begin{array}{c}127.5 \\
9.1 \\
\end{array}$ \\
\hline
\end{tabular}

1. Prepared by the earlier modified process with $0.05 \mathrm{M} \mathrm{NaCl}$ and $0.1 \%$ SDS treatment of alkaline extract, and diafiltration before isoelectric precipitation.

2. Prepared by the further modified process with $0.05 \mathrm{M} \mathrm{NaCl}$ and $0.1 \%$ SDS treatment of alkaline extract, and ultrafiltration followed by diafiltration before isoelectric precipitation, and $1 \%$ PVP treatment of acidic solution after isoelectric precipitation.

3. Labels for the samples. 
Table 16. Comparison in taste intensity of soluble protein isolates (SPI)

\begin{tabular}{|c|c|c|c|c|c|c|}
\hline Processes & $\begin{array}{c}\text { Control with } \\
\text { no treatment } \\
\left(481^{3}\right)\end{array}$ & $\begin{array}{c}\text { Diafiltration } \\
(473) \\
\end{array}$ & $\begin{array}{c}0.05 \mathrm{M} \mathrm{NaCl} \\
(494)\end{array}$ & $\begin{array}{c}\text { Earlier modified } \\
\text { (NaCl \& SDS) } \\
(423)\end{array}$ & $\begin{array}{c}\text { Further modified } \\
(10 \% \text { PVP }) \\
(444)\end{array}$ & $\begin{array}{c}\text { Further modified } \\
(1 \% \text { PVP }) \\
(452)\end{array}$ \\
\hline 1 & 8.0 & 12.2 & 6.8 & 5.4 & 1.2 & 8.5 \\
\hline 2 & 4.2 & 8.3 & 7.3 & 5.3 & 1.4 & 6.3 \\
\hline 3 & 4.0 & 11.1 & 7.1 & 8.5 & 6.3 & 2.8 \\
\hline 4 & 12.8 & 13.6 & 9.7 & 9.0 & 11.5 & 5.2 \\
\hline 5 & 11.0 & 14.7 & 9.1 & 7.2 & 3.0 & 11.1 \\
\hline 6 & 13.7 & 13.2 & 6.8 & 7.9 & 5.5 & 1.6 \\
\hline 7 & 13.9 & 9.9 & 11.7 & 6.0 & 10.5 & 8.1 \\
\hline 8 & 10.4 & 12.5 & 8.6 & 3.5 & 6.1 & 4.6 \\
\hline 9 & 7.6 & 6.4 & 6.9 & 7.4 & 9.9 & 7.5 \\
\hline 10 & 10.3 & 6.5 & 7.1 & 9.1 & 7.1 & 2.5 \\
\hline 11 & 10.6 & 9.1 & 7.6 & 4.5 & 6.2 & 8.3 \\
\hline 12 & 12.7 & 12.7 & 6.0 & 9.9 & 7.9 & 6.9 \\
\hline 13 & 9.0 & 11.5 & 8.3 & 4.1 & 4.9 & 10.3 \\
\hline Total & 128.2 & 141.7 & 103.0 & 87.8 & 81.5 & 83.7 \\
\hline Average & 9.9 & 10.9 & 7.9 & 6.8 & 6.3 & 6.4 \\
\hline
\end{tabular}

Table 17. Comparison in taste pleasantness of soluble protein isolates (SPI)

\begin{tabular}{|c|c|c|c|c|c|c|}
\hline Processes & $\begin{array}{c}\text { Control with } \\
\text { no treatment } \\
\left(481^{3}\right)\end{array}$ & $\begin{array}{c}\text { Diafiltration } \\
(473) \\
\end{array}$ & $\begin{array}{c}0.05 \mathrm{M} \mathrm{NaCl} \\
(494)\end{array}$ & $\begin{array}{c}\text { Earlier modified } \\
(\mathrm{NaCl} \& \mathrm{SDS}) \\
(423)\end{array}$ & $\begin{array}{c}\text { Further modified } \\
\text { (10\% PVP) } \\
(444)\end{array}$ & $\begin{array}{c}\text { Further modified }^{2} \\
(1 \% \text { PVP }) \\
(452)\end{array}$ \\
\hline 1 & 7.4 & 3.4 & 8.1 & 8.6 & 9.4 & 5.0 \\
\hline 2 & 10.0 & 9.0 & 6.7 & 6.5 & 12.5 & 10.6 \\
\hline 3 & 9.7 & 1.7 & 4.7 & 11.0 & 10.4 & 12.0 \\
\hline 4 & 2.1 & 1.4 & 3.9 & 5.7 & 4.9 & 11.2 \\
\hline 5 & 2.4 & 0.7 & 7.3 & 8.6 & 9.4 & 3.5 \\
\hline 6 & 0.8 & 1.4 & 8.2 & 6.3 & 9.0 & 11.2 \\
\hline 7 & 9.1 & 1.9 & 11.0 & 3.3 & 5.5 & 7.0 \\
\hline 8 & 4.9 & 4.2 & 5.7 & 9.2 & 7.8 & 6.8 \\
\hline 9 & 5.1 & 8.8 & 8.0 & 7.5 & 6.7 & 8.4 \\
\hline 10 & 2.0 & 4.8 & 1.4 & 3.9 & 7.4 & 7.3 \\
\hline II & 2.6 & 5.0 & 4.2 & 7.5 & 5.7 & 6.3 \\
\hline 12 & 3.1 & 2.3 & 9.2 & 7.0 & 7.2 & 9.0 \\
\hline 13 & 3.4 & 2.4 & 6.7 & 9.9 & 7.4 & 3.0 \\
\hline Total & 62.6 & 47.0 & 85.1 & 95.0 & 103.3 & 101.3 \\
\hline Average & 4.8 & 3.6 & 6.5 & 7.3 & 7.9 & 7.8 \\
\hline
\end{tabular}

1. Prepared by the earlier modified process with $\mathrm{NaCl}$ and SDS treatment of alkaline extract. and diafiltration before isoelectric precipitation.

2. Prepared by the further modified process with $\mathrm{NaCl}$ and SDS treatment of alkaline extract, and ultrafiltration followed by diafiltration before isoelectric precipitation, and PVP treatment of acidic solution after isoelectric precipitation.

3. Labels for the samples. 
Analysis of variance (ANOVA) was conducted on the numerical values of both taste features using Microsoft Excel 97, and results were summarized in Table 18. To determine if the difference among the treatments was significant. the calculated variance ratios ( $F$ values) were compared with the tabulated critical variance ratios (Fisher and Yates, 1974). The calculated $F$ values must exceed the critical ones in order for the difference to be significant at a certain probability. Since, as mentioned earlier, these sensory tests used people as measuring instrument, the results were subject to human bias in taste. Thus, it is necessary to determine by statistical means whether human bias had a significant effect on the results of the tests. As shown in Table 18 all calculated $F$ values for panelists were less than the critical ones at a probability less than or equal to $0.05(P \leq 0.05)$, indicating that the effect of human bias was insignificant on the test results in this case. On the other hand, the calculated $F$ values for processes were greater than the critical values, hence it could be concluded that there were indeed differences in taste intensity or pleasantness among these canola protein isolates from different processes.

To further determine whether these products were different from one another, Turkey's multiple comparison test was performed (Snedecor and Cochran, 1989). Multiple comparison tests are always used as yardsticks for comparing means from qualitative treatments. In order for any two process means to be significantly different at a certain probability, they must differ by the least significant difference (LSD) at this probability or more. The results of Turkey's test are shown in Tables 19 and 20, using letters to indicate differences. Any two values not followed by the same letter are significantly different at $\mathbf{P} \leq$ 0.05 . 
Table 18. Results of ANOVA of taste intensity and pleasantness of canola protein isolates

\begin{tabular}{|c|c|c|c|c|c|}
\hline Features & Products & $\begin{array}{c}\text { Calculated } F_{\text {panclists }} \\
\text { (Variance ratio) }\end{array}$ & $\begin{array}{l}\text { Critical } \\
F_{\text {panelists }}^{*}\end{array}$ & $\begin{array}{l}\text { Calculated } F_{\text {processes }} \\
\text { (Variance ratio) }\end{array}$ & $\begin{array}{c}\text { Critical } \\
F_{\text {processes }}\end{array}$ \\
\hline Taste intensity & $\begin{array}{l}\text { PPI's } \\
\text { SPI's }\end{array}$ & $\begin{array}{l}0.97 \\
1.84\end{array}$ & $\begin{array}{l}1.87 \\
1.92\end{array}$ & $\begin{array}{c}19.80 \\
7.71\end{array}$ & $\begin{array}{l}2.36 \\
2.37\end{array}$ \\
\hline Pleasantness & $\begin{array}{l}\text { PPI's } \\
\text { SPI's }\end{array}$ & $\begin{array}{l}0.78 \\
1.79\end{array}$ & $\begin{array}{l}1.87 \\
1.92\end{array}$ & $\begin{array}{l}4.92 \\
6.44\end{array}$ & $\begin{array}{l}2.36 \\
2.37\end{array}$ \\
\hline
\end{tabular}


Table 19. Turkey's multiple comparison test for precipitated protein isolates (PPI)

\begin{tabular}{|c|c|c|c|c|c|c|c|c|}
\hline \multirow[b]{2}{*}{ Features } & \multicolumn{6}{|c|}{ Process mean } & \multirow[b]{2}{*}{$\mathrm{SEM}^{+}$} & \multirow[b]{2}{*}{ LSD $^{5}$} \\
\hline & Control & Diafiltration & $0.05 \mathrm{M} \mathrm{NaCl}$ & $\begin{array}{c}\text { Earlier } \\
\text { modified }^{2}\end{array}$ & $\begin{array}{c}\text { Further } \\
\text { modified }^{3}\end{array}$ & Soy protein & & \\
\hline Taste intensity & $11.5 \mathrm{a}$ & $12.1 \mathrm{a}$ & $8.2 b$ & $7.3 b c$ & $4.9 \mathrm{c}$ & $4.4 c$ & 0.73 & 3.04 \\
\hline Pleasantness & $4.9 \mathrm{ab}$ & $4.1 \mathrm{a}$ & 6.0abc & 7.7abc & $7.9 \mathrm{bc}$ & $9.1 \mathrm{c}$ & 0.87 & 3.62 \\
\hline
\end{tabular}

Table 20. Turkey's multiple comparison test for soluble protein isolates (SPI)

\begin{tabular}{|c|c|c|c|c|c|c|c|c|}
\hline \multirow[b]{2}{*}{ Features } & \multicolumn{6}{|c|}{ Process mean } & \multirow[b]{2}{*}{ SEM $^{4}$} & \multirow[b]{2}{*}{$\mathrm{LSD}^{5}$} \\
\hline & Control & Diafiltration & $0.05 \mathrm{M} \mathrm{NaCl}$ & $\begin{array}{c}\text { Earlier } \\
\text { modified }^{2}\end{array}$ & $\begin{array}{l}\text { Further modified } \\
(10 \% \text { PVP })\end{array}$ & $\begin{array}{l}\text { Further modified } \\
(1 \% \text { PVP) }\end{array}$ & & \\
\hline Taste intensity & $9.9 \mathrm{ab}$ & $10.9 a$ & $7.9 \mathrm{bc}$ & $6.8 \mathrm{c}$ & $6.3 c$ & $6.4 c$ & 0.70 & 2.91 \\
\hline Pleasantness & $4.8 \mathrm{ab}$ & $3.6 a$ & $6.5 b c$ & $7.3 b c$ & $7.9 \mathrm{c}$ & $7.8 \mathrm{c}$ & 0.69 & 2.87 \\
\hline
\end{tabular}

1. Different letters indicate significant difference.

2. Prepared by the earlier modified process with $\mathrm{NaCl}$ and SDS treatment of alkaline extract, and diafiltration before isoclectric precipitation.

3. Prepared by the further modified process with $\mathrm{NaCl}$ and SDS treatment of alkaline extract, and ultrafiltration followed by diafiltration before isoelectric precipitation, and PVP treatment of acidic solution after isoelectric precipitation.

4. Standard error of process mean.

5. Least significant difference. 
As shown by the results of sensory evaluation. much like the colour, the taste of the products was also improved in terms of both the strength and acceptability as the phenolic compounds were removed by the treatments. While both canola protein isolates from the control run with no treatment had a considerable bitter and astringent flavour, the low taste intensity of the PPI from the last process (further modified) was comparable to that of a commercial soy protein isolate (Table 19). However, the difference in their pleasantness was far less significant than their taste intensity as the panelists did not find the blander products much more pleasant to taste than the products from the control run (Table 19). They also seemed to like the PPI's from both earlier and further modified processes as much as the commercial soy protein isolate, as suggested by the data. As for the SPI from the further modified process, not only did the panelists find it much blander than that from the control run, they also had an obvious preference for it to the control products (Table 20). It was shown that the application of insoluble PVP in the final process further improved the taste of SPI, but the fact that $10 \%$ PVP addition did not make a difference in either taste intensity or pleasantness (Table 20) indicated that $1 \%$ addition was adequate, and further addition of PVP was unnecessary. 


\subsection{Basic Economic Assessment}

The results of both colour measurement and sensory evaluation have shown that the further modified process, with the treatments aimed at removing phenolic compounds, was technically viable to produce high-quality canola protein isolates light in colour and bland in taste. Its economic viability was then examined to determine the processing margin.

Some basic economic assessment was carried out, based on the current marketing situation of canola meal and the well-established soy protein products. Canola meal is the starting material of the process, its cost would have a significant impact on the process economics. Fortunately, the cost of commercial canola meal is relatively low. Although varying daily, it is usually about $\$ 160 /$ tonne (Canola Council of Canada, 1998). Therefore, with a meal residue value of $\$ 100 /$ tonne after protein extraction, the two canola protein isolates would only need to be both sold at a price of $\$ 405 /$ tonne $(\$ 0.41 / \mathrm{kg})$ just to break even with the cost of the starting material (Figure 30), assuming that they were both of the same value. This is known as the minimum or raw material cost of the products. In order to compete with the soy protein isolate sold in the market for approximate $55.00 / \mathrm{kg}$ (U.S. Soyfoods Directory, 1998), it is feasible to sell either canola protein isolate at a price such as $\$ 2.50 / \mathrm{kg}$ (\$2500/ton). A processing margin of $\$ 2.09 / \mathrm{kg}$ was then available at the disposal of the manufacturer, which was five times the minimum cost of the products $(\$ 0.41 / \mathrm{kg})$. In addition to the cost of the raw material, the actual processing cost would also include that of power consumption, materials used, labour, and equipment. Among the cost of all the chemical materials used, that of $\mathrm{NaCl}, \mathrm{NaOH}$, and $\mathrm{HCl}$ is almost negligible due to low price 
Figure 30: Minimum cost evaluation of products

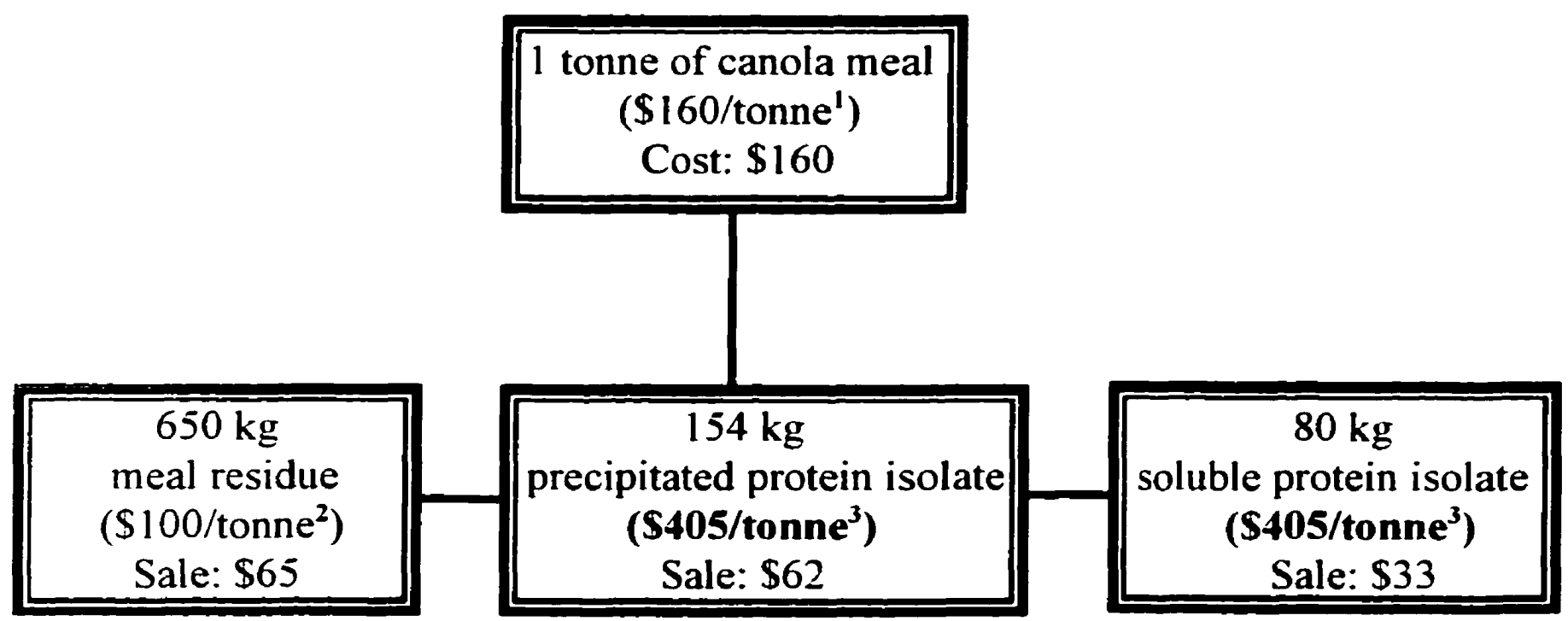

1. Given values

2. Assumed values

3. Calculated values 
or small quantity needed, but both SDS and insoluble PVP could be very expensive, and their cost would affect the profit significantly. However, there are workable solutions to reduce the cost to a reasonable level. For example, if purchased in bulk (one tonne or up) the price of SDS could be brought down to less than $\$ 9 / \mathrm{kg}$ (Charles Tenant Company, Toronto), implying a cost as low as $\$ 162$ for SDS to treat one tonne starting meal. For PVP, both reusing and recycling (regeneration) are likely to reduce its cost greatly, and yet both techniques need to be studied. Although at this point precise cost evaluation was still difficult to perform, by experience and common sense it was reasonable to estimate that 3 times the raw material cost would be more than enough $(-\$ 1.20 / \mathrm{kg})$, which indicated a potential profit in the vicinity of $\$ 1.00$ per kilogram of the two products combined, or $\$ 230$ per tonne of the meal processed. Noting that this is only the profit if either canola protein isolate is assumed to be sold at $\$ 2.50 / \mathrm{kg}$. a much lower price than that of their soybean counterpart, the actually profit could be much higher when the market recognizes the fact that these canola protein products are essentially comparable to soy protein in both nutritional value and functional properties.

The entire process involves the use of a tremendous amount of water (approximately $100 \mathrm{~m}^{3}$ per tonne of meal), thus, the recycling of water must be considered and implemented so as to reduce its environmental impact and cost. While the permeate from membrane processing of the $\mathrm{pH} 3.5$ solution after isoelectric precipitation could probably be directly used again, the waste water from the ultrafiltration and diafiltration of the alkaline extract of canola protein must not be reused without treatment due to the presence of the undesirable substances removed from canola protein as well as the chemicals added to remove them. However, since the solids content in these water streams was essentially low $(<0.5 \%)$, its 
recycling should be achievable with some well-established treatments such as activated carbon, ion exchange, or membrane separation provided the use of any of them was technically and economically justifiable. Recently, reverse osmosis (RO) has been extensively used for sea water desalination and wastewater treatment. As a membrane process, RO is energy efficient and able to produce high-quality processed water (Buckley, et al., 1993). Wastewater of various sources can be treated by RO, e.g., electroplating solutions, power station or pulp and paper bleaching effluents. RO applications in industry fall into four configurations: total recycle of retentate and permeate, as a component of a chemical recovery process, as a concentration step before disposal, and as a component of pretreatment before disposal. The choice of each configuration is determined by the technical and economic aspects of the process. For the recycling of effluents from canola protein isolation, RO seems to be a promising candidate among all treatments. However, studies need to be carried out on factors such as suitable membrane types, fouling tendencies, and rejection characteristics of different membranes in the presence of these effluents. 


\section{CONCLUSIONS}

- The analytical method developed in this study for total phenolic acids determination was relatively simple, accurate, and has a low detection limit of less than $5 \mathrm{mg} / 100 \mathrm{~g}$ sample, thus was suitable for the determination of total phenolic acid content in a wide variety of rapeseed and canola protein products.

- Most of the phenolic acids and tannins in canola meal were readily extracted at alkaline $\mathrm{pH}$ values. At $\mathrm{pH} 12.0$ where about $70 \%$ of canola protein was extractable, over $80 \%$ of the phenolic acids and more than $90 \%$ of tannins ended up in the extract.

- The rejection coefficients of both phenolic acids and tannins from canola meal were determined to be 0.12 and 0.27 , respectively, indicating that they had molecular weights much below 10,000, and the membrane chosen for this study was able to separate the free phenolic compounds from canola protein.

- The fractionation system comprising a series of chemical treatments and membrane processing determined that nearly $50 \%$ of the extractable phenolic compounds were bound to canola protein in both alkaline and acidic media by different mechanisms, including ionic bonding, hydrophobic interactions, hydrogen bonding, and covalent bonding.

- The simple pretreatments prior to canola protein isolation, chosen based on the phenolic fractionation, were effective in removing certain fractions of phenolic acids and tannins. 
The treatment with low concentrations of $\mathrm{NaCl}$ and SDS was able to reduce phenolic acids in the products by $80 \%$ and tannins by $90 \%$.

- After isoelectric precipitation, the treatment with insoluble polyvinylpyrrolidone (PVP) further removed about half of the phenolic acids remaining in the acidic solution of canola protein while $\mathrm{Na}_{2} \mathrm{SO}_{3}$ failed to break the covalent bonds between phenolic acids and canola protein.

- The original membrane-based protein isolation process was modified by including the treatments that proved effective in phenolic removal. It produced two protein isolates, precipitated and soluble (PPI and SPI), with a total protein recovery of approximately $56 \%$ as of the meal protein. Both protein isolates had a high protein content $(>85 \%)$, were low in phenolic acids ( $200 \mathrm{mg} / 100 \mathrm{~g}$ sample), and essentially free of tannins. The residual SDS content in the products was well within acceptable levels.

- Colour measurement and sensory evaluation showed that both the colour and taste of the products were improved as a result of the removal of phenolic compounds. The PPI from the modified process exhibited a much lighter yellow colour than that from the original process. Similar colour improvement was achieved with the solution of SPI. Both canola protein isolates from the modified process were essentially bland in taste, and the blandness of the PPI was comparable to that of a commercial soy protein isolate. 
- Basic economic assessment indicated that the modified process had commercial potential, with estimated processing margins in excess of $\$ 500$ per tonne meal processed. 


\section{RECOMMENDATIONS}

- The amino acid composition of both protein isolates must be determined to confirm their nutritional value.

- A complete set of chemical analyses needs to be conducted to confirm the composition of the non-protein fraction of both protein isolates.

- The toxicological and nutritional properties of the products should be studied for safe utilization of them in food formulations.

- The functional properties of the products need to be evaluated to determine the forms in which they will be used in food.

- The formulations of model food systems should be developed containing canola protein isolates, and taste and utility must be tested in these food systems.

- In process development, the reusability and/or regeneration of insoluble polyvinylpyrrolidone (PVP) must be studied for cost reduction if it is used for phenolic removal.

- The modified processes need to be scaled up. Pilot-plant or semi-pilot-plant scale tests are necessary for equipment design and detailed economic assessment in the future commercialization of the process. 
- The recycling of processed water streams should be attempted for scaled-up process in order to reduce water consumption and environmental impact of the process. 


\section{REFERENCES}

AACC. 1976. Approved methods of the American Association of Cereal Chemists. American Association of Cereal Chemists, Inc., St. Paul, MN.

Appelquist, L.-A. 1972. Chemical constituents in rapeseed. -in Rapeseed: Cultivation, Composition, Processing, and Utilization. Appelquist, L.-A. and Olson, R., Eds. Elsvier Publishing Co., Amsterdam, Holland. p.123.

Arai, S., Suzuki, H., Fujimaki, M., and Sakurai, Y. 1966. Studies on flavour components in soybean. Part II. Phenolic acids in defatted soybean flour. Agr. Biol. Chem. 30(4):364.

Bate-Smith, E. C. 1954. Astringency in foods. Food 23:124.

Bate-Smith, E. C. and Ribereau-Gayon, P. Leucoanthocyanins in seeds. 1959. Qual. Plant Mater. Veg. 5:189.

Beare, J. L., Campbell, J. A., Youngs, C. G., and Graig, B. M. 1963. Effects of saturated fat in rats fed rapeseed oil. Can. J. Biochem. Physiol. 41:605.

Beare-Rogers, J. L. 1978. Nutritional evaluation of rapeseed oil and protein for food use. -in Proceedings of 5 th International Rapeseed Conference. Vol. 2. Malmo, Sweden. Lagerblads Tryckeri: Karlshamn, Sweden. p.74.

Bhatty, R. S. and Sosulski, F. W. 1972. Diffusion extraction of rapeseed glucosinolates with ethanolic sodium hydroxide. J. Am. Oil Chem. Soc. 49:346.

Bhatty, R. S., McKenzie, S. L., and Finlayson, A. J. 1968. The proteins of rapeseed (Brassica napus L.) soluble in salt solutions. Can. J. Biochem. 46:1191.

Blaicher, F. M., Elstner, F., Stein, W., and Mukherjee, K. D. 1983. Rapeseed protein isolates: Effect of processing on yield and composition of protein. J. Agric. Food Chem. 3 1:358.

Blair, R. and Reichert, R. D. 1984. Carbohydrate and phenolic constituents in a comprehensive range of rapeseed and canola fractions: nutritional significance for animals. $J$. Sci. Food Agric. 35:29.

Blouin, F. A., Zarins, Z. M., and Cherry, J. P. 1982. Discoloration of proteins by binding with phenolic compounds. -in Food Protein Deterioration. American Chemical Society, Washington, D. C..

Buckley, C. A., Brouckaert, C. J., and Kerr, C. A. 1993. RO application in brackish water desalination and in the treatment of industrial effluents. -in Reverse Osmosis - Membrane Technology, Water Chemistry, and Industrial Applications. Amjad, Z., Ed. Van Nostrand Reinhold, New York, New York. p.275. 
Burn, R. E. 1971. Method for estimation of tannin in grain sorghum. Agron. J. 63:511.

Butler, L. G. 1989. New perspectives on the antinutritional effects of tannins. In Food Proteins. Kinsella, J. E. and Soucie, W. G., Eds. Am. Oil Chem. Soc. Champaign, Illinois. p.402.

Cai, Y., Gaffney, S. H., Lilley, T. H., Magnolate, D., Martin, R, Spencer, C. M., and Haslam, E. 1990. Polyphenol interactions. Part 4. Model studies with caffeine and cyclodextrins. J. Chem. Soc. Perk. Trans. 2:2197.

Canola Council of Canada. 1983. Research Summary No. 2. Winnipeg, Manitoba.

Canola Council of Canada. 1998. Markets and Statistics. www.canola-council.org.

Carey, P. L. 1966. Process for the production of oilseed isolate. U. S. Patent 3, 966,702.

Carroll, K. K. and Noble, R. L. 1956. Erucic acid and cholesterol excretion in the rat. Can. J. Biochem. and Physiol. 34:981.

Chang, R., Schwimmer, S., and Burr, H. K. 1977. Phytate: removal from whoie dry beans by enzymatic hydrolysis and diffusion. J. Food Sci. 42:1098.

Cheryan, M. 1980. Phytic acid interaction in food systems. CRC Crit. Rev. Food Sci. Nutri. 13:297.

Cheryan, M. 1986. Ultrafiltration Handbook. Technomic Publishing Co., Lancaster, Pennsylvania.

Clandinin, D. R. and Heard, J. 1968. Tannins in prepress-solvent and solvent processed rapeseed meal. Poultry Sci. 47:688.

Delisle, J., Amiot, J., Goule, G., Simard, C., Brisson, G.J., and Jones, J. D. 1984. Nutritive value of protein fractions extracted from soybean, rapeseed and wheat flours in the rat. Qual Plant - Plant Foods Hum. Nutri. 34:243.

Deng, Q. Y., Barefoot, R. R., Diosady, L. L., Rubin, L. J., and Tzeng, Y-M. 1990. Lysinoalanine concentrations inrapeseed protein meals and isolates. Can. Inst. Food Sci. Technol. J. 23:140.

deRahm, O. and Jost, T. 1979. Phytate-protein interactions in soybean extracts and manufacture of low-phytate soy protein products. J. Food Sci. 44:596.

Deshpande, S. S. and Salunkhe, D. K. 1982. Interactions of tannic acid and catechin with legume starches. J. Food Sci. 47:2080. 
De Valois, R. L., Abrmov, I., and Jacobs, G. H. 1966. Analysis of response patterns of LGN cells. J. Opt. Soc. Am. 56:966.

Diosady, L. L., and Tzeng, Y-M., and Rubin, L. J. 1984. Preparation of rapeseed protein concentrates and isolates using ultrafiltration. J. Food Sci. 49:768.

Diosady, L. L., Rubin, L. J., and Trass, O. 1983. Proc. 6th Internatl. Rapeseed Conf., Vol. II, Groupe Consultatif International de Recherche sur le Colza, Paris, May 17-19. p. 1460.

Diosady, L. L., Tar, C. G., Rubin, L. J., and Naczk, M. 1987. Scale-up of the production of glucosinolate-free canola meal. Acta Alimentaria 16:167.

Donnelly, B. J., and Tabekhia, M. M. 1977. Durum wheat and its milled products: effect of variety and envirenment on the phytic acid content. Cereal Foods World 22:483.

Durkee, A. B. 1971. The nature of tannins in rapeseed (Brassica campestris). Phytochemistry. 10:1583.

Durkee, A. B. and Thivierge, P. A. 1975. Bound phenolic acids in Brassica and Sinapis oilseeds. J. Food Sci. 40:820.

El Nockrashy, A. S., Mukherjee, K. D., and Mangold, H. K. 1977. Rapeseed protein isolates by countercurrent extraction and isoelectric precipitation. J. Agric. Food Chem. 25:193.

Ellis, P. G. 1959. The Maillard reaction. Advances in Carbohydrate Chemistry 14:63.

Faithful, N. T. 1984. The in-vitro digestibility of feedstuff - a century of ferment. J. Sci. Food Argic. 35:819.

Fan, T. Y., Sosulski, F. W., and Hamon, N. W. 1976. New techniques for preparation of improved sunflower protein concentrates. Cereal Chem. 53:118.

Fenton, T. W., Leung, J., and Clandinin, D. R. 1980. Phenolic components of rapeseed meal. J. Food Sci. 45:1702.

Fenwick, R. G. and Hoggan, S. A. 1976. The tannin content of rapeseed meals. Br. Poult. Sci. 17:59.

Finlayson, A. J. 1976. The seed protein contents of some cruciferae. Biol. Chem. Cruciferae, [pap. conf.]. Vaughan, J. G., Macleod, A. J., and Jones, B. M. G. Eds. Academic , London, England. p.279.

Finlayson, A. J., Bhatty, R. S., and Christ, C. M. 1969. Species and varietal differences in the proteins of rapeseed. Can. J. Bot. 47:679. 
Finnigan, T. J. A. and Lewis, M. J. 1985. Nitrogen extraction from defatted rapeseed, with particular reference to United Kingdom commercial rapeseed meal. J. Sci. Food Agric. $36: 520$.

Fisher, R. A. and Yates, F. 1974. Statistical tables for biological, agricultural and medical research. 6th edition. Oliver and Boyd Ltd., Edinburgh, UK.

Gheysuddin, S., Cater, C. M., and Mattil, K. F. 1970. Preparation of a colorless sunflower protein isolate. Food Technol. 24:243.

Gillberg, L. and Tornell, B. 1976. Preparation of rapeseed protein isolates: Dissolution and precipitation behavior of rapeseed proteins. J. Food Sci. 41:1063.

Giraul, A. 1973. The study of some properties of rapeseed protein with a view to protein concentrate production. J. Sci. Food Agric. 24:509.

Glover, F. A., Skudder, P. J., Stothart, P. H., and Evans, E. W. 1978. Reviews of the progress of dairy science: reverse osmosis and ultrafiltration indairying. J. Dairy Research, 45:29l.

Goh, Y. K., Shires, A., Robblee, A. R., and Clandinin, D. R. 1983. The effec of ammoniation on the the sinapine content of canola meal. -in Research on Canola Meal, Oil and Seed. 7th Congress Report. McGregor, E. E., Ed. Canola Council of Canada. p. 143.

Goldsmith, R. L., de Filipi, R. P., Hossain, S., and Timmins, R. S. 1971. Industrial ultrfiltration. -in Membrane Processes in Industry and Biomedicine. Bier, M., Ed. Plenum Press, New York, New York. p.267.

Goodnight, K. C., Hartman, G. H., and Marquardt, R. F. 1978. low-phytate isoelectricprecipitated soybean protein isolate. U. S. Patent 4,072,670.

Griffiths, D. W. 1979. The inhibition of digestive enzymes by extracts of field bean (Vicia faba). J. Sci. Food Agric. 30:458.

Gustavson, K. H. 1956. The Chemistry of Tanning Processes. Academic Press, New York.

Hagerman, A. E. and Butler, L. G. 1978. Protein precipitation method for the quantification of tannins. J. Agric. Food Chem. 26:809.

Hagerman, A. E. and Butler, L. G. 1980. Determination of protein in tannin-protein precipitates. J. Agric. Food Chem. 28:944.

Haslam, E. 1988. Plant polyphenols and chemical defense - a reappraisal. J. Chem. Ecol. $14: 1789$.

Health Canada. 1994. The Food and Drug Act and Regulations. Part B - Foods; Division 16, Food Additives. 
Holme, J. 1975. Utilization of protein supplements in human foods. -in Oilseed and Pulse Crops in Western Canada. Harapiak, J. T., Ed. Modern Press, Saskatoon, Saskatchewan, Canada. p.657.

How, J. S. L. and Morr, C. V. 1982. Removal of phenolic compounds from soy protein extracts using activated carbon. J. Food Sci. 47:933.

Hunter, R. S. 1942. Photoelectric tristimulus colorimetry with three filters. NBS Circ. C429.

Hunter, R. S. 1958. Photoelectric colour difference meter. J. Opt. Soc. Am. 48:985.

Hunter, R. S. and Harold, R. W. 1987. The Measurement of Appearance. 2nd edition. John Willey and Sons, Inc., New York, New York.

Igor, S. O. 1992. Catalytical deamidation of canola protein in canola meal. M.A.Sc thesis. Department of Chemical Engineering and Applied Chemistry, University of Toronto, Toronto, Ontario.

Igor, S. O., Diosady, L. L., and Rubin, L. J. 1993. Catalytic deamidation of canola proteins. Acta Alimentaria 22:325.

Institute of Food Technologist. 1975. Minutes of sensory evaluation division business meeting at 35th Annual Meeting of Institute of Food Technologists, Chicago, Illinois.

Ismail F., Vaisey-Genser, M., and Fyfe, B. 1981. Bitterness and astrigency of sinapine and its components. J. Food Sci. 46:1241.

Ismail, F. and Eskin, N. A. M. 1979. A new quantitative procedure for determination of sinapine. J. Agric. Food Chem. 27:917.

ISTA. 1998. Oil World Statistics Update. Mielke. GmbH. Hamburg, Germany.

Jones, J. D. 1977. Rapeseed flours, concentrates, isolates: Status and prospects. Proceedings of Rapeseed Oil, Meal and Byproduct Utilization Symposium, Vancouver, British Columbia, Canada.

Jones, J. D. 1979. Rapeseed protein concentrate preparation and evaluation. J. Am. Oil Chem. Soc. 56:716.

Jones, J. D. and Holme, J. 1979. Oilseed processing. U. S. Patent No. 4,158, 656.

Joubert, F. J. 1955. Sunflower seed proteins. Biochim. Biophys. Acta. 16:520.

Keshavarz, E., Cheung, R. K., Lui, R. C. M., and Nakai, S. 1977. Adaptation of the three stage extraction process to rapeseed meal for preparation of colourless protein extracts. Can. Inst. Food Sci. Technol. J. 10:73. 
Kon, S., Olson, A.C., Frederick, D. P., Eggling, S. B., and Wanger, J. R. 1973. Effect of different treatments on phytate and soluble sugars in California white beans. J. Food Sci. 39:215.

Kozlowska, H., Naczk, M., Shahidi, F., and Zadernowski, R. 1990. Phenolic acids and tannins in rapeseed and canola. -in Canola and Rapeseed -Production, Chemistry, Nutrition and Processing Technology. Shahidi, F., Ed. Van Nostrand Reinhold, New York. p. 193.

Kozlowska, H., Rotkiewicz, D. A., Zadernowski, R., and Sosulski, F. W. 1983. Phenolic acids in rapeseed and mustard. J. Am. Oil Chem. Soc. 60:1119.

Kozlowska, H., Sabir, M. A., Sosulski, F. W., and Coxworth, E. 1975. Phenolic constituents in rapeseed flour. Can. Inst. Food Sci. Technol. J. 8:160.

Krygier, K.. Sosulski, F., and Hogge, L. 1982a. Free, esterified, and insoluble-bound phenolic acids. 1. Extraction and purification procedure. J. Agric. Food Chem. 30:330.

Krygier, K., Sosulski, F., and Hogge, L. 1982b. Free, esterified, and insoluble-bound phenolic acids. 2. Composition of phenolic acids in rapeseed flour and hulls. J. Agric. Food Chem. 30:334.

Lawhon, J. T., Manak, L. J., and Lusas, E. W. 1980. An improved process for isolation of glandless cottonseed protein using industrial membrane system. J. Food Sci. 45:197.

Lawhon, J. T., Mulson, D., Cater, C. M., and Mattil, K. F. 1977. Production of protein isolates and concentrates from oilseed flour extracts using industrial ultrafiltration and osmosis systems. J. Food Sci. 42:389.

Leung, J., Fenton, T. W., Mueller, M. M., and Clandinin, D. R. 1979. Condensed tannins of rapeseed meal. J. Food Sci. 44:1313.

Liu, J., Shi, M., Diosady, L. L., and Rubin, L. J. 1995. Three-phase extraction of Chinese rapeseed using the Karr column. J. Food Eng. 24:35.

Lloyd, D. R. and Meluch, T. B. 1985. Selection and evaluation of membrane materials for liquid separations. -in Materials Science of Synthetic Membranes. Lloyd, D. R., Ed. American Chemical Society, Washington, D. C. p.47.

Lo, M. T. and Hill, D. C. 1971. Evaluation of protein concentrates prepared from rapeseed meal. J. Sci. Food Agric. 22:128.

Lonnerdal, B., Gillberg, L., and Tornell, B. 1977. Preparation of rapeseed protein isolate: A study of rapeseed protein isolates by molecular sieve chromatography. J. Food Sci. 42:75.

Loomis, W. D. and Battaile, J. 1966. Plant phenolic compounds and the isolation of plant enzymes. Phytochemistry 5:423. 
Lownang, S. 1994. Reduction of phenolic compounds in pre-press canola meal. B.A.Sc. Thesis. University of Toronto, Toronto, Ontario.

Maga, J. A. and Lorenz, K. 1973. Taste threshold values for phenolic acids which can influence flavour properties of certain flours, grains, and oilseeds. Cereal Sci. Today 18(10):326.

Maheshwari, P. N., Stanley, D. W., and Gray, J. I. 1981. Detoxification of rapeseed products. J. Food Protection 44:459.

Martin, M. M., Rockholm, D. C., and Martin, J. S. 1985. Effects of surfactants, pH, and certain cations on precipitation of proteins by tannins. J. Chem. Ecol. 1 1:485.

Mason, H. S. 1955. Interactions between quinones and proteins. Nature 175:771.

Maubois, J-L. J., Culioli, J., Chopin, A., and Chopin, M. C. 1976. Ultrafiltration progress for obtaining protein isolates of vegetable origin. U. S. Patent 3,993, 636.

McGregor, D. I., Blake, J. A., and Pickard, M. D. 1983. Detoxification of Brassica juncea with ammonia. Proceedings of the 6th International Rapeseed Conference, Paris, France, Vol. II, p. 1426.

McGregor, W. C. 1986. Selection and use of ultrafiltration membranes. -in Membrane Separations in Biotechnology. McGregor, W. C., Ed. Marcel Dekker Inc., New York. p.1.

Meilgaard, M., Civille, G. V., and Carr, B. T. 1987. Sensory Evaluation Techniques. CRC Press, Inc., Boca Raton, Florida.

Michaels, A. S., Nelson, L., and Porter, M. C. 1971. Ultrafiltration. -in Membrane Process in Industry and Biomedicine. Bier, M., Ed. Plenum Press, New York. p.197.

Mikalojcak, K. L. 1970. Phenolic and sugar components of armavirec variety sunflower (Heliamhus ammus) seed meal. J. Agric. Food Chem. 18:27.

Milic, B., Stojanovic, S., Vucurevic, N., and Turcic, M. 1968. Chlorogenic and quinic acids in sunflower meal products. J. Sci. Food Agr. 19:108.

Mitaru, B. N., Blair, R., Bell, J. M., and Rechert, R. D. 1982. Tannin and fiber contents of rapeseed and canola hulls. Can. J. Anim. Sci. 62:661.

Naczk, M., Wanasundara, P. K. J. P. D., and Shahidi, F. 1992. Facile spectrophotometric quantification method of sinapic acid in hexane-extracted and methanol-ammonia-watertreated mustard and rapeseed meals. J. Agric. Food Chem. 40:444. 
O'Dell, B. L. 1969. Effect of dietary components upon zinc availability. Am. J. Clin. Nutri. 22:1315.

Oh, H. I., Hoff, J. E., Armstrong, G. S., and Haff, L. A. 1980. Hydrophobic interactions in tannin-protein complexes. J. Agric. Food Chem. 28:394.

Ohlson, R. 1973. PAG Bulletin 3:21.

Ohlson, R. and Anjou, K. 1979. Rapeseed protein products. J. Am. Oil Chem. Soc. 56:431.

Okubo, K., Waldrop, A. B., lacobucci, G. A., and Myers, D. V. 1975. Preparation of lowphytate soybean protein isolate and concentrate by ultrafiltration. Cereal Chem. 52:263.

Omosaiye, O. and Cheryan, M. 1979. Low-phytate, full-fat soy protein product by ultrafiltration of whole soybeans. Cereal Chem. 56:58.

Owen, D. F. 1973. Detoxification and isolation of rapeseed protein by aqueous saline extraction and isoelectric protein precipitation. U. S. Patent $3,758,452$.

Owen, D. F., Chichester, C. O., Grannadino, J. C., and Monckeberg, F. 1971. A process for producing a non-toxic rapeseed protein isolate and an acceptable feed by-product. Cereal Chem. 48:91.

Pokorny, J., Vodica, M., ard Zalud, J. 1963. Rapeseed. 3. The precipitation of rapeseed proteins from alkaline solutions with diluted acids. Food Technol. 7:167.

Porter, M. R. 1994. Handbook of Surfactants. Blackie Academic and Professional, Glasgow, UK.

Poste L. M., Mackie, D. A., Butler, G., and Larmond E. 1991. Laboratory Methods for Sensory Analysis of Food. Research Branch, Agriculture Canada Publication 1864/E.

Prasad, D. T. 1990. Proteins of the phenolic extracted sunflower meal: 1. Simple method for removal of polyphenolic components and characteristics of salt soluble proteins. Lebensm.Wiss. u. Technol. 23:229.

Prasad, D. T. 1990. Proteins of the phenolic extracted sunflower meal: 1. Simple method for removal of polyphenolic components and characteristics of salt soluble proteins. Lebensm.Wissw. u.-Technol. 23:229.

Price, M. L., Van Scoyoc, S., and Butler, L. G. 1978. A critical evaluation of the vanillin reaction as an assay for tannin in sorghum grain. J. Agric. Food Chem. 26:1214.

Rahma, E. H. and Rao, M. S. N. 1981. Removal of polyphenol from sunflower meal by various solvents: Effects on functional properties. J. Food Sci. 46:1521. 
Rubin, L. J., Diosady, L. L., and Philips, C. R. 1984. Solvent extraction of oil bearing seeds. U. S. Patent No.4,460,504.

Rubin, L. J., Diosady, L. L., Naczk, M., and Halfani, M. 1986. The alkanol-ammoniawater/hexane treatment of canola. Can. Inst. Food Sci. Technol. J. 19:57.

Rubino, M. I., Arntfield, S. D., Nadon, C. A., and Bernatsky, A. 1996. Phenolic protein interactions in relation to the gelation properties of canola protein. Food Res. Intl. 29:653.

Sarwar, G., Blair, R., Friedman, M., Gumbmann, M. R., Hackler, L. R., Pellett, P. L., and Smith, T.K. 1984. Inter- and intra-laboratory variability in rat growth assays for estimating protein quality of foods. J. Assoc. Off. Analyt. Chem. 67:976.

Schnepf, M. I. 1992. Protein-water interactions. In Biochemistry of food proteins. Hudson, B. J. F. Ed. Elsevier Science Publishers, Essex, England. p. 1.

Serraino, M. R. and Thompson, L. U. 1984. Removal of phytic acid and protein-phytic acid interactions in rapeseed. J. Agric. Food Chem. 32:38

Shahidi, F. 1992. Phenolic compounds of Brassica oilseeds. -in Phenolic Compounds in Food and Their Effects on Health I. Ho, C-T., Lee, C. Y., and Huang, M-T., Eds. American Chemical Society, Washington, D. C. p. 130.

Shahidi, F. and Naczk, M. 1989. Effect of processing on the content of condensed tannins in rapeseed meals. J. Food Sci. 54:1082.

Siy, R. D. and Talbot, F. D. F. 1981. Preparation of low-phytate rapeseed protein by ultrafiltration: II. Membrane development and testing. J. Am. Oil Chem. Soc. 58:1021.

Smith, A. K. and Johnson, V. L. 1948. Sunflower seed proteins. Cereal Chem. 25:399.

Smith, C. R., Erale, F. R., and Wolff, I. A. 1959. Comparison of solubility characteristics of selected seed protein. J. Agric. Food Chem. 7:133.

Snedecor, G. W. and Cochran, W. G. 1989. Statistical methods. 8th edition. Iowa State University Press, Ames, Iowa.

Sodini, G. and Canella, M. 1977. Acidic butanol removal of color-forming phenols from sunflower meal. J. Agric. Food Chem.25:822.

Sosulski, F. W., Sabir, M. A., and Fleming, S. E. 1973. Continuous diffusion of chlorogenic acid from sunflower kernels. J. Food Sci. 38:468.

Sosulski, F. W. 1979. Organoleptic and nutritional effects of phenolic compounds on oilseed protein products: A review. J. Am. Oil Chem. Soc. 56:711. 
Sosulski, F. W. and Bakal, A. 1969. Isolated proteins from rapeseed, flax and sunflower meals. Can. Inst. Food Sci. Technol. J. 2:28.

Sosulski, F. W. and Sarwar, G. 1973. Amino acid composition of oilseed meals and protein isolates. Can. Inst. Food Sci. Technol. J. 5:101.

Sosulski, F. W. and Zadernowski, R. 1979. Dehulling of rapeseed or mustard deffated meals. UK Patent 2,005,526.

Sosulsk:, F. W., Soliman, F. S., and Bhatty, R. S. 1972. Diffusion extraction of glucosinolates from rapeseed. Can. Inst. Food Sci. Technol. J. 5:101.

Sripad, G, and Rao, M. S. N. 1987. Effect of methods to remove polyphenols from sunflower meal on the physicochemical properties of the proteins. J. Agric. Food Chem. 35:962.

Tape, N. M., Sabry, Z. I., and Eapen, K. E. 1970. Production of rapeseed flour for human consumption. Can. Inst. Food Sci. Technol. J. 3:78.

Thompson, L. U. 1977. Co-precipitation of rapeseed and cheese whey protein using acid and heat treatment. Can. Inst. Food Sci. J. 10:43.

Thompson, L. U., Poon, P. A., and Procope, C. 1976. Isolation of rapeseed proteins using sodium hexametaphosphate. Can. Inst. Food Sci. Technol. J. 9:15.

Thompson, L. U., Reyes, E., and Jones, J. D. 1982. Modification of the sodium hexametaphosphate extraction-precipitation technique of rapeseed protein concentrate preparation. J. Food Sci. 47:982.

Torchinskii, Y. M. and Dixon, H. B. F. 1974. Sulfhydryl and Disulfide Groups of Proteins. Consultants Bureati, New York, New York.

Tzagoloff A. 1963. Metabolism of sinapine in mustard plants. I. Degradation of sinapine into sinapic acid and choline. Plant Physiol. 38:202.

Tzeng, Y-M. 1987. Process development for the production of high-quality rapeseed (canola) protein isolates using membrane technology. Ph.D. thesis. Department of Chemical Engineering and Applied Chemistry, University of Toronto, Toronto, Ontario.

Tzeng, Y-M., Diosady, L. L., and Rubin, L. J. 1988a. Preparation of a rapeseed protein isolate by sodium hexametaphosphate extraction, ultrafiltration, diafiltration and ion exchange. J. Food Sci. 53:1537.

Tzeng, Y-M., Diosady, L. L., and Rubin, L. J. 1988b. Preparation of rapeseed protein isolate using ultrafiltration, precipitation and diafiltration. Can. Inst. Food Sci. Techno. J. 21:419. 
Tzeng, Y-M., Diosady, L. L., and Rubin, L., J., 1990a. Production of canola protein materials by alkaline extraction, precipitation, and membrane processing. J. Food Sci. 55:1147.

Tzeng, Y-M., Diosady, L. L., and Chen, B. K. 1990b. Ultrafiltration rejection coefficients of canola meal components. Can. Inst. Food Sci. Technol. J. 23:131.

U. S. Soyfoods Directory. 1998. New foods, new uses. www.soyfoods.com.

Vaisey-Genser, M. and Eskin, N. A. M. 1987. Canola Council of Canada Publ. No.60, Winnipeg, Mannitoba.

Van Sumere, C. F., Albrecht, J., Dedonder, A., de Pooter, H., and Pe, I. 1975. Plant proteins and phenolics. -in The Chemistry and Biochemistry of Plant Proteins. Harborne, J. B. and Van Sumere, C. F., Eds. Academic Press, London. p.211.

VanEtten, C. H., Daxenbichler, M. E., and Wolff, I. A. 1969. Natural glucosinolates in foods and feeds. J. Agric. Food Chem. 17:483.

Von Bockelmann, I. V., Dejmek, P., Eriksson, G., and Hallstrom, B. 1977. Potential applications in food processing. -in Reverse Osmosis and Synthetic Membrane. Sourirajan, S., Ed. National Research Council of Canada, Pub. No. NRCC 15627, p.445.

WHO/FAO. 1985. Energy and protein requirements. Report of a joint FAO/WHO/UNU meeting. Technical Report Series No.724. WHO, Geneva, Switzerland.

Williams, V. M. Porter, L. J., and Hemingway, R. W. 1983. Molecular weight profiles of proanthocyanidin polymers. Phytochem. 22:569.

$\mathrm{Xu}$, L. and Diosady, L. L. 1994. Functional properties of Chinese rapeseed protein isolates. J. Food Sci. 59:1127.

Zadernowski, R. and Kozlowska, H. 1983. Phenolic acids in soybean and rapeseed flours. Lebensm. Wiss. technol. 16:110. 


\section{APPENDICES}

\subsection{Determination of Protein Content (Kjeldahl Method, AACC 46-12)}

1. Weigh out each sample in to nitrogen-free paper. The weight of the sample is selected so that the total quantity of nitrogen in the sample is not less than $30 \mathrm{mg}$.

2. Put one sample into each digestion tube and the tubes

3. Add to each tube: 3 pellets of FOSS Tabs and approximately $25 \mathrm{~mL}$ concentrated aqueous $\mathrm{H}_{2} \mathrm{SO}_{4}$ but no more than $25 \mathrm{~mL}$.

4. Preheat Büchi 425 Digester at \#4 setting.

5. Clamp suction tube onto the digestion tubes and turn on suction. Place digestion tubes in heater and heat at \#4 setting for $20 \mathrm{~min}$. Raise heat to $\# 6$ and maintain for $10 \mathrm{~min}$. Increase temperature setting to $\# 10$ and heat for $30 \mathrm{~min}$. Digestion is completed when the mixture in the tubes becomes clear.

6. Turn off Büchi 425 Digester. Remove the digestion tubes from the digester and allow to cool for $30 \mathrm{~min}$.

7. To each digestion tube containing the digested sample carefully add $100 \mathrm{~mL}$ distilled water. Well mix the solution in the tube by shaking the tube gently and allow to cool for another $15 \mathrm{~min}$.

8. Turn on the water flow to Büchi 315 Distillation Unit and warm up the unit.

9. Add to a $500 \mathrm{~mL}$ Erlenmeyer flask $50 \mathrm{~mL} 4 \%$ boric acid solution and 4 drops of $\mathrm{N}$-Point indicator (endpoint colour is light pink).

10. Insert the flask into Büchi 315 and make sure that the end of the end plastic tube is as far below the surface of boric acid solution as possible.

11. Install the digestion tube which contains the digested sample and $150 \mathrm{~mL}$ aqueous $25 \%$ $\mathrm{NaOH}$ solution to it.

12. Distill until $225 \mathrm{~mL}$ of condensate is collected (total of $275 \mathrm{~mL}$ ).

13. Lower the collection flask and rinse the plastic tube with distilled water into the flask.

14. Turn off steam valve and empty the digestion tube by drain.

15. Immediately titrate the collected condensate against $0.1 \mathrm{~N} \mathrm{H}_{2} \mathrm{SO}_{4}$ solution.

16. The nitrogen content of the sample is calculated as: 


$$
N \%=\frac{\left(V-V_{b}\right)}{W} \times N \times 100 \%
$$

where

$$
\begin{aligned}
& \mathrm{V}=\text { volume of } 0.1 \mathrm{~N} \mathrm{H}_{2} \mathrm{SO}_{4} \text { used for sample in } \mathrm{mL} \\
& \mathrm{V}_{\mathrm{b}}=\text { volume of } 0.1 \mathrm{~N} \mathrm{H}_{2} \mathrm{SO}_{4} \text { used for blank in } \mathrm{mL} \\
& \mathrm{N}=\text { normality of } \mathrm{H}_{2} \mathrm{SO}_{4}=0.1 \\
& \mathrm{~W}=\text { weight of sample in } \mathrm{mg}
\end{aligned}
$$

The protein content is further calculated as :

$$
\text { protein } \%=N \% \times 6.25
$$




\subsection{Determination of Sodium Dodecyl Sulphate (SDS) Content}

1. Weigh about two grams of a sample of the protein isolate in a $500 \mathrm{~mL}$ boiling flask.

2. Add $300 \mathrm{~mL}$ distilled water and $15 \mathrm{~mL}$ concentrated $\mathrm{HCl}$ to the flask. Boil the mixture for $1.5 \mathrm{hr}$, and allow to cool for $10 \mathrm{~min}$.

3. Filter the mixture with Whatman No.41 filter paper, and wash the filter cake with approximately $100 \mathrm{~mL}$ hot water.

4. The filtrate with the washing liquid is collected and diluted to $500 \mathrm{~mL}$.

5. A $100 \mathrm{~mL}$ portion of this solution is heated to the boiling point and $\mathrm{BaCl}_{2}$ solution ( $10 \%$ $\mathrm{w} / \mathrm{w}$ ) is added to it slowly until no more precipitate is formed. The boiling continues for another $5 \mathrm{~min}$ or so. The mixture is kept overnight in a forced air oven at $40^{\circ} \mathrm{C}$.

6. The precipitate is collected by filtering through ashless filter paper and wash twice with hot water $(-100 \mathrm{~mL}$ each time) to remove residual free chlorides. It is air dried for $10 \mathrm{hr}$.

7. The dried precipitate is ignited burned in a crucible to constant weight. The amount of barium sulphate is then determined according to AACC Official Method 40-66. 


\subsection{Statistical Analyses}

\subsubsection{Determination of phenolic acid content using different methods}

Phenolic acid analysis of Altex meal (mg/100g meal)

\begin{tabular}{ccccc}
\hline New method & 1702 & 1634 & 1657 & 1739 \\
Naczk et al. & $1+51$ & 1329 & 1253 & 1498 \\
Ismail and Eskin : & 2614 & 2478 & 2230 & 2602 \\
\hline
\end{tabular}

Anova: Single Factor for Altex

SUMMARY

\begin{tabular}{lrrrrr}
\hline \multicolumn{1}{c}{ I lethods } & Count & \multicolumn{1}{c}{ Sum } & Average & Tariance \\
\hline New method & + & 6732 & 1683 & 2191 \\
Naczk et al. & + & 5531 & 1383 & 12555 \\
Ismail and Eskin & + & 9924 & 2481 & 31780 \\
\hline
\end{tabular}

\begin{tabular}{|c|c|c|c|c|c|c|}
\hline $\begin{array}{l}\text { Source of } \\
\text { lariation }\end{array}$ & $S S$ & $d f$ & $.1 S$ & $F$ & P-value & $F$ crit \\
\hline Between Methods & $2577+76$ & 2 & $12 \overline{88738}$ & 83.10 & $1.58 E-06$ & 8.02 \\
\hline Within Methods & 139579 & 9 & 15509 & & & \\
\hline Total & $271705+.92$ & 11 & & & & \\
\hline
\end{tabular}

$F>F_{\text {sit }}$ therefore. there is significant difference among the three methods for phenolic acid analysis in Altex meal $(P \leq 0.01)$.

Phenolic acid analysis of Tower meal (mg/100g meal)

\begin{tabular}{ccccc}
\hline New method & 1724 & 1803 & 1877 & 1688 \\
Naczk et al. & 1328 & 1147 & 1473 & 1224 \\
Ismail and Eskin & 2582 & 2436 & 2605 & 2433 \\
\hline
\end{tabular}

Anova: Single Factor for Tower SUMMARY

\begin{tabular}{lrrrrr}
\hline \multicolumn{1}{c}{ Ifethods } & Count & \multicolumn{1}{c}{ Sum } & Average & Tariance \\
\hline New method & + & 7092 & 1773 & 7114 \\
Naczk et al. & + & 5172 & 1293 & 19901 \\
Ismail and Eskin & + & 10056 & 2514 & 8517 \\
\hline
\end{tabular}

ANOVA

\begin{tabular}{|c|c|c|c|c|c|c|}
\hline $\begin{array}{l}\text { Source of } \\
\text { lariation }\end{array}$ & $\mathbf{S S}$ & $d f$ & $I \boldsymbol{I S}$ & $F$ & $P$-value & F crit \\
\hline Between Methods & 3027096 & 2 & 1513548 & 127.79 & $2.47 \bar{E}-07$ & $\overline{8.02}$ \\
\hline Within Methods & 106594 & 9 & $118+4$ & & & \\
\hline Total & 3133690 & 11 & & & & \\
\hline
\end{tabular}

$F>F_{\text {rirs }}$ therefore. there is significant difference among the three methods for phenolic acid analysis in Tower meal $(\mathrm{P} \leq 0.01)$. 
Phenolic acid analysis of commercial prepress meal ( $\mathbf{m g} / \mathbf{1 0 0 g}$ meal)

\begin{tabular}{|c|c|c|c|c|}
\hline New method & $18+4$ & 1763 & 1662 & 2007 \\
\hline Naczk et al. & 1531 & $1+37$ & $12+8$ & 1501 \\
\hline Ismail and Eskin & 2186 & 2325 & 2152 & 2469 \\
\hline \multicolumn{5}{|c|}{$\begin{array}{l}\text { Anova: Single Factor } \\
\text { SUMMARY }\end{array}$} \\
\hline Iethods & Count & Sum & Average & Tariance \\
\hline New method & $f$ & 7276 & 1819 & 21251 \\
\hline Naczk et al. & 4 & 5717 & $1+29$ & 16138 \\
\hline Ismail and Eskin & 4 & 9132 & 2283 & 20977 \\
\hline
\end{tabular}

ANOVA

\begin{tabular}{|c|c|c|c|c|c|c|}
\hline $\begin{array}{l}\text { Source of } \\
\text { I ariation }\end{array}$ & $S S$ & $d f$ &.$\overline{L S}$ & $F$ & P-value & $F$ crit \\
\hline Between Methods & 1461454 & 2 & 730727 & 37.56 & $+.29 E-05$ & 8.02 \\
\hline Within Methods & 175097 & 9 & $19+55$ & & & \\
\hline Total & 1636550 & 11 & & & & \\
\hline
\end{tabular}

$F>F_{\text {sit }}$. therefore. there is significant difference among the three methods for phenolic acid analysis in commercial prepress meal $(P \leq 0.01)$. 
8.3.2. Effects of the treatments on composition of the products

\section{PPI}

\begin{tabular}{l|cccc}
\hline Treatments & Protein(\%) & LN & LN mean & (LN-LN mean) \\
\hline l.Control & 84.5 & 4.43675 & 4.43852 & $3.14 \mathrm{E}-06$ \\
& 84.8 & 4.44030 & 4.43852 & $3.14 \mathrm{E}-06$ \\
$2 . \mathrm{DF}$ & 87.8 & 4.47506 & 4.47392 & $1.30017 \mathrm{E}-06$ \\
& 87.6 & 4.47278 & +.47392 & $1.30017 \mathrm{E}-06$ \\
& & & & \\
$3 . \mathrm{NaCl}$ & 88.3 & 4.48074 & 4.48300 & $5.10711 \mathrm{E}-06$ \\
& 88.7 & 4.48526 & 4.48300 & $5.10711 \mathrm{E}-06$ \\
$4 . \mathrm{NaCl} \&$ & 73.3 & 4.29456 & 4.29999 & $2.94573 \mathrm{E}-05$ \\
SDS & 74.1 & 4.30542 & 4.29999 & $2.94573 \mathrm{E}-05$ \\
\hline SUM & & & & $7.80092 \mathrm{E}-05$ \\
LN variance & & & & $1.95023 \mathrm{E}-05$ \\
ACV(\%) & & & & 0.44
\end{tabular}

SPI

\begin{tabular}{l|cccc}
\hline Trcatments & Protein(\%) & LN & LN mean & (LN-LN mean) $^{-}$ \\
\hline I.Control & 90.8 & 4.50866 & 4.51195 & $1.08445 \mathrm{E}-05$ \\
& 91.4 & 4.51525 & 4.51195 & $1.08445 \mathrm{E}-05$ \\
& & & & \\
& 92.4 & 4.52613 & 4.52829 & $4.66487 \mathrm{E}-06$ \\
& 92.8 & 4.53045 & 4.52829 & $4.66487 \mathrm{E}-06$ \\
$3 . \mathrm{NaCl}$ & 94.6 & 4.54966 & 4.55229 & $6.94716 \mathrm{E}-06$ \\
& 95.1 & 4.55493 & 4.55229 & $6.94716 \mathrm{E}-06$ \\
& & & & \\
$4 . \mathrm{NaCl} \&$ & 83.6 & 4.42604 & 4.42545 & $3.58135 \mathrm{E}-07$ \\
SDS & 83.5 & 4.42485 & 4.42545 & $3.58135 \mathrm{E}-07$ \\
\hline SUM & & & & $4.56293 \mathrm{E}-05$ \\
LN variance & & & & $1.14073 \mathrm{E}-05$ \\
ACV(\%) & & & & 0.34
\end{tabular}


PPI

\begin{tabular}{|c|c|c|c|c|}
\hline Treatments & $\begin{array}{l}\text { Phenolic } \\
\text { acids } \\
\text { (mg/100 g) }\end{array}$ & LN & LN mean & $(\mathrm{LN}-\mathrm{LN} \text { mean })^{2}$ \\
\hline \multirow[t]{2}{*}{ 1.Control } & 1167 & 7.06219 & $6.99 \overline{36}$ & 0.004465836 \\
\hline & 1021 & 6.92854 & 6.99536 & 0.004465836 \\
\hline \multirow[t]{2}{*}{ 2. DF } & 960 & 6.86693 & 6.82001 & 0.002202092 \\
\hline & 874 & 6.77308 & 6.82001 & 0.002202092 \\
\hline \multirow[t]{2}{*}{$3 . \mathrm{NaCl}$} & 431 & 6.06611 & 6.11048 & 0.001969141 \\
\hline & 471 & 6.15486 & 6.11048 & 0.001969141 \\
\hline 4. $\mathrm{NaCl} \&$ & I 88 & 5.23644 & 5.34159 & 0.01105604 \\
\hline SDS & 232 & 5.44674 & 5.34159 & 0.01105604 \\
\hline \multicolumn{4}{|l|}{ SUM } & 0.039386216 \\
\hline \multirow{2}{*}{\multicolumn{4}{|c|}{$\begin{array}{l}\text { LN variance } \\
\operatorname{ACV}(\%)\end{array}$}} & 0.009846554 \\
\hline & & & & 9.9 \\
\hline
\end{tabular}

SPI

\begin{tabular}{l|cccc}
\hline & $\begin{array}{c}\text { Phenolic } \\
\text { acids } \\
(\mathrm{mg} / \mathrm{l} 00 \mathrm{~g})\end{array}$ & LN & LN mean & (LN-LN mean) \\
\hline Treatments & 1089 & 6.99302 & 6.95881 & 0.001169733 \\
& 1017 & 6.92461 & 6.95881 & 0.001169733 \\
& & & & \\
$2 . \mathrm{DF}$ & 789 & 6.67077 & 6.71210 & 0.001708648 \\
& 857 & 6.75344 & 6.71210 & 0.001708648 \\
$3 . \mathrm{NaCl}$ & 489 & 6.19236 & 6.15191 & 0.001636006 \\
& 451 & 6.11147 & 6.15191 & 0.001636006 \\
$4 . \mathrm{NaCl} \&$ & 254 & 5.53733 & 5.47893 & 0.003410517 \\
SDS & 226 & 5.42053 & 5.47893 & 0.003410517 \\
\hline SUM & & & & 0.01584981 \\
LN variance & & & & 0.003962453 \\
ACV(\%) & & & & 6.3
\end{tabular}


PPI

\begin{tabular}{l|cccc}
\hline Treatments & $\begin{array}{c}\text { Tannins } \\
(\mathrm{mg} / 100 \mathrm{~g})\end{array}$ & LN & LN mean & $(\text { LN-LN mean) })^{2}$ \\
\hline l.Control & 692 & 6.53959 & 6.51440 & 0.000634562 \\
& 658 & 6.48920 & 6.51440 & 0.000634562 \\
$2 . \mathrm{DF}$ & 423 & 6.04737 & 6.12191 & 0.005555611 \\
& 491 & 6.19644 & 6.12191 & 0.005555611 \\
$3 . \mathrm{NaCl}$ & 367 & 5.90536 & 5.84613 & 0.003508457 \\
& 326 & 5.78690 & 5.84613 & 0.003508457 \\
\hline SUM & & & & 0.019397262 \\
LN variance & & & & 0.006465754 \\
ACV(\%) & & & & 8.0
\end{tabular}

SPI

\begin{tabular}{l|cccc}
\hline Treatments & $\begin{array}{c}\text { Tannins } \\
(\mathrm{mg} / 100 \mathrm{~g})\end{array}$ & LN & LN mean & (LN-LN mean) \\
\hline 1.Control & 811 & 6.69827 & 6.74643 & 0.002319315 \\
& 893 & 6.79459 & 6.74643 & 0.002319315 \\
& & & & \\
& 667 & 6.50279 & 6.47346 & 0.000860213 \\
& 629 & 6.44413 & 6.47346 & 0.000860213 \\
$3 . \mathrm{NaCl}$ & 538 & 6.28786 & 6.33059 & 0.001825905 \\
& 586 & 6.37332 & 6.33059 & 0.001825905 \\
\hline SUM & & & & 0.010010867 \\
LN variance & & & & 0.003336956 \\
ACV(\%) & & & & 5.8
\end{tabular}


8.3.3. Effects of reduced SDS amount and elimination of second diafiltration on composition of the products

PPI

\begin{tabular}{l|cccc}
\hline Processes & Protein(\%) & LN & LN mean & (LN-LN mean) $^{-}$ \\
\hline Excess & 73.3 & 4.29456 & 4.29999 & $2.94573 \mathrm{E}-05$ \\
amount of & 74.1 & 4.30542 & 4.29999 & $2.94573 \mathrm{E}-05$ \\
SDS & & & & \\
& & & & \\
Reduced & 87.4 & 4.47050 & 4.46820 & $5.26052 \mathrm{E}-06$ \\
amount of & 87.0 & 4.46591 & 4.46820 & $5.26052 \mathrm{E}-06$ \\
SDS & & & & \\
Elimination & 86.5 & 4.46014 & 4.46417 & $1.62406 \mathrm{E}-05$ \\
of second & 87.2 & 4.46820 & 4.46417 & $1.62406 \mathrm{E}-05$ \\
diafiltration & & & & \\
\hline SUM & & & & 0.000101917 \\
LN variance & & & & $3.39723 \mathrm{E}-05$ \\
ACV(\%) & & & & 0.58
\end{tabular}

\section{SPI}

\begin{tabular}{l|cccc}
\hline Processes & Protein(\%) & LN & LN mean & (LN-LN mean) $^{-}$ \\
\hline Excess & 83.6 & 4.42604 & 4.42425 & $3.23095 \mathrm{E}-06$ \\
amount of & 83.3 & 4.42245 & 4.42425 & $3.23095 \mathrm{E}-06$ \\
SDS & & & & \\
& & & & \\
Reduced & 92.1 & 4.52287 & 4.52450 & $2.64393 \mathrm{E}-06$ \\
amount of & 92.4 & 4.52613 & 4.52450 & $2.64393 \mathrm{E}-06$ \\
SDS & & & & \\
Elimination & 86.2 & 4.45667 & 4.45841 & $3.01758 \mathrm{E}-06$ \\
of second & 86.5 & 4.46014 & 4.45841 & $3.01758 \mathrm{E}-06$ \\
diafiltration & & & & \\
\hline SUM & & & & $1.77849 \mathrm{E}-05$ \\
LN variance & & & & $5.92831 \mathrm{E}-06$ \\
ACV(\%) & & & & 0.24
\end{tabular}




\section{PPI}

\begin{tabular}{|c|c|c|c|c|}
\hline Processes & $\begin{array}{c}\text { Phenolic } \\
\text { acids } \\
\text { (mg/100 g) }\end{array}$ & LN & LN mean & $(\mathrm{LN}-\mathrm{LN} \text { mean })^{2}$ \\
\hline Excess & 188 & 5.23644 & 5.34159 & 0.01105604 \\
\hline $\begin{array}{l}\text { amount of } \\
\text { SDS }\end{array}$ & 232 & 5.44674 & 5.34159 & 0.01105604 \\
\hline Reduced & 312 & 5.74300 & 5.70644 & 0.001336716 \\
\hline $\begin{array}{l}\text { amount of } \\
\text { SDS }\end{array}$ & 290 & 5.66988 & 5.70644 & 0.001336716 \\
\hline Elimination & 299 & 5.70044 & 5.73594 & 0.001260163 \\
\hline $\begin{array}{l}\text { of second } \\
\text { diafiltration }\end{array}$ & 321 & 5.77144 & 5.73594 & 0.001260163 \\
\hline$\overline{\text { SUM }}$ & & & & 0.027305838 \\
\hline LN variance & & & & 0.009101946 \\
\hline $\operatorname{ACV}(\%)$ & & & & 9.5 \\
\hline
\end{tabular}

SPI

\begin{tabular}{l|cccc}
\hline & $\begin{array}{c}\text { Phenolic } \\
\text { acids } \\
(\mathrm{mg} / 100 \mathrm{~g})\end{array}$ & $\mathrm{LN}$ & LN mean & (LN-LN mean) \\
Processes & 254 & 5.53733 & 5.47893 & 0.003410517 \\
\hline $\begin{array}{l}\text { Excess } \\
\text { amount of }\end{array}$ & 226 & 5.42053 & 5.47893 & 0.003410517 \\
SDS & & & & \\
$\begin{array}{l}\text { Reduced } \\
\text { amount of }\end{array}$ & 334 & 5.81114 & 5.84304 & 0.001017283 \\
SDS & 356 & 5.87493 & 5.84304 & 0.001017283 \\
$\begin{array}{l}\text { Elimination } \\
\text { of second } \\
\text { diafiltration }\end{array}$ & 282 & 5.64191 & 5.65933 & 0.000303574 \\
$\begin{array}{l}\text { SUM } \\
\text { LN variance }\end{array}$ & 292 & 5.67675 & 5.65933 & 0.000303574 \\
ACV(\%) & & & & 0.009462747 \\
& & & & 0.003154249 \\
\end{tabular}




\section{PPI}

\begin{tabular}{l|cccc}
\hline Processes & $\begin{array}{c}\text { Tannins } \\
(\mathrm{mg} / \mathrm{l00} \mathrm{g})\end{array}$ & LN & LN mean & $(\text { LN-LN mean) })^{2}$ \\
\hline Excess & 38 & 3.63759 & 3.38654 & 0.06302408 \\
amount of & 23 & 3.13549 & 3.38654 & 0.06302408 \\
SDS & & & & \\
Reduced & 55 & 4.00733 & 4.12072 & 0.012856535 \\
amount of & 69 & 4.23411 & 4.12072 & 0.012856535 \\
SDS & & & & \\
& 52 & 3.95124 & 3.92153 & 0.000882786 \\
Elimination & 49 & 3.89182 & 3.92153 & 0.000882786 \\
of second & & & & 0.153526801 \\
diafiltration & & & & 0.0511756 \\
SUM & & & & 22.6 \\
LN variance & & & &
\end{tabular}

SPI

\begin{tabular}{l|cccc}
\hline Processes & $\begin{array}{c}\text { Tannins } \\
(\mathrm{mg} / 100 \mathrm{~g})\end{array}$ & LN & LN mean & (LN-LN mean) $)^{2}$ \\
\hline Excess & 38 & 3.63759 & 3.38654 & 0.06302408 \\
amount of & 23 & 3.13549 & 3.38654 & 0.06302408 \\
SDS & & & & \\
Reduced & 30 & 3.40120 & 3.51939 & 0.013969914 \\
amount of & 38 & 3.63759 & 3.51939 & 0.013969914 \\
SDS & & & & \\
Elimination & 32 & 3.46574 & 3.55166 & 0.007383128 \\
of second & 38 & 3.63759 & 3.55166 & 0.007383128 \\
diafiltration & & & & 0.168754243 \\
\hline $\begin{array}{l}\text { SUM } \\
\text { LN variance }\end{array}$ & & & & 0.056251414 \\
ACV(\%) & & & & 23.7
\end{tabular}




\subsubsection{Effects of PVP on removal of phenolic acids}

Concentrations of phenolic acid not removed by $\mathrm{PVP}$ in the $\mathrm{pH} 3.5$ solution $(\mathrm{mg} / \mathrm{mL})$

\begin{tabular}{lccc}
\hline & No PVP & $10 \%$ PVP & $20 \%$ PVP \\
\hline Run I & 0.0201 & 0.0101 & 0.0114 \\
& 0.0221 & 0.0092 & 0.0118 \\
Run2 & 0.0184 & 0.0124 & 0.0109 \\
& 0.0207 & 0.0112 & 0.0097 \\
\hline
\end{tabular}

Anova: Two-Factor With Replication

\begin{tabular}{lrrrr}
\hline $\begin{array}{l}\text { SUMMARY } \\
\text { Rum I }\end{array}$ & O PVP & $10 \%$ PVP & $20 \%$ PVP & \multicolumn{1}{l}{ Total } \\
\hline Count & & & & \\
Sum & 2 & 2 & 2 & 6 \\
Average & 0.0422 & 0.0193 & 0.0232 & $0.08+7$ \\
Variance & 0.0211 & 0.00965 & 0.0116 & $0.01+1$ \\
& $2 \mathrm{E}-06$ & $4.05 \mathrm{E}-07$ & $8 \mathrm{E}-08$ & $3.05 \mathrm{E}-05$
\end{tabular}

Run?

\begin{tabular}{lrrrr}
\hline Count & 2 & 2 & 2 & 6 \\
Sum & 0.0391 & 0.0236 & 0.0206 & 0.0833 \\
Average & 0.0196 & 0.0118 & 0.0103 & 0.0139 \\
Variance & $2.65 \mathrm{E}-06$ & $7.20 \mathrm{E}-07$ & $7.20 \mathrm{E}-07$ & $2.05 \mathrm{E}-05$
\end{tabular}

Total

\begin{tabular}{lrrr}
\hline Count & 4 & + & + \\
Sum & 0.0813 & 0.0429 & 0.0438 \\
Average & 0.0203 & 0.0107 & 0.0110 \\
Variance & $2.35 \mathrm{E}-06$ & $1.92 \mathrm{E}-06$ & $8.3 \mathrm{E}-07$ \\
\hline
\end{tabular}

ANOVA

\begin{tabular}{|c|c|c|c|c|c|c|}
\hline Source of lariation & $S S$ & $d f$ & $I / S$ & $F$ & P-value & $F_{\text {crit }}$ \\
\hline Runs & $1.63 \mathrm{E}-07$ & $\bar{l}$ & $1.63 \mathrm{E}-07$ & 0.15 & 0.71 & 5.99 \\
\hline Treatments & 2. $40 \mathrm{E}-1) 4$ & 2 & $1.20 \mathrm{E}-04$ & 109.65 & 0.00 & 5.14 \\
\hline Interactions & $8.55 E-06$ & 2 & $+.28 \mathrm{E}-06$ & 3.90 & 0.08 & 5.14 \\
\hline Within & $6.57 \mathrm{E}-06$ & 6 & 1. $10 \mathrm{E}-06$ & & & \\
\hline
\end{tabular}

Total $0.000255 \quad 11$

For the treatments. since $F>F_{\text {crit. }}$ there is significant difference among the treatments $(\mathrm{P} \leq 0.05)$. but eventhing else is insignificant.

Dunnetts test (one-tailed):

$$
\mathrm{SEM}=\sqrt{0.00000110 / 4}=0.000524
$$

For two treatments (excluding the control) and 11 degrees of freedom:

$$
\operatorname{LSD}(P=0.05)=2.13 \times \sqrt{2} \times 0.000524=0.00158
$$

Compare the control with each mean:

$$
\begin{aligned}
& \text { No PVP }-20 \% \text { PVP }=0.0211-0.0116=0.0095>0.00158 \\
& \text { No PVP }-10 \% \text { PVP }=0.0211-0.00965=0.0115>0.00158
\end{aligned}
$$

Therefore. it is concluded that PVP treatment has significant effects on the removal of phenolic acids in pH 3.5 solution. 
8.3.5. Effects of $\mathrm{Na}_{2} \mathrm{SO}_{3}$ on removal of phenolic acids

Concentrations of phenolic acid released by $\mathrm{Na}_{2} \mathrm{SO}_{3}(\mathrm{mg} / \mathrm{mL})$

\begin{tabular}{lccc}
\hline & $\mathrm{No} \mathrm{Na}_{2} \mathrm{SO}_{3}$ & $0.1 \% \mathrm{Na}_{2} \mathrm{SO}_{3}$ & $0.5 \% \mathrm{Na}_{2} \mathrm{SO}_{3}$ \\
\hline Run I & 0.0051 & $0.00+1$ & 0.0039 \\
& 0.0049 & 0.0048 & 0.0052 \\
Run II & 0.0057 & 0.0052 & \\
& 0.0051 & 0.0048 & \\
\hline
\end{tabular}

Anova: Two-Factor With Replication

\begin{tabular}{|c|c|c|c|}
\hline $\begin{array}{l}\text { SUMMARY } \\
R u n l\end{array}$ & $\mathrm{No} \mathrm{Na}_{2} \mathrm{SO}_{3}$ & $0.1 \% \mathrm{Na}_{2} \mathrm{SO}_{3}$ & Total \\
\hline Count & 2 & 2 & 4 \\
\hline Sum & 0.01 & 0.0089 & 0.0189 \\
\hline Average & 0.005 & $0.00+45$ & 0.0047 \\
\hline Variance & $2 E-08$ & $2 .+5 E-07$ & $1.89167 E-07$ \\
\hline \multicolumn{4}{|l|}{ Rum II } \\
\hline$\overline{\text { Count }}$ & 2 & 2 & 4 \\
\hline Sum & 0.0108 & 0.01 & 0.0208 \\
\hline Average & 0.0054 & 0.005 & 0.0052 \\
\hline Variance & $1.8 \mathrm{E}-07$ & $8 E-08$ & 0.0000 \\
\hline \multicolumn{4}{|l|}{ Total } \\
\hline Count & $t$ & 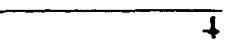 & \\
\hline Sum & 0.0208 & 0.0189 & \\
\hline Average & 0.0052 & $0.00+73$ & \\
\hline Variance & $1.2 \mathrm{E}-07$ & $2.09 \mathrm{E}-07$ & \\
\hline
\end{tabular}

ANOVA

\begin{tabular}{|c|c|c|c|c|c|c|}
\hline $\begin{array}{l}\text { Source of } \\
\text { l'ariation }\end{array}$ & $S S$ & & $I / S$ & $F$ & $P$-value & $F$ crit \\
\hline Runs & $4.51 E-07$ & I & $+.51 \mathrm{E}-07$ & 3.44 & 0.14 & $\overline{7.71}$ \\
\hline Treatments & $+.51 E-07$ & ! & $+.51 \mathrm{E}-07$ & 3.44 & 0.14 & 7.71 \\
\hline Interactions & $1.13 E-08$ & 1 & $1.13 E-08$ & 0.09 & 0.78 & 7.71 \\
\hline Within & $5.25 E-07$ & 4 & $1.31 E-07$ & & & \\
\hline Total & $1 .+4 E-06$ & 7 & & & & \\
\hline
\end{tabular}

For the treatments, since $F<F_{\text {cris. }}$ there is no significant difference among the treatments $(P \leq 0.05)$. 
8.3.6. Comparison in composition of the products from different modified processes

\section{PPI}

\begin{tabular}{l|cccc}
\hline Processes & Protein(\%) & LN & LN mean & (LN-LN mean) \\
\hline Control & 84.5 & 4.43675 & 4.43852 & $3.14 \mathrm{E}-06$ \\
& 84.8 & 4.44030 & 4.43852 & $3.14 \mathrm{E}-06$ \\
& & & & \\
Earlier & 87.4 & 4.47050 & 4.46820 & $5.26052 \mathrm{E}-06$ \\
modified & 87.0 & 4.46591 & 4.46820 & $5.26052 \mathrm{E}-06$ \\
& & & & \\
Further & 87.6 & 4.47278 & 4.46588 & $4.75639 \mathrm{E}-05$ \\
modified & 86.4 & 4.45899 & 4.46588 & $4.75639 \mathrm{E}-05$ \\
\hline SUM & & & & 0.000111929 \\
LN variance & & & & $3.73096 \mathrm{E}-05$ \\
ACV(\%) & & & & 0.61
\end{tabular}

\section{SPI}

\begin{tabular}{l|cccc}
\hline Processes & Protein(\%) & LN & LN mean & (LN-LN mean) $^{-}$ \\
\hline Control & 90.8 & 4.50866 & 4.51195 & $1.08445 \mathrm{E}-05$ \\
& 91.4 & 4.51525 & 4.51195 & $1.08445 \mathrm{E}-05$ \\
& & & & \\
Earlier & 92.1 & 4.52287 & 4.52450 & $2.64393 \mathrm{E}-06$ \\
modified & 92.4 & 4.52613 & 4.52450 & $2.64393 \mathrm{E}-06$ \\
& & & & \\
Further & 90.8 & 4.50866 & 4.51741 & $7.65023 \mathrm{E}-05$ \\
modified & 92.4 & 4.52613 & 4.51741 & $7.60582 \mathrm{E}-05$ \\
& 91.6 & 4.51743 & 4.51741 & $6.465 \mathrm{E}-10$ \\
\hline SUM & & & & 0.000179537 \\
LN variance & & & & $4.48843 \mathrm{E}-05$ \\
ACV(\%) & & & & 0.67
\end{tabular}


PPI

\begin{tabular}{l|cccc}
\hline & $\begin{array}{c}\text { Phenolic } \\
\text { acids } \\
(\mathrm{mg} / 100 \mathrm{~g})\end{array}$ & LN & LN mean & (LN-LN mean) \\
Processes & 1167 & 7.06219 & 6.99536 & 0.004465836 \\
\hline Control & 1021 & 6.92854 & 6.99536 & 0.004465836 \\
& 312 & 5.74300 & 5.70644 & 0.001336716 \\
Earlier & 290 & 5.66988 & 5.70644 & 0.001336716 \\
modified & & & & \\
Further & 276 & 5.62040 & 5.61126 & $8.35583 \mathrm{E}-05$ \\
modified & 271 & 5.60212 & 5.61126 & $\mathbf{8 . 3 5 5 8 3 \mathrm { E } - 0 5}$ \\
\hline SUM & & & & 0.01177222 \\
LN variance & & & & 0.003924073 \\
ACV(\%) & & & & 6.3
\end{tabular}

SPI

\begin{tabular}{l|cccc}
\hline & $\begin{array}{c}\text { Phenolic } \\
\text { acids } \\
(\mathrm{mg} / 100 \mathrm{~g})\end{array}$ & LN & LN mean & (LN-LN mean) \\
Processes & 1089 & 6.99302 & 6.95881 & 0.001169733 \\
\hline Control & 1017 & 6.92461 & 6.95881 & 0.001169733 \\
& & & & \\
Earlier & 334 & 5.81114 & 5.84304 & 0.001017283 \\
modified & 356 & 5.87493 & 5.84304 & 0.001017283 \\
& & & & \\
Further & 131 & 4.87520 & 4.83549 & 0.001576359 \\
modified & 121 & 4.79579 & 4.83549 & 0.001576359 \\
\hline SUM & & & & 0.00752675 \\
LN variance & & & & 0.002508917 \\
ACV(\%) & & & & 5.0
\end{tabular}




\subsubsection{Comparison between $10 \%$ and $1 \%$ PVP treatment on SPI}

\begin{tabular}{l|cccc}
\hline $\begin{array}{l}\text { PVP } \\
\text { treatment }\end{array}$ & $\begin{array}{c}\text { Protein } \\
(\%)\end{array}$ & LN & LN mean & (LN-LN mean) \\
\hline $10 \%$ & 90.8 & 4.50866 & 4.51741 & $7.65023 \mathrm{E}-05$ \\
& 92.4 & 4.52613 & 4.51741 & $7.60582 \mathrm{E}-05$ \\
& 91.6 & 4.51743 & 4.51741 & $6.465 \mathrm{E}-10$ \\
& & & & \\
$1 \%$ & 91.2 & 4.51305 & 4.51141 & $2.71408 \mathrm{E}-06$ \\
& 90.9 & 4.50976 & 4.51141 & $2.71408 \mathrm{E}-06$ \\
\hline SUM & & & & 0.000157989 \\
LN variance & & & & $5.26631 \mathrm{E}-05$ \\
ACV(\%) & & & & 0.7
\end{tabular}

\begin{tabular}{l|cccc}
\hline $\begin{array}{l}\text { PVP } \\
\text { treatment }\end{array}$ & $\begin{array}{c}\text { Phenolic } \\
\text { acid } \\
(\mathrm{mg} / \mathrm{l} 00 \mathrm{~g})\end{array}$ & LN & LN mean & (LN-LN mean) \\
\hline $10 \%$ & 131 & 4.87520 & 4.83549 & 0.001576359 \\
& 121 & 4.79579 & 4.83549 & 0.001576359 \\
$1 \%$ & 120 & 4.78749 & 4.73016 & 0.003286896 \\
& 107 & 4.67283 & 4.73016 & 0.003286896 \\
\hline SUM & & & & 0.009726509 \\
LN variance & & & & 0.004863255 \\
ACV(\%) & & & & 7.0
\end{tabular}




\subsubsection{Sensory evaluation}

Anova: Two-Factor Without Replication for PPI taste intensity

\begin{tabular}{|c|c|c|c|c|}
\hline SLIALARY & Count & Sum & Average & Tariance \\
\hline Panelist 1 & 6 & 54.0 & 9.00 & 37.18 \\
\hline Panelist 2 & 6 & 40.7 & 6.78 & 12.73 \\
\hline Panelist 3 & 6 & 42.2 & 7.03 & 11.28 \\
\hline Panelist 4 & 6 & 48.6 & 8.10 & $2+.63$ \\
\hline Panclist 5 & 6 & 50.1 & 8.35 & 8.15 \\
\hline Panelist 6 & 6 & 40.6 & 6.77 & +.67 \\
\hline Panelist 7 & 6 & 59.7 & 9.95 & 23.45 \\
\hline Panelist 8 & 6 & +7.6 & 7.93 & 10.84 \\
\hline Panelist 9 & 6 & 43.9 & 7.32 & 10.31 \\
\hline Panelist 10 & 6 & 44.0 & 7.33 & 30.29 \\
\hline Panelist 11 & 6 & +4.3 & 7.38 & 25.55 \\
\hline Panelist 12 & 6 & 52.4 & 8.73 & 18.76 \\
\hline Panelist 13 & 6 & 61.3 & 10.22 & 11.75 \\
\hline Panelist 14 & 6 & 47.5 & 7.92 & 14.70 \\
\hline Control & 14 & 161.2 & 11.5 & 5.47 \\
\hline DF & 14 & 169.3 & 12.1 & 8.94 \\
\hline $\mathrm{NaCl}$ & 14 & 115.4 & 8.2 & 12.67 \\
\hline Earlict modified & 14 & 101.7 & 7.3 & 2.14 \\
\hline Further moditied & 14 & 67.9 & 4.9 & 5.05 \\
\hline Soy protein & 14 & 61.4 & 4.4 & 10.16 \\
\hline
\end{tabular}

ANOVA

\begin{tabular}{lrrrrrr}
\hline $\begin{array}{l}\text { Source of } \\
\text { Iariation }\end{array}$ & SS & df & \multicolumn{1}{c}{ IS } & F & P-value & F crit \\
\hline Panelists & 93.5 & 13 & 7.19 & 0.97 & 0.49 & 1.87 \\
Processes & 737.3 & 5 & $1+7.47$ & 19.80 & 0.00 & 2.36 \\
Error & 484.1 & 65 & 7.45 & & & \\
& & & & & & \\
Total & 1314.9 & 83 & & & & \\
\hline
\end{tabular}

Turkey'test for PPI taste intensity:

$$
\operatorname{SEM}=\sqrt{7 .+5 / 14}=0.73
$$

For six treatments and 65 degrees of freedom: $\operatorname{LSD}(P=0.05)=4.16 \times 0.73=3.04$

Compare each process mean with the others:
$11.5+4.4=7.1>3.04$
$11.5-4.9=6.6>3.04$
$12.1-4.9=7.2>3.04$
$12.1-7.3=4.8>3.04$
$12.1-8.2=3.8>3.04$
$8.2-4 . t=3.8>3.04$
$11.5-8.2=3.3>3.04$
$8.2-4.9=3.3>3.04$
$12.1-1 ! .5=0.6<3.04$
$8.2-7.3=0.9<3.04$
$12.1+t .4=7.7>3.04$

$7.3-4 . t=2.9<3.04$

$7.3-4.9=2.4<3.04$

$+.9+.4=0.5<3.04$ 
Anova: Two-Factor Without Replication for PPI pleasantness

\begin{tabular}{|c|c|c|c|c|}
\hline$S L I A L U R F$ & Count & Sum & Average & lariance \\
\hline Panelist I & 6 & 35.9 & 5.98 & 36.80 \\
\hline Panelist 2 & 6 & $\$ 7.0$ & 7.83 & 12.97 \\
\hline Panelist 3 & 6 & 39.1 & 6.52 & 9.34 \\
\hline Panelist 4 & 6 & 29.1 & 4.85 & 14.78 \\
\hline Panclist 5 & 6 & +1.4 & 6.90 & 4.39 \\
\hline Panclist 6 & 6 & +6.9 & 7.82 & 2.32 \\
\hline Panelist 7 & 6 & 34.8 & 5.80 & 10.67 \\
\hline Panelist 8 & 6 & 45.1 & 7.52 & +.47 \\
\hline Panelist 9 & 6 & +4.5 & 7.42 & 17.28 \\
\hline Panclist 10 & 6 & 47.2 & 7.87 & 15.46 \\
\hline Panelist I I & 6 & 46.0 & 7.67 & 21.74 \\
\hline Panelist 12 & 6 & 33.1 & 5.52 & 16.33 \\
\hline Panelist 13 & 6 & 25.4 & 4.23 & 9.73 \\
\hline Panelist $1+$ & 6 & 39.9 & 6.65 & 15.74 \\
\hline Control & 14 & 68.2 & 4.87 & 10.72 \\
\hline DF & 14 & 57.5 & +.11 & 14.88 \\
\hline $\mathrm{NaCl}$ & 14 & 83.5 & 5.96 & 10.39 \\
\hline Earlict moditicd & 14 & $108 . t$ & 7.74 & +.98 \\
\hline Further moditied & 14 & 110.3 & 7.88 & 9.01 \\
\hline Soy protein & 14 & 127.5 & 9.11 & 12.01 \\
\hline
\end{tabular}

\begin{tabular}{|c|c|c|c|c|c|c|}
\hline $\begin{array}{l}\text { Source of } \\
\text { lariation }\end{array}$ & $\overline{S S}$ & $d f$ & $\overline{I S}$ & $\bar{F}$ & P-ivalue & $F$ crit \\
\hline Panclists & 109.2 & 13 & 8.40 & 0.78 & 0.67 & 1.87 \\
\hline Processes & 263.7 & 5 & 52.73 & 4.92 & 0.00 & 2.36 \\
\hline Error & 696.5 & 65 & 10.72 & & & \\
\hline Total & 1069.4 & 83 & & & & \\
\hline
\end{tabular}

Turkey's test for PPI pleasantness:

$$
\operatorname{SEM}=\sqrt{10.72 / 14}=0.87
$$

For six treatments and 65 degrees of freedom: $\operatorname{LSD}(P=0.05)=4.16 \times 0.87=3.62$

Compare ach process mean with the others:

$9.1-4.87=4.24>3.62$

$9.11-4.11=5.00103 .62$

$9.11-5.96=3.15<3.62$

$9.11-7.7+=1.37<3.62$

$9.11-7.88=1.23<3.62$
$7.88+.87=3.01<3.62$

$7.88+.11=3.77>3.62$

$7.88-5.96=1.92<3.62$

$7.88-7.7+=0.1+<3.62$
$7.7+4.87=2.87<3.62$

$7.74+1.11=3.63>3.62$

$7.7+-5.96=1.78<3.62$
$5.96-4.87=1.09<3.62$ $5.96-4.11=1.85<3.62$

$+.87+.11=0.76<3.62$ 
Anova: Two-Factor Without Replication for SPI taste intensity

\begin{tabular}{lrrrr}
\hline \multicolumn{1}{c}{ SCIA LARI } & Count & \multicolumn{1}{c}{ Sum } & Average & Tariance \\
\hline Panelist 1 & 6 & +2.1 & 7.02 & 13.31 \\
Panelist 2 & 6 & 32.8 & 5.47 & 6.05 \\
Panelist 3 & 6 & 39.8 & 6.63 & 9.08 \\
Panelist 4 & 6 & 61.8 & 10.30 & 9.33 \\
Panelist 5 & 6 & 56.1 & 9.35 & 15.88 \\
Panelist 6 & 6 & 48.7 & 8.12 & 21.62 \\
Panclist 7 & 6 & 60.1 & 10.02 & 7.59 \\
Panclist 8 & 6 & +5.7 & 7.62 & 12.18 \\
Panclist 9 & 6 & +5.7 & 7.62 & 1.45 \\
Panclist 10 & 6 & 42.6 & 7.10 & 7.15 \\
Panelist 11 & 6 & 46.3 & 7.72 & 4.65 \\
Panelist 12 & 6 & 56.1 & 9.35 & 8.42 \\
Panelist 13 & 6 & 48.1 & 8.02 & 8.69 \\
& & & & \\
Control & 13 & 128.2 & 9.9 & 10.48 \\
DF & 13 & $1+1.7$ & 10.9 & 7.13 \\
NaCl & 13 & 103 & 7.9 & 2.38 \\
Earlict moditied & 13 & 87.8 & 6.8 & 4.39 \\
10\% PVP & 13 & 81.5 & 6.3 & 10.37 \\
1\% PVP & 13 & 83.7 & 6.4 & 8.80 \\
\hline
\end{tabular}

ANOVA

\begin{tabular}{lrrrrrr}
\hline $\begin{array}{l}\text { Source of } \\
\text { rariation }\end{array}$ & $S S$ & $d f$ & \multicolumn{1}{c}{ SS } & $F$ & P-value & F crit \\
\hline Panclists & $1+0.67$ & 12 & 11.72 & 1.84 & 0.06 & 1.92 \\
Processes & 245.24 & 5 & +9.05 & 7.71 & 0.00 & 2.37 \\
Error & 381.76 & 60 & 6.36 & & & \\
& & & & & & \\
Total & 767.66 & 77 & & & & \\
\hline
\end{tabular}

Turkcy's test for SPI tatse intensity

$$
\operatorname{SEM}=\sqrt{6.36 / 13}=0.70
$$

For six treatments and 60 degrees of freedom: $L S D=4.16 \times 0.70=2.91$

Compare each process mean with the others:

$9.9-6.4=3.5>2.91$

$9.9-6.3=3.6>2.91$

$9.9-6.8=3.1>2.91$

9.9-7.9=2.0<2.91

$10.9-9.9=1.0<2.91$

$\begin{array}{ll}10.9-6 . t=4.5>2.91 & 7.9-6.4=1.5<2.91 \\ 10.9-6.3=4.6>2.91 & 7.9-6.3=1.6<2.91 \\ 10.9-6.8=4.1>2.91 & 7.9-6.8=1.1<2.91\end{array}$

$6.8-6 . t=0 . t<2.91$

$6.8-6.3=0.5<2.91$

$6 .+-6.3=0.1<2.91$ 
Anova: Two-Factor Without Replication for SPI taste pleasantness

\begin{tabular}{lrrrr}
\hline \multicolumn{1}{c}{ SCIML-LRI } & Count & \multicolumn{1}{c}{ Sum } & .Average & Tariance \\
\hline Panelist 1 & 6 & +1.9 & 6.98 & 5.33 \\
Panclist 2 & 6 & 55.3 & 9.22 & 5.41 \\
Panelist 3 & 6 & +9.5 & 8.25 & 16.77 \\
Panelist 4 & 6 & 29.2 & 4.87 & 12.28 \\
Panelist 5 & 6 & 31.9 & 5.32 & 12.90 \\
Panelist 6 & 6 & 36.9 & 6.15 & 17.81 \\
Panelist 7 & 6 & 37.8 & 6.30 & 11.88 \\
Panelist 8 & 6 & 38.6 & 6.43 & 3.51 \\
Panclist 9 & 6 & 4.5 & 7.42 & 1.82 \\
Panelist 10 & 6 & 26.8 & 4.47 & 6.51 \\
Panclist 11 & 6 & 31.3 & 5.22 & 2.91 \\
Panclist 12 & 6 & 37.8 & 6.30 & 8.65 \\
Panclist 13 & 6 & 32.8 & 5.47 & 8.93 \\
& & & & \\
Control & 13 & 62.6 & 4.8 & 10.25 \\
DF & 13 & 47.0 & 3.6 & 7.31 \\
NaCl & 13 & 85.1 & 6.5 & 6.49 \\
NaCl \& SDS & 13 & 95.0 & 7.3 & 4.95 \\
10\% PVP & 13 & 103.3 & 7.9 & 4.59 \\
1\% PVP & 13 & 101.3 & 7.8 & 8.66 \\
\hline
\end{tabular}

\begin{tabular}{|c|c|c|c|c|c|c|}
\hline $\begin{array}{l}\text { Source of } \\
\text { lariation }\end{array}$ & SS & $d f$ & $.1 \Delta$ & $F$ & $P$-l:alue & $F$ crit \\
\hline Panelists & $1 \overline{33.8}$ & 12 & 11.15 & 1.79 & 0.07 & 1.92 \\
\hline Processes & 200.4 & 5 & 40.08 & 6.44 & 0.00 & 2.37 \\
\hline Error & 373.2 & 60 & 6.22 & & & \\
\hline Total & 707.4 & 77 & & & & \\
\hline
\end{tabular}

Turkey's test for SPI taste pleasantness

$$
\mathrm{SEM}=\sqrt{6.22 / 13}=0.69
$$

For six treatments and 60 degrees of freedom: $\operatorname{LSD}(P=0.05)=4.16 \times 0.69=2.87$

Compare each mean with the others:

$\begin{array}{llll}7.8-4.8=3.0>2.87 & 7.9-4.8=3.1>2.87 & 7.3-1.8=2.5<2.87 & 6.5-4.8=1.7<2.87 \\ 7.8-3.6=4.2>2.87 & 7.9-3.6=4.3>2.87 & 7.3-3.6=3.7>2.87 & 6.5-3.6=2.9>2.87 \\ 7.8-6.5=1.3<2.87 & 7.9-6.5=1.4<2.87 & 7.3-6.5=0.8<2.87 & +.8-3.6=1.2<2.87 \\ 7.8-7.3=0.5<2.87 & 7.9-7.3=0.6<2.87 & & \end{array}$

$7.9-7.8=0.1<2.87$

$7.9-6.5=1.4<2.87$
$7.9-7.3=0.6<2.87$ 